NBER WORKING PAPER SERIES

\title{
THE EFFECTS OF E-CIGARETTE TAXES ON \\ E-CIGARETTE PRICES AND TOBACCO PRODUCT SALES: EVIDENCE FROM RETAIL PANEL DATA
}

\author{
Chad D. Cotti \\ Charles J. Courtemanche \\ Johanna Catherine Maclean \\ Erik T. Nesson \\ Michael F. Pesko \\ Nathan Tefft \\ Working Paper 26724 \\ http://www.nber.org/papers/w26724 \\ NATIONAL BUREAU OF ECONOMIC RESEARCH \\ 1050 Massachusetts Avenue \\ Cambridge, MA 02138 \\ January 2020, Revised July 2022
}

Author order is alphabetic and lead authorship is shared amongst all the authors. Research reported in this publication was supported by the National Institute on Drug Abuse of the National Institutes of Health under Award Number R01DA045016 (PI: Michael Pesko). There are no conflicts of interest. Tefft completed work on the project prior to joining Amazon while a faculty member at Bates College. The views expressed herein are those of the authors and do not necessarily reflect the views of the National Bureau of Economic Research, Institute for the Labor Economics, or the National Institutes of Health. We thank audiences at the American Society for Health Economists Conference (2022), American Economic Association Annual Meeting (2022), University of Victoria Department of Economics (2021), Society for Research on Nicotine \& Tobacco Conference (2021), Midwest Health Economics Conference (2020), Tobacco Online Policy Seminar (2020), Southern Economic Association Conference (2020), National Bureau of Economic Research Summer Institute Health Economics Program (2020), Society for Benefit-Cost Analysis Conference (2020), and Iowa State Department of Economics (2020) for helpful comments. We also thank Hunt Allcott, Brant Callaway, Scott Cunningham, Dhaval Dave, Daniel Dench, Andrew Goodman-Bacon, Michael Grossman, Donald Kenkel, Alex McGlothlin, David Powell, Charlie Rafkin, Henry Saffer, Pedro Sant'Anna, and Douglas Webber for helpful comments and suggestions. Researcher(s)' own analyses calculated (or derived) based in part on data from Nielsen Consumer LLC and marketing databases provided through the NielsenIQ Datasets at the Kilts Center for Marketing Data Center at The University of Chicago Booth School of Business. The conclusions drawn from the NielsenIQ data are those of the researcher(s) and do not reflect the views of NielsenIQ. NielsenIQ is not responsible for, had no role in, and was not involved in analyzing and preparing the results reported herein. The views expressed herein are those of the authors and do not necessarily reflect the views of the National Bureau of Economic Research.

NBER working papers are circulated for discussion and comment purposes. They have not been peer-reviewed or been subject to the review by the NBER Board of Directors that accompanies official NBER publications.

(C) 2020 by Chad D. Cotti, Charles J. Courtemanche, Johanna Catherine Maclean, Erik T. Nesson, Michael F. Pesko, and Nathan Tefft. All rights reserved. Short sections of text, not to exceed two paragraphs, may be quoted without explicit permission provided that full credit, including (C) notice, is given to the source. 
The Effects of E-Cigarette Taxes on E-Cigarette Prices and Tobacco Product Sales: Evidence from Retail Panel Data

Chad D. Cotti, Charles J. Courtemanche, Johanna Catherine Maclean, Erik T. Nesson, Michael

F. Pesko, and Nathan Tefft

NBER Working Paper No. 26724

January 2020, Revised July 2022

JEL No. I1,I12

\section{ABSTRACT}

We estimate the effect of e-cigarette tax rates on e-cigarette prices, e-cigarette sales, and sales of other tobacco products using NielsenIQ Retail Scanner data from 2013 to 2019. We find that $90 \%$ of e-cigarette taxes are passed on to consumer retail prices. We then estimate reduced form and instrumental variables regressions to examine the effects of e-cigarette and cigarette taxes and prices on sales. We calculate an e-cigarette own-price elasticity of -2.2 and particularly large elasticity of demand for flavored e-cigarettes. Further, we document a cigarette own-price elasticity of -0.4 and positive cross-price elasticities of demand between e-cigarettes and cigarettes, suggesting economic substitution.

Chad D. Cotti

Department of Economics University of Wisconsin-Oshkosh and Center for Demography of Health and Aging University of Wisconsin-Madison

cottic@uwosh.edu

Charles J. Courtemanche

Department of Economics

Gatton College of Business and Economics

University of Kentucky

Lexington, KY 40506-0034

and NBER

courtemanche@uky.edu

Johanna Catherine Maclean

Department of Economics

Temple University

Ritter Annex 869

Philadelphia, PA 19122

and NBER

catherine.maclean@ temple.edu
Erik T. Nesson

Department of Economics

Ball State University

Muncie, IN 47306

and NBER

etnesson@bsu.edu

Michael F. Pesko

Department of Economics

Andrew Young School of Policy Studies

PO Box 3992

Atlanta, GA 30302-3992

and IZA

mpesko@gsu.edu

Nathan Tefft

Department of Economics

Bates College

Lewiston, ME 04240

no email available 


\section{Introduction}

In 2019, $4.5 \%$ of adults and 32.9\% of high school students in the United States used electronic cigarettes ('e-cigarettes'), and a third of these students used e-cigarettes on 20 or more days out of the past 30 (Centers for Disease Control and Prevention 2020a, b). The rapid rise in vaping, particularly among youth, has led to concerns among public health officials and a focus on tobacco control policies aimed at curbing e-cigarette use. As of June 2022, 30 states and Washington DC have enacted an e-cigarette tax (Public Health Law Center 2022).

In this paper, we provide evidence of the effects of e-cigarette taxes on the prices and sales of e-cigarettes and other tobacco products using the NielsenIQ Retail Scanner Dataset (NRSD) over the years 2013 to 2019. The NRSD tracks weekly sales of a national panel of retailers and covers a large percentage of total sales among drug stores, mass merchandisers, food stores, dollar stores, and club stores. ${ }^{1}$ Utilizing these data, this paper is among the first to estimate the passthrough rate for e-cigarette taxes, as well as own and cross-price elasticities between e-cigarettes and cigarettes. Further, utilizing a 98.1\% match of e-cigarette sales to e-cigarette characteristics by Universal Product Codes (UPC), we estimate elasticities across heterogenous e-cigarette flavors and other measures of e-cigarette sales composition. ${ }^{2}$

Recent theoretical work on the demand for nicotine motivates our findings for own- and cross-price elasticities of demand. In particular, Lillard (2020) develops a model suggesting that

\footnotetext{
${ }^{1}$ We use the NRSD instead of the NielsenIQ Consumer Panel Dataset because the NRSD provides approximately a 4.8\% sample of national e-cigarette sales, whereas the NielsenIQ Consumer Panel Dataset covers only a 0.05\% sample of e-cigarette sales (see Allcott and Rafkin (2021)).

2 To estimate the pass-through rate of e-cigarette taxes to prices and price elasticities of demand, we match ecigarette UPC available in the NRSD to liquid volume information hand-collected from internet searches, correspondences with companies, and visits to retailers. This unique product characteristic database also includes product type, liquid flavor, and nicotine content. These additional product characteristics allow us to standardize ecigarette products. In particular, different e-cigarette products may contain different levels of liquid as well as nicotine. We utilize the product characteristics to examine milliliter of fluid sold, instead of raw counts of products, to more accurately identify the effects of taxation that is possible using only the information in the NRSD.
} 
the demand for tobacco products is a derived demand based on the demand for nicotine. The choice of products is determined by the shadow price of nicotine, which is driven by the cost of the product, the efficiency of nicotine delivery, and the health and social effects of different products. Depending on these factors, different categories of nicotine products could theoretically be complements or substitutes.

We first estimate the pass-through rate of e-cigarette and cigarettes tax rates to e-cigarette prices. Our paper utilizes recently developed standardized e-cigarette taxes from Cotti et. al. (2021), which compensates for substantial heterogeneity both in how e-cigarette taxes are levied and in the level of the tax. We find that e-cigarette taxes are almost fully passed through to consumer retail prices. Specifically, we estimate that a $\$ 1.00$ increase in e-cigarette taxes raises ecigarette prices by $\$ 0.90$. We do not find significant pass-through effects of cigarette tax increases on the prices of e-cigarettes.

Next, we estimate reduced-form models of the effects of e-cigarette and cigarette taxes on sales of each product, and then use taxes as instruments to examine the own- and cross-price elasticities of demand for e-cigarettes and cigarettes. Estimates suggest an e-cigarette own-price elasticity of demand of -2.2, and approximately twice as elastic of demand for non-mentholated flavored e-cigarettes compared to non-flavored and mentholated e-cigarettes. These results are consistent with younger e-cigarette users - who are perhaps more price sensitive than older ecigarette users due to their relatively low incomes - being more likely to use flavored e-cigarettes. ${ }^{3}$

We find a cigarette own-price elasticity of -0.4 , similar to previous studies (for reviews, see Chaloupka and Warner 2000, DeCicca et al. 2018, and DeCicca, Kenkel, and Lovenheim

\footnotetext{
${ }^{3}$ Schneller et al. (2019) found that in 2015-16, 84\% of e-cigarette purchases made by youth were non-tobacco and non-menthol flavored, $11 \%$ were menthol flavored, and $5.1 \%$ were tobacco flavored. Among adults, $58 \%$ of ecigarette purchases flavored, 18\% were menthol flavored, and 25\% were tobacco flavored.
} 
2020). Finally, we find evidence that cigarettes and e-cigarettes are economic substitutes (cigarette cross-price elasticity $=1.1$; e-cigarette cross-price elasticity $=0.4$ ), though only the latter is statistically significant.

\section{Literature Review}

\section{a. The pass-through of e-cigarette and cigarette taxes to prices}

In a perfectly competitive market, the rate at which a tax change impacts the after-tax price (i.e., the 'pass-through rate') ranges from zero to one and is a function of demand and supply elasticities. The pass-through rate will be zero if consumers have perfectly elastic demand (suggesting that suppliers pay the full incidence of the tax) or one if consumers have perfectly inelastic demand (consumers pay all the tax). However, over-shifting - when the pass-through rate exceeds one - is possible in imperfectly competitive markets (e.g., Stern 1987, Besley 1989, and Hamilton 1999). Several studies have estimated the effect of cigarette tax increases on cigarette prices. The estimated pass-through rates range from 0.80 to 1.2 , with a mean of approximately one (Lillard and Sfekas 2013, DeCicca, Kenkel, and Liu 2013, Rozema and Ziebarth 2017, Hanson and Sullivan 2009, Hoehn-Velasco, Pesko, and Phillips 2020, Harding, Leibtag, and Lovenheim 2012).

Researchers also estimate pass-through rates for other 'sin goods:' alcohol and sugarsweetened beverages. Several studies find that alcohol taxes are more than fully passed through to prices (Kenkel 2005, Shrestha and Markowitz 2016, Gehrsitz, Saffer, and Grossman 2021, Shang, Ngo, and Chaloupka 2020). Recently, Cawley et al. (2019) review 15 pass-through rate studies for sugar-sweetened beverages, concluding that trends in prices after nationwide tax implementations are in line with the hypothesis that prices rise by the full amount of the tax. However, local taxes 
generally have lower estimated pass-through rate, potentially due to tax evasion opportunities created by cross-border shopping.

\section{b. The effect of e-cigarette prices on e-cigarette and cigarette sales and use}

Multiple studies estimate the effect of e-cigarette prices on e-cigarette and cigarette sales. For example, Saffer et al. (2018) use data on adults from the 2014 to 2015 Current Population Survey Tobacco Use Supplements, Huang et al. (2018) use scanner data in the U.S, Pesko et al. (2018) use two years of the Monitoring the Future data to examine middle and high school students, Cantrell et al. (2019) use national longitudinal cohort data on a sample of 15- to 21-yearolds from 2014 to 2016, and Stoklosa, Drope, and Chaloupka (2016) use data from Europe. Using data over the period 2009 to 2013 Zheng et al. (2017) estimate an e-cigarette own-price elasticity of demand of -2.1, a cross-price elasticity of cigarette prices on e-cigarettes sales of 1.9, and a cross-price elasticity of e-cigarette prices on cigarette sales of 0.004. In a related paper, Zheng et al. (2016) estimate a dynamic demand system for tobacco products using market-level scanner data for convenience stores from 2009 to 2013. They find that e-cigarettes and cigarettes are neither complements nor substitutes. The possible endogeneity of prices - which represent the equilibrium outcome of both demand- and supply-side forces, is a potential limitation of these papers. Demandand supply-side shocks could influence both prices and sales/use, biasing estimates of price effects.

\section{c. The effects of e-cigarette taxes on e-cigarette and cigarette sales and use}

Our study aims to overcome the challenge of price endogeneity by using plausibly exogenous variation from the implementation of taxes. At the time of writing, there are only a few other papers on the effect of e-cigarette taxes on e-cigarette or cigarette sales or use. Pesko, Courtemanche, and Maclean (2020) use the Behavioral Risk Factor Surveillance Survey and the National Health Interview Survey and find that higher e-cigarette tax rates reduce e-cigarette use 
and increase cigarette use, especially for adults less than 40 years of age. Friedman and Pesko (2022) use Current Population Survey data to find large e-cigarette tax responsiveness and substitution among young adults 18-25 years of age. Saffer et al. (2020) document that the firstin-the-nation e-cigarette tax in Minnesota increases adult smoking and reduces smoking cessation; Pesko and Warman (2022) find the same tax increases youth smoking. These papers all use survey data on reported use rather than sales data.

The paper with the closest overlap to ours, written concurrently and independently, is Allcott and Rafkin's (2021) study of the effects of e-cigarette taxes on e-cigarette and cigarette sales. Among other findings, they estimate an e-cigarette price elasticity of demand of between -1.09 and $-1.67 .{ }^{4}$ There are some potentially important differences in their approach compared to this research, which allows both studies to complement each other well. First, while both studies use the NRSD, Allcott and Rafkin (2021) uses a shorter time period, from 2013-2017 (instead of 2013-2019). ${ }^{5}$ This difference in time period is salient as the e-cigarette market has changed dramatically post-2017. Only seven states taxed e-cigarettes at the end of 2017 compared to 17 by the end of 2019. Our study therefore leverages considerably more tax variation. Additionally, in 2018-2019 the e-cigarette market grew substantially (Ali et al. 2020), JUUL increased its dominance of e-cigarette market share, and cigarette companies purchased ownership stakes in e-cigarette companies. Second, Allcott and Rafkin use an alternative standardization

\footnotetext{
${ }^{4}$ Allcott and Rafkin (2021) also estimate instrumental variable models to estimate cross-price elasticities using NRSD data from 2013 to 2017. In Table 1b, they find some evidence that cigarette prices are positively associated with ecigarette sales (cross-price elasticity $=0.42$ in the fully-specified model). In Online Appendix Table A3, they examine the effect of e-cigarette prices on the demand for cigarettes. Here, they find evidence that higher e-cigarette prices increase sales of cigarettes (column 5 shows a cross-price elasticity of 0.76 ), although though when area-specific linear trends are added these results switch sign (cross-price elasticity $=-0.26$ in column 6). As discussed in Meer and West (2016), inclusion of such trends can lead to an overcontrolling bias if the treatment variable leads to a change in the area-specific outcome trends. In such a case, adding area-specific trends to the regression model can 'control away' part of the causal effect that the researcher is seeking to estimate. Hence, we interpret findings based on regression models that include area-specific time trends with some caution.

${ }^{5}$ We also use a balanced panel of retailers and provide a sensitivity analysis extending our analysis back to 2011.
} 
approach that assumes that there is no retailer markup rate. We assume the retailer markup is either $20 \%$ or $35 \%$ of retailer price which is based on industry standards (Cotti et al. 2021). Third, for analyses of sales outcomes, Allcott and Rafkin use a locality-by-UPC-level model whereas we use a locality-level model, in line with Harding, Leibtag, and Lovenheim (2012). We discuss in the methods section below why this difference could be a consequential distinction.

Additionally, the questions asked by our study also differ from those asked by Allcott and Rafkin in two important ways that lead each paper to offer distinct contributions to the literature. First, their interest in the relationship between taxes and prices is as a first stage in an instrumental variable model estimating the price elasticity of demand for use in welfare calculations. Accordingly, they use a logarithmic, not linear, functional form for both taxes and prices. This specification implies that their estimate relates percentage changes in taxes to percentage changes in prices, which is not informative about over- versus under-shifting. In contrast, quantifying the pass-through rate and exploring the extent of tax shifting in e-cigarette retail markets is one of our main contributions. Second, we examine differences across e-cigarette and cigarette flavors, which allows us to offer suggestive evidence on heterogenous tax effects across demographic groups. This analysis is potentially quite important as reducing e-cigarette use among youth (a group that disproportionally uses flavored tobacco products) is a key rationale for state and local e-cigarette tax implementation in the U.S.

\section{d. Other policies}

Relatedly, a growing literature examines the relationship between e-cigarettes and cigarettes using other sources of policy variation besides taxes. ${ }^{6}$ For example, Friedman (2015)

\footnotetext{
${ }^{6}$ A related set of papers examine the economic relationship between cigarettes and other tobacco products, largely between cigarettes and smokeless tobacco (e.g., Ohsfeldt, Boyle, and Capilouto 1997, Ohsfeldt and Boyle 1994, Dave and Saffer 2013, Adams, Cotti, and Fuhrmann 2013, and Cotti, Nesson, and Tefft 2016).
} 
uses the National Survey on Drug Use and Health and finds that states implementing restrictions on youth access to e-cigarettes see increases in youth past 30 day smoking rates, suggesting that e-cigarettes and cigarettes are substitutes among adolescents. Similarly, Pesko, Hughes, and Faisal (2016) and Dave, Feng, and Pesko (2019) use the Youth Risk Behavior Surveillance System data and restrictions on youth access to e-cigarettes, finding evidence that the two products are substitutes for this population. Pesko and Currie (2019) have comparable findings for pregnant adolescents using birth record data. Contrary to these findings, Abouk and Adams (2017) use the same restrictions on youth access to e-cigarettes and individual-level data for underage high school seniors from Monitoring the Future and find that the products are economic complements. Finally, Dave et al. (2019) and Tuchman (2019) find that exposure to e-cigarette advertising helps adult smokers quit smoking.

A few studies estimate the effect of cigarette policies on e-cigarette use. Cotti, Nesson, and Tefft (2018) examine the effects of cigarette taxes and other tobacco control policies, including indoor vaping restrictions and indoor smoking restrictions, on adult households' purchases of ecigarettes and other tobacco products using the Nielsen Consumer Panel data. The authors document that cigarette tax increases induce households to purchase fewer e-cigarette products, suggesting a complementary relationship between e-cigarettes and cigarettes. Pesko, Courtemanche, and Maclean (2020) and Friedman and Pesko (2022) find evidence that cigarette taxes increase e-cigarette use.

\section{Data}

\section{a. NielsenIQ Retail Scanner Data (NRSD)}


Our main data source is the 2013 to 2019 NRSD. From 2013 to 2017, the NRSD contains between 34,000-36,000 stores, ${ }^{7}$ and this increased to approximately 49,000 in 2018 and 2019. To compensate for this change in survey scope, we include only stores that appear in the NRSD in each year from 2013 to 2019 ( $N=27,817)$. In other words, we rely on the balanced panel, thus reducing the possibility that our regression coefficients capture compositional change in participating stores rather than causal estimates of tax effects. The weekly volume and average price paid for each UPC purchased at each store is recorded, including all taxes except sales taxes. E-cigarette products are identified by NielsenIQ, and we include only devices with liquid in our analysis sample (e.g., tank systems without liquid are not considered e-cigarettes). Each e-cigarette product has a unique UPC, and any change in the product triggers the creation of a new UPC. Therefore, UPCs are perfectly nested within brands and many brands have multiple UPCs for the numerous variations of e-cigarettes sold under a given brand.

For e-cigarette sales in the NRSD, we match hand-collected product characteristics by UPC. These data are collected from correspondence with e-cigarette companies, internet searches, and in-person visits to retailers conducted by members of the research team. Cotti, Nesson, and Tefft (2018) developed this database and we have expanded upon it to account for changes in the e-cigarette market. Product characteristic information allows us to accurately determine e-cigarette product type (i.e., disposable e-cigarettes, starter kits, and cartridge refills), ${ }^{8}$ the milliliters (mls) of fluid in each e-cigarette UPC, and the flavor of the e-cigarette. We are able to match $98.1 \%$ of e-cigarette sales in the NRSD to tobacco product characteristics in this way. Given that nicotine is

\footnotetext{
7 The Kilts Center most recently released information on the share of sales their data collects in 2017. In that year, the NRSD included between $15 \%$ and $26 \%$ of all food store, mass merchandiser, dollar store, and club store sales, and over $50 \%$ of drug store sales. The NRSD contains a smaller percentage of sales in convenience stores and liquor stores (approximately 2\% each).

${ }^{8}$ Starter kits include a reusable battery and atomizer along with a selection of disposable cartridges.
} 
the primary ingredient sought by tobacco product consumers (Lillard 2020), we exclude a small number of e-cigarettes that do not contain nicotine (less than $0.1 \%$ of total e-cigarette sales in the NRSD).

For nicotine-containing e-cigarette sales in the NRSD, the original unit of observation is sales of a specific UPC in a store per week. We construct sales-weighted e-cigarette prices at both the UPC-locality-period level and locality-period level. A locality is defined as a state or county (depending on the geographical extent of a tax) and a period refers to a quarter-by-year.

We aggregate sales data to the locality-period level for e-cigarettes, cigarettes, cigars, chewing tobacco, and loose tobacco. For e-cigarettes, we use our hand-collected data to create the number of fluid ml sold. For the other tobacco products, we create variables counting the sales for each product in terms of the units provided by NielsenIQ. We thus separately count the number of cigarette packs, the number of cigars, the ounces of chewing tobacco, and the ounces of loose tobacco sold. We also separately analyze cartridge refills only, thus focusing more exclusively on liquid nicotine demand rather than combining nicotine with devices included in starter kits and disposables (Lillard 2020).

\section{b. Tobacco control policies}

Through 2019, 17 states, Washington DC, and two large counties have adopted e-cigarette taxes. These e-cigarette taxes are levied in one of three ways: 1) a unit tax per ml of liquid volume (either per container, per fluid ml, or both), 2) an ad valorem tax as a percent of the wholesale price, or 3) a sales tax as a percent of the pre-tax retail price. To facilitate empirical investigation, we convert the different tax rates into a standardized tax measure. We utilize a standardized tax measure from Cotti et al. (2021) (detailed in Online Appendix Discussion 1) that uses 2013 market information from the NRSD and alternative assumptions about the retailer mark-up rate to convert 
ad valorem taxes into a dollar value per fluid ml. One appealing feature of this standardized tax measure is that only legislated tax changes affect the standardized tax values, versus other factors occurring in the marketplace that could endogenously affect wholesale prices. Cotti et al. (2021) show small variation in e-cigarette prices across the country for top selling brands, suggesting that retailers use national rather than regional pricing strategies. Online Appendix Table 1 provides information on the effective dates, unit taxed, tax amount, and relative tax value (in the $4^{\text {th }}$ quarter of 2019) for each e-cigarette tax implemented during our study period.

We collect state-level data on cigarette unit taxes from the Centers for Disease Control and Prevention STATE System, and we supplement these data with population-weighted local cigarette taxes from the American Non-Smokers' Rights Foundation and federal cigarette tax data from the Tax Burden on Tobacco. Our cigarette tax measure therefore sums the state cigarette tax, local cigarette taxes (population-weighted to the locality level), and federal cigarette tax (\$1.01 per pack). We transform these taxes into the cigarette unit taxes measured in real 2019 dollars (using the Consumer Price Index-Urban Consumers) in each locality and period (Centers for Disease Control and Prevention 2021).

Additionally, we collect data on indoor air laws from the American Non-Smokers' Rights Foundation. The American Non-Smokers' Rights Foundation tracks when municipalities, counties, and states pass indoor air laws for vaping or smoking in different venues. We use this information to create two separate measures for the share of the population in each county living with indoor vaping restrictions and indoor smoking restrictions for private workplaces, restaurants, or bars. For both indoor vaping restrictions and indoor smoking restrictions, we consider only complete bans and weight laws applying to bars, restaurants, and private workplaces equally. We aggregate the county-level bans up to the state using population as a weight (such aggregation is 
not necessary for Cook County and Montgomery County). Additionally, we use data on state laws banning smoking and vaping in K-12 public schools and laws requiring licensing to sell ecigarettes or other tobacco products from the Centers for Disease Control and Prevention STATE system (Centers for Disease Control and Prevention 2021). Finally, we collect data on e-cigarette bans adopted by some states late in 2019 in response to the outbreak of vaping-related lung injuries using original legal research.

\section{Methods}

Prices reflect a market equilibrium outcome, which is determined by both supply- and demand-side factors. We take a reduced form approach, which allows us to analyze the extent to which taxes are passed through to consumer prices without making specific assumptions regarding the underlying e-cigarette market structure (Harding, Leibtag, and Lovenheim 2012). We note that some scholars hypothesize a Cournot model to characterize the e-cigarette market (Saffer et al. 2020), our reduced form model allows for such a model to describe the e-cigarette market (if this assumption is correct). The controls we include in our regression model (outlined below) are selected to proxy for salient tobacco product market factors. We include locality-level demographics and policies, which likely shape demand for e-cigarettes which, in turn, impact equilibrium e-cigarette prices. Additionally, we include labor market and area-level controls that plausibly capture supply-side factors that affect e-cigarette production. We select our controls using insight drawn from previous economic studies that seek to estimate pass-through rates with reduced-form methods in American tobacco product markets (Lillard and Sfekas 2013, Harding, Leibtag, and Lovenheim 2012, Saffer et al. 2020). 
We implement a standard two-way fixed effects regression by leveraging within-localitylevel variation in e-cigarette and cigarette taxes that occurs between 2013 and 2019 to estimate treatment effects. ${ }^{9}$ Specifically, we estimate the following regression model:

$$
Y_{i, l, t}=\beta_{0}+\beta_{E} \operatorname{Etax}_{l, t}+\beta_{C} \operatorname{Ctax}_{l, t}+W_{l, t} \beta_{W}+X_{l, t} \beta_{X}+\sigma_{i, l}+\partial_{i, t}+\tau_{t}+\varepsilon_{i, l, t},
$$

where $Y_{i, l, t}$ is the price for e-cigarette product (i.e., UPC) $i$ in locality $l$ at time $t$ (i.e., quarter-byyear). We use 51 localities, one for each state and Washington DC (we do not include Alaska and Hawaii as these states are not in the NRSD for our full sample period) but separating Cook County from Illinois and Montgomery County from Maryland since these sub-state localities also adopt ecigarette taxes during our study period. We aggregate $Y_{i, l, t}$ to the UPC-by-locality-by-period level by creating an average price for each UPC-locality-period. We measure both e-cigarette taxes $\left(\operatorname{Etax}_{l, t}\right)$ and cigarette taxes $\left(\operatorname{Ctax}_{l, t}\right) . \operatorname{Etax}_{l, t}$ is a continuous variable measuring the magnitude of e-cigarette taxes as described in Cotti et al. (2021). $\operatorname{Ctax}_{l, t}$ is a continuous variable measuring the locality-level cigarette unit tax per pack (i.e., summing across local, state, and federal taxes).

We include additional tobacco control policies in $\left.W_{l, t}: 1\right)$ a vector of indoor smoking restrictions and indoor vaping restrictions (measured as the percent of the locality's population living under an indoor smoking restriction, and separately as the percent of the locality's population living under an indoor vaping restriction), 2) state laws banning smoking and vaping in K-12 public schools, 3) the percent share of all locality borders that do not have an e-cigarette tax (a proxy for tax avoidance propensity), ${ }^{10} 4$ ) licensure laws affecting the sale of e-cigarettes and

\footnotetext{
${ }^{9}$ Between 2013 and 2019, the correlation between population-weighted state-level, quarterly e-cigarette taxes and cigarette taxes was 0.285 , suggesting significant independent variation for the two taxes.

${ }^{10}$ As an additional strategy to compensate for tax avoidance, we re-estimate our models dropping counties that are within 50 miles of a reduced tax source as of the end of 2017 (approximately 50\% of all counties that eventually have e-cigarette taxes). This strategy requires dropping Cook County, Montgomery County, Washington DC, and many other counties near reduced-tax borders in states taxing e-cigarettes. Our results based on this smaller sample are similar.
} 
other tobacco (two separate measures), and 5) e-cigarette bans adopted by some states late in 2019 in response to the outbreak of vaping-related lung injuries. ${ }^{11}$ We include locality-level characteristics in $X_{l, t}$ : beer tax (dollars per gallon), Affordable Care Act Medicaid expansions, ${ }^{12}$ Bureau of Labor Statistics’ unemployment rate, and Current Population Survey demographics (e.g., age, sex, and race/ethnicity). We also include UPC-by-locality, UPC-by-quarter, and time period (i.e., quarter-by-year) fixed effects in our regression models, represented by $\sigma_{i, l}, \partial_{i, t}$ and $\tau_{t}$, respectively. The product fixed effects hold product availability and quality constant, thus allowing us to study the pass-through rate independent of manufacturers changing their mix of products offered for sale in response to e-cigarette taxes. ${ }^{13}$ Time period fixed effects account for timevarying national level factors such as social media advertisements.

We cluster standard errors at the locality level in all specifications, and we weight the data by the share of each e-cigarette UPC's sales in localities that do not adopt an e-cigarette tax by 2020. We demonstrate that our main findings are robust to a number of alternative specifications, as well as different analytical samples, weighting schemes, and aggregations. Unless otherwise stated, monetary variables are CPI-adjusted to real 2019 dollars.

After examining the pass-through rate of e-cigarette taxes to e-cigarette prices, we next examine whether e-cigarette and cigarette prices affect sales of tobacco products. The economic literature has moved towards using taxes, rather than prices, as the former are viewed as more

\footnotetext{
11 These states had active bans on all or some e-cigarettes (e.g., flavored e-cigarettes) for any period of time: Massachusetts, Michigan, Montana, Oregon, Rhode Island, Utah, and Washington. We control for the percent of the quarter with the ban in place.

12 https://www.kff.org/health-reform/state-indicator/state-activity-around-expanding-medicaid-under-the-affordablecare-act (last accessed July 13, 2022).

${ }^{13}$ Faced with a tax change, manufacturers could either raise prices or reduce the quality (and costs) of their product, such as by using a less esthetically pleasing exterior or lower quality flavor ingredients in the context of e-cigarettes, or lower-quality tobacco in the context of cigarettes. As described in Section 3.a, any notable change in a tobacco product would trigger a new UPC in the NielsenIQ. Therefore, holding product quality constant by including UPC fixed effects in our regression models allows us to isolate the effect of taxes on consumer prices.
} 
exogenous after conditioning on observable characteristics (see Pesko, Courtemanche, and Maclean (2020) for a discussion of this issue). However, this focus does not imply that taxes are truly exogenous. Indeed, similar to all policies of which we are aware, taxes are developed within the local political economy (see Besley and Case (2000) for a discussion of this issue).

Our study faces two identification challenges. The first is the classic economic problem posed by using aggregate sales data which reflect a market equilibrium determined by supply and demand factors. Since unobservable demand-side shocks influence both prices and sales, estimates of price effects could be biased. We refer readers to excellent discussions of this issue by Manski (2003) and Hannon (1971). We address this challenge by using taxes as instruments for prices. However, this solution leads to the second identification challenge, which is that the use of policies as sources of variation leads to concerns regarding policy endogeneity and omitted variable bias. We address this by providing evidence that, after conditioning on observables and various fixed effects, our tax variable is plausibly exogenous. First, we estimate event studies and observe no evidence of differential pre-trends between adopting and non-adopting localities (see Sections 5b and 5c and Figures 2, 4 and 5). ${ }^{14}$ Second, we conduct a covariate balance analysis to examine differences in observable characteristics between jurisdictions that do and do not tax e-cigarettes in Online Appendix Table 3 (Pei, Pischke, and Schwandt 2019). This analysis demonstrates that, to a large degree, localities with and without e-cigarette taxes are similar in terms of the included variables. Two differences are that cigarette taxes are higher and e-cigarette licensure laws are more common in localities with e-cigarette taxes. Further, we include controls for political factors

\footnotetext{
${ }^{14}$ In unreported analyses, we incorporate tax adoptions that occurred through the second quarter of 2022 in an event study for our canonical pass-through event study. Results (available on request) are not appreciably different than those reported later in the manuscript. More specifically, we observe no evidence that our data violate the parallel trends assumption necessary for identification in two-way fixed-effects models.
} 
that could be correlated with both tax rates and tobacco sales, and results are not appreciably different.

We examine five categories of tobacco products: e-cigarettes, cigarettes, cigars, chewing tobacco, and loose tobacco. We also analyze non-flavored and flavored e-cigarettes and cigarettes separately. To this end, we separate e-cigarettes into three flavored categories using our handcollected product characteristics data: 1) tobacco flavored e-cigarettes (non-flavored), 2) menthol and mint flavored e-cigarettes, and 3) other flavors (which may include fruit, chocolate, coffee, etc.). We separate cigarettes into regular cigarettes and menthol cigarettes (the only legal flavor) using flavor information available in the NRSD.

In these models, we aggregate our data to the locality-by-period level for each category of tobacco products, which is different from the UPC-by-locality-by-period aggregation in equation (1) to permit new product offerings to be reflected in tax responsiveness. Our approach closely follows Harding, Leibtag, and Lovenheim (2012). The authors estimate a UPC fixed effects model to calculate pass-through in order to study tax-to-price pass-through while accounting for the possibility that producers may change the quality of cigarettes available on the market in response to the tax. Separately, Harding et al. estimate state fixed effect models for sales outcomes to avoid restricting cigarette products to those UPCs existing both before and after the tax. ${ }^{15}$ For example, e-cigarette manufacturers may introduce discount e-cigarettes following e-cigarette tax increases, which would be captured within a locality-level e-cigarette tax model, but not a UPC-level e-

\footnotetext{
${ }^{15}$ Analyzing sales at the locality level also provides estimates that may be more directly related to the questions faced by policymakers, who are likely more interested in the effect of taxes on tobacco product purchases made in their locality (which has tax revenue and public health implications), rather than UPC-specific effects of e-cigarette taxes. Relatedly, previous research suggests that consumers may switch products in response to tax changes (Cotti, Nesson, and Tefft 2016), and thus including UPC fixed effects in our regression models could lead to overcontrolling bias (i.e., bias from conditioning on an outcome variable). Finally, during our sample period, many products enter or exit or may not be sold in all locations. To estimate a model at the UPC-level would require assumptions about which UPC-locality-period observations with no sales should be filled in to be zero sales and which should be kept as missing and not included in the regression.
} 
cigarette tax model. For e-cigarette products, our unit of measure is ml of liquid purchased in order to match the units of our standardized tax variable. We examine counts of the products purchased for other tobacco product categories. We estimate a similar model to that reported in equation (1), but at the locality-by-period level:

$$
Y_{l, t}=\gamma_{0}+\gamma_{E} \operatorname{Etax}_{l, t}+\gamma_{C} \operatorname{Ctax}_{l, t}+W_{l, t} \gamma_{W}+X_{l, t} \alpha_{X}+\delta_{l}+\chi_{t}+\mu_{l, t}
$$

Here, $Y_{l, t}$ represents sales of a tobacco product in locality $l$ and time $t$, and the other variables are the same as in equation (1). We estimate sales in levels because we did not observe evidence of curvature in the relationship between e-cigarette taxes (which are predominantly zero since few localities have e-cigarette taxes) and e-cigarette sales. ${ }^{16}$ We weight equation (2) regressions using locality population and cluster standard errors at the locality level.

We also study the impact of prices on tobacco product purchases. A potential empirical problem with estimating this relationship, in addition to the classical identification problem when using sales data described earlier in the manuscript, is that e-cigarette and cigarette prices are endogenously determined. Put differently, prices are determined by demand- and supply-factors that are difficult to fully capture with observable characteristics available in data. Examples of such factors include underlying preferences for nicotine and harm reduction among consumers, which would shape e-cigarette demand, and labor market structure (e.g., perfect competition, monopsony) which would impact wages paid to workers involved with producing and selling ecigarettes. Therefore, we simultaneously instrument for e-cigarette prices $\left(E P_{l, t}\right)$ and cigarette

\footnotetext{
${ }^{16}$ We use Stata's semipar command (Robinson 1988). Such evidence would support log-transforming the dependent variable. More specifically, in order to log-transform the e-cigarette tax variable, we would need to add a positive value to the vast majority of our data given that e-cigarette taxes are recent policy changes, thereby substantially altering the tax data. Recent work suggests that alternative methods such as the inverse hyperbolic sign transformation do not perform well (Mullahy 2021).
} 
prices $\left(C P_{l, t}\right)$ using e-cigarette and cigarette taxes in the two-stage least squares (instrumental variable) regression:

$$
Y_{l, t}=\alpha_{0}+\alpha_{E} \widehat{E P}_{l, t}+\alpha_{C} \widehat{C P}_{l, t}+W_{l, t} \alpha_{W}+X_{l, t} \alpha_{X}+\delta_{l}+\chi_{t}+\epsilon_{l, t},
$$

where $E P_{l, t}$ and $C P_{l, t}$ are replaced with their predicted values, $\widehat{E P}_{l, t}$ and $\widehat{C P}_{l, t}$, from first stage regressions. Our identifying assumption is that e-cigarette and cigarette taxes affect demand only through their effects on e-cigarette and cigarette prices. Thus, we assume that there are no other channels though which taxes can influence sales. ${ }^{17}$

\section{Results}

\section{a. Summary statistics}

We begin by discussing summary statistics and the variation in e-cigarette taxes. Online Appendix Table 2 shows summary statistics for our sample when aggregated to the locality-byperiod level. This sample includes 1,428 locality-by-period observations, of which 369 are subject to an e-cigarette tax. The conditional (non-zero) mean e-cigarette tax is $\$ 1.22$ per fluid ml. The unconditional mean is $\$ 0.18$ per fluid $\mathrm{ml}$. The unconditional mean is markedly lower than the conditional mean as many localities do not adopt a tax during our study period, and those localities that adopt a tax implement this policy do so during the latter portion of our study period. The cigarette tax is $\$ 2.97$ over our study period, which reflects the imbalance in taxation of the two tobacco products. The average e-cigarette price per $\mathrm{ml}$ of liquid is $\$ 4.82$, and the average price is slightly lower in localities that adopt an e-cigarette tax (measured before the tax is imposed) than in localities that did not adopt a tax by the end of our study period (\$4.62 vs. \$4.68). Cigarette prices are higher at $\$ 6.71$ per pack.

\footnotetext{
${ }^{17}$ Our reduced form model results do not require this assumption. In general, price elasticity estimates from the instrumental variable model are similar to implied price elasticity estimates from the reduced form models, suggesting that this assumption has little impact on our results.
} 
E-cigarette and cigarette sales are lower in localities that adopt an e-cigarette tax, pre-tax, than in localities not adopting taxes. Across our sample, about 39\% of e-cigarette liquid purchased is tobacco flavored, while $22 \%$ is menthol flavored and $39 \%$ is another flavor. The majority of liquid purchases, about 75\%, are for refill cartridges. Cigarettes are weighted towards tobacco flavor, with menthol cigarettes making up $26 \%$ of cigarette sales. These descriptive statistics also show only $23 \%$ of locality-period observations are covered by an indoor vaping ban, while cigarette indoor smoking bans are much more prevalent (71\%).

Figure 1 displays trends in e-cigarette (in nominal dollars per fluid ml) and cigarette (in nominal dollars per pack) taxes in each year between 2013 and 2019. Both e-cigarette and cigarette taxes increase over our study period. E-cigarette taxes per fluid ml increased from \$0.03 in 2013 to $\$ 0.38$ by 2019; whereas cigarette taxes increased from $\$ 2.64$ per pack in 2013 to over $\$ 3.05$ in 2019.

Online Figure 1 displays the geographic and dollar variation in our (nominal) standardized e-cigarette tax measure at the end of our sample period in the $4^{\text {th }}$ quarter of 2019 (additional details are also provided in Online Appendix Table 1). There is substantial variation in the size of ecigarette taxes, as Delaware, Kansas, Louisiana, North Carolina, Ohio, and West Virginia have unit tax values of $\leq \$ 0.10$ per fluid ml, while Minnesota, Vermont, and Washington DC have a standardized e-cigarette tax value over approximately $\$ 2.50$ per fluid ml.

\section{b. Estimates of e-cigarette tax pass-through rate}

\section{Pass-through, main results}

We first present results estimating the effects of e-cigarette taxes on e-cigarette prices. Table 1 presents results estimating equation (1), where the unit of analysis is a UPC-locality-period (where period indicates quarter-by-year) and the dependent variable is e-cigarette price. Moving 
from left to right across the table, we begin with a parsimonious specification that only includes ecigarette taxes, cigarette taxes, locality fixed effects, and period fixed effects. Next, we add timevarying controls (tobacco control policies, then other substance use policies, and then demographics), then UPC-by-period fixed effects, and finally UPC-by-locality fixed effects in the last column.

We find that every $\$ 1.00$ increase in e-cigarette taxes raises e-cigarette prices by between $\$ 0.90$ and $\$ 1.01$ across these specifications. These estimates are all statistically significantly different from zero at the $1 \%$ level, although we do not find that the coefficient estimates are statistically significantly different from one in our preferred model that includes a full set of controls. In our preferred fully specified model, e-cigarette taxes are almost fully passed on to consumer prices (at a rate of 0.90 ). Our preferred pass-through rate of 0.90 is somewhat smaller than an e-cigarette pass-through rate of 1.33 estimated for Minnesota (Saffer et al. 2020). ${ }^{18}$ Changes in cigarette taxes do not lead to statistically significant changes in e-cigarette prices, and these coefficient estimates are small in magnitude across all specifications.

\section{Pass-through identification}

Next, we estimate event study models to test the parallel trends assumption of our two-way fixed effects models, to address potential concerns regarding policy endogeneity, and to examine whether there are anticipatory price increases. The optimal event study approach is not immediately clear since our analysis presents a number of deviations from the canonical setting with a binary treatment variable that follows a staggered rollout pattern across localities. Our treatment variable is a continuous variable, and some of the 'treatments' are tax decreases. Relatedly, some localities have multiple treatment changes within our study period.

\footnotetext{
${ }^{18}$ Allcott and Rafkin (2021) do not estimate a pass-through rate directly, but find that a $1 \%$ increase in $\log (1+\mathrm{e}-$ cigarette tax rate) yields a $0.54 \%$ increase in the e-cigarette price.
} 
We therefore take two approaches to specifying an event study model. First, we examine changes in e-cigarette prices before and after the presence of any e-cigarette tax within each locality (using a dichotomous variable and ignoring any future tax changes). We then construct eight quarter leads, i.e., interactions between an indicator variable for a tax adopting locality and the time-to-event, and eight quarter lags around the event. In our main results, we restrict our event studies to only include periods (quarter-years) within eight quarters in advance of or after the effective date, but estimates are highly robust to using all periods. All non-adopting localities are coded as zero for all event-time bins, and we treat the period just prior to the tax adoption as the omitted period.

Second, we follow an approach developed by Cotti, Nesson, and Tefft (2018) in a study of cigarette taxes, which is comparable to event study methods used in Allcott and Rafkin (2021). Similar to our setting, Cotti, Nesson, and Tefft (2018) examine a continuous treatment variable that both increases and decreases, and for which some localities experience multiple changes over the study period. ${ }^{19}$ More specifically, we consider all changes to the nominal e-cigarette tax rate attributable to policy changes (i.e., we do not incorporate changes due to inflation) and model future and past changes for each adopting locality. We include legislated changes that occur eight periods in the future through eight periods in the past; these variables are similar to lead and lag indicators in a standard event study, although we use the value of the nominal tax change and incorporate multiple changes within-locality. For example, in California in the second quarter 2015

\footnotetext{
${ }^{19}$ We do not stack our event study. That is, we do not estimate the stacked event study as proposed by Cengiz et al. (2019) and instead estimate a canonical event study in the spirit of Autor (2003). Our rationale for using the canonical rather than stacked event study is due to the nature of the policy variation we study. Many localities only have one tax change and, among those that localities that have multiple changes (typically increases in the rate over time), the changes occur in relatively quick succession and do not offer sufficient time for a reasonably long preand post-period. For example, California implemented its first e-cigarette tax in April 2017 and then increased the tax rate in July 2017, July 2018, and July 2019. In this locality, we could not have a pre- and post-period longer than one quarter in a stacked event study. For this reason (requiring a short pre- and post- period and required assumptions about the duration of anticipation and dynamics), we have elected to use the canonical event study.
} 
and third quarter 2015, the e-cigarette tax nominal changes that occur eight periods in the future in this state are $\$ 0.82$ and $\$ 1.13$ respectively. The $\$ 0.82$ change is attributable to the state’s initial tax of $\$ 0.82$ effective in the second quarter of 2017 and the second change is attributable to the legislated tax increase from \$0.82 to \$1.95 effective in the third quarter of 2017. All non-adopting localities are coded as zero for event-time bins. The omitted category, as in our canonical event study, is the period (quarter-year) just prior to policy adoption (e.g., quarter minus one).

Figure 2 shows the results from these event study analyses. The top panel uses event-time bins indicating the effective date of any e-cigarette tax ('canonical event study'), whereas the bottom panel uses future and past nominal tax changes in the standardized e-cigarette tax amount ('Cotti et al. event study'). As both event studies illustrate, there is no evidence of a differential trend in e-cigarette prices in adopting and non-adopting localities prior to the tax increase. In the first quarter after the tax increase, the coefficient estimate increases and stabilizes between 0.56 and 0.83 , suggesting that the implementation of an e-cigarette tax (without consideration of the tax magnitude) raises prices by $\$ 0.56$ to $\$ 0.83$, on average. When considering the size of the ecigarette tax change in the bottom panel of Figure 2, the coefficient estimate is between $\$ 0.93$ to $\$ 1.49$ from the second quarter after the tax increase to the final event-time bin of two years after the tax change.

\section{Pass-through robustness}

We also test the robustness of our findings in a number of ways. Figure 3 displays results from a number of specification tests. In the top panel, we test the robustness of our results to various changes in our sample. First, we drop the enactment period of each e-cigarette tax change. Next, we explore whether there is heterogeneity in the estimates between state vs. local taxes by estimating separate regression models that use 1) sub-state variation in taxes, i.e., drop treated 
states, and 2) state-level variation in taxes, i.e., drop treated sub-states. Our results here suggest that state-level e-cigarette taxes are passed through to prices at roughly the same level as e-cigarette taxes implemented at the sub-state level.

Next, to examine whether the existence of cross-border shopping affects the pass-through of e-cigarette sales to prices, we drop counties for all periods that are within 50 miles of a reduced tax source as of the end of 2019. This action implies that we exclude Cook County, Montgomery County, Washington DC, and many other counties near reduced-tax borders in states taxing ecigarettes. In the final two analyses that explore robustness across alternative samples, we use forward imputation for missing e-cigarette prices for localities with zero sales for a given UPC code, and include the years 2011-2012 (i.e., the time period prior to NielsenIQ adding a specific UPC category for e-cigarettes) from the analysis sample. Across our different samples we find similar pass-through rates of around 0.9 .

The bottom panel of Figure 3 shows pass-through results from different model specifications for the same sample. First, our results are robust to adding Census division-byperiod fixed effects. Second, we control for the e-cigarette tax enactment period. Next, we include additional political controls that may affect whether localities pass e-cigarette taxes (Maclean et al. 2018). This is motivated by the hypotheses that legislatures weigh the costs (e.g., lost votes) and benefits (e.g., increased revenue) when deciding whether or not to levy an e-cigarette tax. We control for the political party of the Governor (University of Kentucky Center for Poverty Research 2021), the state government ideology index (Berry et al. 1998), a lag in the state legislature budget shortfall as legislatures may elect to enhance revenues through taxation during times when they 
have recently fallen short of expenditures (Kaplan 2021), ${ }^{20}$ the amount of tobacco campaign contributions to state and national legislative candidates using data from Open Secrets (2021), and the locality-level population-weighted distance to the nearest county without an e-cigarette tax (to account for smuggling possibilities which legislators may consider in the context of e-cigarette tax adoption). ${ }^{21}$ Then we additionally add in the adult smoking rate (Centers for Disease Control and Prevention 2021), as this rate may affect the passage of e-cigarette taxes and the pass-through of e-cigarette taxes to prices. ${ }^{22}$ To further examine the influence of cross-border purchases, we also include the locality-level population-weighted distance to the nearest county without an e-cigarette tax without the additional political variables.

We also examine whether our coefficient estimates are sensitive to different sample weights. Finally, we examine robustness to variations in tax measurements: we lag the e-cigarette tax variable by one quarter and one year to allow for dynamic effects, examine only refills (rather than starter kits and disposables) in our tax pass-through analysis, dichotomize our e-cigarette tax, and use only state cigarette taxes (not including population-weighted local cigarette taxes or the federal tax). Results across this table are broadly similar to our main findings, except in the case when we lag the e-cigarette tax by one year (thus assigning treated units to the pre-period) or when we use an any e-cigarette tax binary variable (thus ignoring considerable variation in e-cigarette tax magnitudes).

\footnotetext{
${ }^{20}$ We calculate this variable as the difference between (lagged) state revenue and state expenditures. Washington DC is not a state, and we impute the mean lagged short-fall value. Results, available on request, are robust to excluding Washington DC. We assign counties the value of their state

${ }^{21}$ Data available here: https://rcfording.com/state-ideology-data/ (last accessed July 13, 2022). Washington DC is not a state and thus political variables are not defined. Following Maclean and Saloner (2018) we treat the Mayor of Washington DC as the de factor Governor of that locality. We assign the most liberal government ideology score observed in the empirical distribution to Washington DC. Results (available on request) are robust to excluding Washington DC. We assign counties the value of their state.

${ }^{22}$ Since e-cigarette taxes could affect smoking rates directly, this control is possibly endogenous.
} 
In Online Appendix Figure 2, we show estimated e-cigarette tax pass-through coefficients for various estimated e-cigarette wholesale prices to explore sensitivity of our results to the use of an e-cigarette wholesale price of \$2.99 per fluid ml. We show results using assumed wholesale prices that range from $\$ 1.50$ to $\$ 4.50$. We first show results using an assumed wholesale price of $\$ 3.00$ that closely matches our assumed wholesale price of $\$ 2.99$. These results show that the pass-through rate is roughly 1:1 or less if the wholesale price is $\$ 3.00$ or more but would be higher than 1:1 if the e-cigarette wholesale price is lower. Next, in Online Appendix Figure 3 we sequentially drop each treatment locality to examine whether any single treatment locality has an outsized impact on our coefficient estimates (i.e., a leave-one-out analysis). These results are stable across the leave-one-out samples.

\section{c. Estimates of effects of e-cigarette taxes and prices on tobacco product sales}

\section{$\underline{\text { Sales main results }}$}

Next, we examine the effects of e-cigarette and cigarette taxes on the sales of e-cigarettes and other tobacco products. For these analyses, we examine sales at the locality-period level with a reduced form model and also use an instrumental variables model where e-cigarette and cigarette prices are instrumented with taxes.

The top panel of Table 2 shows reduced form model results for e-cigarettes and cigarettes. The first column for each product shows regressions including locality and time period fixed effects, and the second through fourth columns for each product additionally include time-varying controls (tobacco control policies, substance use policies, and demographics). Our results suggest that every $\$ 1.00$ increase in e-cigarette taxes reduces e-cigarette sales by $919 \mathrm{ml}$ in the fourth column (implied price elasticity $=-2.2$ ). ${ }^{23}$ Conversely, each dollar increase in cigarette taxes

\footnotetext{
${ }^{23}$ Please see the footnote for Table 2 for a description on how elasticities are calculated.
} 
suggests an increases e-cigarette sales by $403 \mathrm{ml}$ (implied cross-price elasticity $=1.5$ ), but this coefficient estimate is not statistically significant. We also observe a similar pattern of economic substitution between cigarettes and e-cigarettes. Shown in the final column of Table 2, we observe that a $\$ 1.00$ increase in cigarette taxes reduces cigarette sales by 5,226 packs, which translates to an implied own-price elasticity of roughly -0.4, while a \$1.00 increase in e-cigarette taxes increases cigarette sales by 4,863 packs, which corresponds to an implied cross-price elasticity of approximately 0.4 .

The bottom panel of Table 2 shows results from instrumental variable models where we instrument for e-cigarette prices and cigarette prices with e-cigarette taxes and cigarette taxes (Equation 3). We find that a $\$ 1.00$ increase in e-cigarette prices reduces e-cigarette sales by roughly $837 \mathrm{ml}$ (see panel B, column 4), while a \$1.00 increase in cigarette prices reduces cigarette sales by roughly 4,223 packs (see panel B, column 8). These coefficient estimates translate into own-price elasticities of roughly -2.2 and -0.4 , respectively. ${ }^{24}$ Overall, the cigarette price elasticities estimated in the reduced form and instrumental variable models are in line with both the implied price elasticities in the reduced form models and many previous estimates of the price elasticity of demand for cigarettes (Chaloupka and Warner 2000, DeCicca et al. 2018, DeCicca, Kenkel, and Lovenheim 2020). By showing comparability between implied price elasticity estimates from reduced form models and price elasticity estimates from instrumental variable models that has the additional assumption of the exclusion restriction (i.e., taxes influence sales only through prices), this suggests limited influence of other factors that may be affected by e-

\footnotetext{
${ }^{24}$ Elasticity standard errors are approximately 0.5 and 0.1 respectively, which are estimated using a non-parametric bootstrapping procedure with 999 repetitions
} 
cigarette taxes (as pointed out by Rees-Jones and Rozema (2019)), such as risk perceptions (Abouk

et al. 2021; Abouk et al. 2022), lobbying, and other tobacco control efforts. ${ }^{25}$

Our instrumental variable results again suggest that cigarettes are economic substitutes for e-cigarettes, evident in the positive and statistically significant effect of e-cigarette prices on cigarette sales. A $\$ 1.00$ increase in the price of e-cigarettes per fluid $\mathrm{ml}$ is estimated to increase cigarette sales by 4,417 packs which translates into a cross-price elasticity of roughly 0.4 . When looking at the cross-price relationship the other direction (the cigarette tax relationship with ecigarette sales), we again observe a positive cross-price estimate, but it is not statistically significant (cross-price elasticity $=1.1) .{ }^{26}$

\section{$\underline{\text { Sales identification }}$}

Figures 4 and 5 examine event study estimates of the effects of e-cigarette and cigarette taxes on sales. ${ }^{27}$ In Figure 4, trends in both e-cigarette and cigarette sales are stable prior to the adoption of an e-cigarette tax, though there is evidence in the e-cigarette sales figure of anticipation in the quarter prior to the tax coming into place. ${ }^{28}$ However, after the tax is implemented e-cigarette sales drop steadily over the next eight quarters. Correspondingly, substitution toward cigarettes is

\footnotetext{
${ }^{25}$ One possibility is that the revenue from some taxes could be targeted toward specific tobacco control initiatives (such as information-spreading campaigns) that could affect sales irrespective of prices. To investigate this possibility, we read the statutes that established or raised e-cigarette taxes (Public Health Law Center 2021). We only found evidence that e-cigarette taxes are used for tobacco control in California, where some e-cigarette tax revenue is earmarked for enforcing tobacco control laws, tobacco use prevention, and other tobacco-related initiatives. This earmarking of revenue contributes to California being the only e-cigarette tax state within $60 \%+$ of CDC recommended tobacco prevention and cessation program funding levels in 2018 (Campaign for Tobacco Free Kids 2017). In a subsequent leave-one-out robustness check, we show that e-cigarette tax effects are broadly similar if we drop California from the sample, suggesting any violation of the exclusion restriction from California impacts our results little. ${ }^{26}$ Elasticity standard errors are 0.11 and 0.58 respectively, which are estimated using a nonparametric bootstrapping procedure with 999 repetitions.

${ }^{26}$ Elasticity standard errors are 0.11 and 0.58 respectively, which are estimated using a non-parametric bootstrapping procedure with 999 repetitions.

${ }^{27}$ These event studies include all policy controls and end points restricted to eight period before or eight periods after policy implementation. Online Appendix Discussion 2 describes and presents a series of event study specifications that demonstrate the robustness of the results in Figures 4 and 5 to various model choices. ${ }^{28}$ The choice of reference group for e-cigarette sales causes some pre-period coefficients to be statistically significant positive, though importantly these coefficients do not have a pre-period trend.
} 
observed in the bottom panel of Figure 4, as cigarette sales slowly increase over time. In Figure 5, sales of both products are also steady in the quarters before a cigarette tax increase, after which sales of cigarettes fall sharply, although sales of e-cigarettes do not show a statistically significant increase, which is consistent with the estimates in Table 2. Across these two figures, e-cigarette and cigarette results appear to be opposite of each other in the post-period at any point in time. Ecigarette taxes appear to have larger effects over time, which could be caused by e-cigarette taxes having little impact on the relatively small share of current users and instead discouraging new ecigarette users in the future. Cigarette taxes meanwhile have short-term effects that fade over time. This could reflect individuals attempting to quit smoking at the time of the tax and being unsuccessful long-term. ${ }^{29}$

\section{$\underline{\text { Sales Robustness }}$}

Figures 6 and 7 demonstrate that our e-cigarette tax findings in Table 2 are largely robust to various samples and estimation strategies described above, with the only clear outlier again being using an any e-cigarette tax binary variable, thus ignoring considerable variation in conditional e-cigarette tax rates. ${ }^{30}$ When controlling for distance to a locality's reduced tax source, the e-cigarette tax coefficient is attenuated by roughly 1/3 (from -919 to -626) and the distance measure suggests that increases in the locality’s average distance to a no-tax source reduces e-

\footnotetext{
${ }^{29}$ Current estimates from Cochrane find that for every 100 people using nicotine e-cigarettes to stop smoking, nine to 14 might successfully stop, compared with only six of 100 people using nicotine-replacement therapy, seven of 100 using nicotine-free e-cigarettes, or four of 100 people having no support or behavioral support only (HartmannBoyce et al. 2021).

${ }^{30}$ In Online Appendix Table 4 we also show coefficient estimates using the ad valorem tax rate (as a percent of the wholesale price) rather than transforming this to fluid ml. We drop states using different tax schema than ad valorem. We do not include these estimates in the various alternative specification figures because the e-cigarette tax is scaled differently, but the coefficient estimate directionality and precision remain the same as previously reported results for all three outcomes (e-cigarette prices, e-cigarette sales, and cigarette sales). The elasticity point estimate is larger here than those reported in Table 2, which is a mechanical feature of calculating point estimate elasticities since the ad valorem taxes are larger in value than excise and sales taxes (see Online Appendix Table 1), hence the numerator for calculating the tax elasticity point estimate is larger.
} 
cigarette sales by another 9.7 fluid $\mathrm{ml}(\mathrm{p}<0.01)$. In Online Appendix Figures 5 and 6 we show that results are insensitive to excluding one treatment locality at a time.

One final concern with our results is the extent to which our two-way fixed effects results may be biased by heterogeneity and dynamic treatment effects as described in the growing literature on difference-in-differences models with staggered treatment rollout (Goodman-Bacon 2021). A central concern raised within this literature is that, in the presence of treatment effect heterogeneity and dynamics, two-way fixed effects models compare later treated units to earlier treated units ('forbidden comparisons'), which can lead to negative weighting and biased estimates of the overall average treatment effect on the treated. To assess the potential importance of such bias, we apply a Goodman-Bacon decomposition. To focus exclusively on comparisons across localities treated at different times, which is the objective of this exercise, we exclude time-varying covariates and remove population weights. Further, we must dichotomize the e-cigarette tax variable prior to preforming this decomposition. ${ }^{31}$ Second, we apply a procedure proposed by Callaway and Sant'Anna (2021) that is robust to heterogeneity and dynamics in treatment effects with a staggered treatment rollout. The procedure estimates average treatment effects for groups that adopt treatment in the same period (i.e., localities adopting e-cigarette taxes in the same period in our context) and weights these group-specific estimates by treatment group size to produce a group-weighted estimate of the average treatment effect on the treated. ${ }^{32}$ The results of these analyses are shown in Table 3.

\footnotetext{
${ }^{31}$ We acknowledge that while our exercise is focused on assessing potential estimation bias from heterogeneity and dynamic treatment effects, this exercise prevents us from estimating a specification comparable to our preferred model (e.g., we must dichotomize the tax variable), which could introduce other sources of bias. Nevertheless, the similarity in results from these models and our two-way fixed effect models is reassuring of limited estimation bias. ${ }^{32}$ We must exclude always treated units (i.e., Minnesota) when applying the Callaway and Sant'Anna procedure, and we exclude covariates and remove weights to mimic our application of the Goodman-Bacon decomposition. More generally, the recent literature on difference-in-differences with staggered treatment rollout has emphasized a setting without covariates. We apply the Callaway and Sant'Anna procedure using a doubly robust DiD estimator
} 
The Goodman-Bacon decomposition suggests that the majority of our effects are driven by comparisons of treated localities and never-treated localities, that is 'clean' comparisons that do not use previously treated groups as the comparison group. The coefficient estimates from the Callaway and Sant'Anna procedure also closely mirror the coefficient estimates from our two-way fixed effects model. Thus, we do not find evidence from these tests that estimation bias from treatment effect heterogeneity and dynamics is a significant source of concern for our primary model. This finding is perhaps not surprising as our application offers a large comparison group (i.e., most localities have not adopted a tax by the end of our study period and taxes are adopted in the second half of the study period), which is a setting where estimation bias from heterogeneity and dynamic treatment effects is expected to be small.

\section{Extension: Flavors}

Tables 4 and 5 examine sales responses by e-cigarette and cigarette flavor and whether taxes affect e-cigarette product characteristics. Examination of tax effects across tobacco products with different flavoring may help understand the effect of e-cigarette taxes on youth in particular, who are much more likely to use flavors than adults. According to the 2014-15 Population Assessment of Tobacco and Health data, 74\% of adults 25 years of age and older used tobacco or mentholated/mint flavored e-cigarettes compared to only $42 \%$ of 18 - to 24 -year-olds and $36 \%$ of 12- to 17-year-olds (Soneji, Knutzen, and Villanti 2019). Thus, studying the effect of e-cigarette prices on sales of flavored e-cigarettes can allow us to explore heterogeneity in tax and price responsiveness by age to some extent. In Table 4, we find that sales of all flavor categories of ecigarettes and cigarettes respond to changes in both cigarette and e-cigarette taxes. Specifically, we estimate that e-cigarette taxes decreased non-flavored, menthol, and flavored e-cigarette sales, 
while increasing unflavored cigarette sales. Notably, flavored e-cigarette sales are especially sensitive to e-cigarette taxes and contribute heavily to the large own tax elasticities of demand measured in Table 2. Further, we estimate that increases in cigarette taxes increase e-cigarette sales while decreasing both unflavored and menthol cigarette sales. In the bottom panel of Table 4, we document similar heterogeneity in price elasticities of demand as shown in our reduced form regressions. ${ }^{33}$

\section{Extension: E-cigarette Market Characteristics and Other Tobacco Products}

Table 5 examines whether e-cigarette and cigarette taxes lead to increases in the number of new e-cigarette products sold in localities, the average liquid per unit, or the nicotine percentage of the liquid. A \$1.00 increase in e-cigarette taxes is estimated to bring 2.3 new e-cigarette products to market ( $13 \%$ of the mean), but this is not statistically significant. We do see that cigarette taxes increase the liquid per unit sold, suggesting that consumers substitute away from cigarettes and toward e-cigarettes with larger liquid volumes (Lillard 2020). In Online Appendix Table 5, we do not see statistically significant relationships between e-cigarette or cigarette taxes and sales of cigars, chewing tobacco, or loose tobacco.

\section{Discussion}

In this paper, we examine the effects of e-cigarette taxes on e-cigarette prices, e-cigarette sales, and other tobacco product sales. We find that e-cigarette taxes are almost fully shifted to consumer prices. This pattern of results suggests that policymakers almost fully control e-cigarette retail prices through the setting of tax policy. We also find that e-cigarettes are an elastic good,

\footnotetext{
${ }^{33}$ We continue to use overall e-cigarette and cigarette prices for these models instead of product-by-flavor specific prices since doing so would require including up to five endogenous variables for each product-by-flavor category (leading to under-identification) and because the e-cigarette standardized tax is constructed for use with market-level data and may not be appropriate for e-cigarette subgroups since, for example, wholesale prices for flavored ecigarette products may be different than for unflavored e-cigarette products.
} 
with an estimated price elasticity of demand of -2.2. Further, our models find that the elasticity of demand for non-mentholated flavored e-cigarettes is substantially larger than for unflavored ecigarettes and mentholated e-cigarettes. The substantially larger tax responsiveness for nonmentholated flavored e-cigarettes perhaps reflects larger responsiveness among younger ecigarette users that are more likely to use flavored e-cigarettes.

Our results are subject to several limitations. First, our data captures tobacco products sold through retail stores, and so we do not observe e-cigarettes sold through specialty vape shops and online. One study estimates that in $2015,40 \%$ of e-cigarette sales occurred in retail stores similar to those we study in the NRSD (Levy et al. 2019), and another study finds that in 2016 30\% of U.S. adult vaporers purchased e-cigarettes in retail stores (Braak et al. 2019). However, e-cigarette taxes are collected for both online and vape shop purchases in the same way they are collected in retail stores, so we are unaware of any financial incentive to change shopping venue in response to an e-cigarette tax. ${ }^{34}$ Second, since our study extends through 2019 and all but one state adopt their e-cigarettes taxes in 2015 and after, our results should be interpreted as short-term effects. Long-term effects may differ. In particular, our event study estimates suggest that e-cigarette tax effects may grow larger over time and that a sizable share of our responsiveness estimates may occur two or more years after taxes change, possibly suggesting e-cigarette taxes discourage future uptake of e-cigarettes among people not using them at the time of the tax but that would have used them in the future in the absence of the tax.

Subject to these caveats, our paper finds evidence that e-cigarettes and cigarettes are economic substitutes, particularly with respect to e-cigarette taxes increasing cigarette sales (cross-

\footnotetext{
${ }^{34}$ Moreover, e-cigarette tax rates are found to operate similarly in studies using survey data on adult and young adult e-cigarette and cigarette use (Pesko, Courtemanche, and Maclean 2020; Friedman and Pesko 2022), administrative and survey data for pregnant women (Abouk et al. 2022), and for youth (Abouk et al. 2021) suggesting external validity.
} 
price elasticity $=0.4)$. A $\$ 1.00$ increase in e-cigarette taxes, per 100,000 adult residents, is anticipated to reduce e-cigarette sales in NRSD-tracked stores by 919 fluid $\mathrm{ml}$ and increase cigarette sales by 4,863 packs. To estimate a substitution rate, we assume that a 0.7 fluid $\mathrm{ml}$ JUUL pod is equivalent to one pack of cigarettes and compensate for NRSD-tracked stores capturing roughly twice the share of cigarette sales than e-cigarette sales. This calculation suggests that for every one e-cigarette pod eliminated due to an e-cigarette tax, approximately 1.9 packs of cigarettes are sold instead. ${ }^{35}$ This finding is concerning from a public health perspective given that e-cigarettes are less dangerous products (National Academies of Sciences Engineering and Medicine 2018, Royal College of Physicians 2019, Allcott and Rafkin 2021) and given that we estimate that e-cigarette taxes lead to more cigarette packs purchased than e-cigarette pods eliminated. This substitution estimate can be used along with others in the literature, ${ }^{36}$ along with uninternalized distortion of existing taxes, to determine optimal taxation from a social welfare standpoint (Allcott and Rafkin 2021). One concept endorsed by a number of leading national experts (e.g., Chaloupka, Sweanor, and Warner 2015, Sindelar 2020, Balfour et al. 2021) is to tax e-cigarettes proportionate to their risk relative to cigarettes as a way to reduce public health harm (which is related to but different from overall social welfare).

Since the end of our study period in 2019, e-cigarette taxes continue to be debated and adopted. Between the end of our study period (December 2019) and June 2022, 13 additional states

\footnotetext{
352.1 = 4,863 / (919 x 200\% / 0.7). Tax-paid cigarette sales are provided by Tax Burden on Tobacco reports, and ecigarette sales are provided by a Cowan financial report. The issue of the NRSD capturing different shares of the cigarette and e-cigarette market should not be a threat to accurately estimating cross-elasticities, since the baseline level of sales will reflect the relative proportion of each market in the NRSD.

${ }^{36}$ Please see Section 2 for a review. Of 13 studies in total assessing the relationship between e-cigarettes and cigarettes, we document 10 studies finding they are substitutes (Pesko, Courtemanche, and Maclean 2020, Friedman and Pesko 2022, Saffer et al. 2020, Pesko and Warman 2022, Friedman 2015, Pesko Hughes, and Faisal 2016, Dave Feng, and Pesko 2019, Pesko and Currie 2019, Dave et al. 2019, and Tuchman 2019), one study finding they are largely unrelated goods (though some evidence of substitution is present) (Allcott and Rafkin 2021), and two studies finding they are complements (Abouk and Adams 2017 and Cotti, Nesson, and Tefft 2018).
} 
enacted e-cigarette taxes, bringing the total number of states taxing these products to 30 (Public Health Law Center 2022). As of September 30, 2020, 39 jurisdictions and three American Indian tribes have banned the sale of all e-cigarettes (Truth Initiative 2020). In November 2021, the House of Representatives passed a bill that increased the e-cigarette tax roughly proportionate to the federal cigarette tax of \$1.01 per pack (Build Back Better Act 2021). Generalizability concerns aside, our e-cigarette tax marginal effect estimates are therefore similar to what we could expect if this bill were to become law.

Our finding of substitution between e-cigarettes and cigarettes may be explained by several factors. First, a randomized controlled trial in England demonstrates that e-cigarettes are nearly twice as effective as existing nicotine replacement therapy at achieving one-year cigarette abstinence: $18.0 \%$ versus $9.9 \%$ (Hajek et al. 2019). This relatively high effectiveness of ecigarettes occurs despite England capping e-cigarette nicotine content at no more than 20 milligrams/ml (CNN 2019), which is only one third of JUUL's nicotine concentration of 59 milligrams $/ \mathrm{ml}$ (at 5\% nicotine). American e-cigarettes therefore contain more nicotine and may be more effective smoking cessation products, as nicotine is the product ultimately demanded by tobacco product consumers (Lillard 2020). ${ }^{37}$ Second, e-cigarettes are more widely used for smoking cessation than nicotine replacement therapies, e.g., 32\% of current and past-year former smokers used e-cigarettes as their single method to quit smoking, compared to $18 \%$ using nicotine replacement therapy (Rodu and Plurphanswat 2017). Third, evidence from a longitudinal cohort study finds that daily e-cigarette use may help smokers to transition to non-smoking even if these

\footnotetext{
${ }^{37}$ We note that the Lillard (2020) model suggests that cigarettes may complement e-cigarettes over some periods of the lifecycle (for example, during quit attempts) and serve as substitutes over different periods (e.g., during initiation). The model does not make predictions regarding the average relationship between the products, this average is likely a complex weighted average of different types of smokers in the market at that time. Our data, aggregate sales data, are not sufficiently fine to allow us to study these interesting predictions from the Lillard (2020) model. We encourage future work on this important question, using different sources of data that allow analysis of individual consumption of tobacco products over time.
} 
individuals had no interest in quitting (Kasza et al. 2021). This finding suggests that focusing exclusively on smokers who want to quit may underestimate the full impact that e-cigarettes have in reducing smoking. Finally, if e-cigarettes help to prevent or reduce cigarette use among young adults, this may be a factor in generating a high rate of substitution. ${ }^{38}$ Our high rate of substitution also appears in line with financial reporting statements made by Philip Morris that claims cigarettes may disappear from some countries within the next ten to 15 years (Lester 2020).

Our study contributes important insights on the effect of e-cigarette taxes on a variety of ecigarette and other tobacco products. Smoking remains the leading estimated cause of preventable death in the United States (Centers for Disease Control and Prevention 2019). Further research on the role reduced-risk tobacco products play in contributing to or lessening smoking related preventable deaths will remain important going forward, especially as the tobacco marketplace continues to rapidly evolve.

\footnotetext{
${ }^{38}$ Analysis of the 2011 National Youth Tobacco Survey shows that 3.3\% of youth had already used e-cigarettes in their lifetime. Friedman and Pesko (2022) found young adults 18-25 years of age that stop using cigarettes or ecigarettes due to taxes substitute to use the other tobacco product nearly 1:1.
} 


\section{References}

Abouk, Rahi, and Scott Adams. 2017.“"Bans on electronic cigarette sales to minors and smoking among high school students"" Journal of Health Economics 54:17-24.

Abouk, Rahi, Scott Adams, Bo Feng, Johanna Catherine Maclean, and Michael F Pesko. 2022."'The Effect of E-Cigarette Taxes on Pre-Pregnancy and Prenatal Smoking, and Birth Outcomes"" NBER Working Paper No. 26126.

Abouk, Rahi, Charles J Courtemanche, Dhaval M Dave, Bo Feng, Abigail S Friedman, Johanna Catherine Maclean, Michael F Pesko, Joseph J Sabia, and Samuel Safford.

2021.""Intended and unintended effects of e-cigarette taxes on youth tobacco use”" NBER Working Paper No. 29216.

Adams, Scott, Chad D Cotti, and Daniel M Fuhrmann. 2013.“"'Smokeless tobacco use following smoking bans in bars”" Southern Economic Journal 80 (1):147-161.

Ali, Fatma Romeh M., Megan C. Diaz, Donna Vallone, Michael A. Tynan, Jamie Cordova, Elizabeth L. Seaman, Katrina F. Trivers, Barbara A. Schillo, Brandon Talley, and Brian A. King. 2020.“"E-cigarette unit sales, by product and flavor type-United States, 20142020”" Morbidity and Mortality Weekly Report 69(37): 1313.

Allcott, Hunt, and Charlie Rafkin. 2021."'Optimal Regulation of E-cigarettes: Theory and Evidence”" American Economic Journal: Economic Policy forthcoming.

Autor, D.H., 2003. Outsourcing at will: The contribution of unjust dismissal doctrine to the growth of employment outsourcing. Journal of labor economics, 21(1), pp.1-42.

Balfour, David JK, Neal L Benowitz, Suzanne M Colby, Dorothy K Hatsukami, Harry A Lando, Scott J Leischow, Caryn Lerman, Robin J Mermelstein, Raymond Niaura, and Kenneth A Perkins. 2021.“"Balancing Consideration of the Risks and Benefits of E-Cigarettes”" American Journal of Public Health (0):e1-e12.

Berry, William D, Evan J Ringquist, Richard C Fording, and Russell L Hanson. 1998.“"Measuring citizen and government ideology in the American states, 1960-93”" American Journal of Political Science:327-348.

Besley, Timothy. 1989."'Commodity taxation and imperfect competition: A note on the effects of entry"" Journal of Public Economics 40 (3):359-367.

Besley, Timothy, and Anne Case. 2000.“"Unnatural experiments? Estimating the incidence of endogenous policies”" The Economic Journal 110 (467):672-694.

Braak, David C, K Michael Cummings, Georges J Nahhas, Bryan W Heckman, Ron Borland, Geoffrey T Fong, David Hammond, Christian Boudreau, Ann McNeill, and David T Levy. 2019.“"Where do vapers buy their vaping supplies? Findings from the international tobacco control (ITC) 4 country smoking and vaping survey”" International Journal of Environmental Research and Public Health 16 (3):338.

Build Back Better Act, H.R. 5376, 119 ${ }^{\text {th }}$ Cong. 2021. https://rules.house.gov/sites/democrats.rules.house.gov/files/BILLS-117HR5376RHRCP117-18.pdf

Callaway, Brantly, and Pedro HC Sant’Anna. 2021.“"Difference-in-differences with multiple time periods”" Journal of Econometrics 225 (2):200-230.

Cantrell, Jennifer, Jidong Huang, Marisa S Greenberg, Haijuan Xiao, Elizabeth C Hair, and Donna Vallone. 2019.“"Impact of e-cigarette and cigarette prices on youth and young adult e-cigarette and cigarette behaviour: Evidence from a national longitudinal cohort”" Tobacco Control 29 (4):374-380. 
Campaign for Tobacco Free Kids. 2017. "Broken Promises to Our Children - A State-by-State Look at the 1998 Tobacco Settlement 19 Years Later.” Retrieved from https://www.tobaccofreekids.org/assets/content/what_we_do/state_local_issues/settlemen t/FY2018/FY2018_state_settlement_report.pdf.

Cawley, John, Anne Marie Thow, Katherine Wen, and David Frisvold. 2019.“"The Economics of Taxes on Sugar-Sweetened Beverages: A Review of the Effects on Prices, Sales, Cross-Border Shopping, and Consumption”" Annual Review of Nutrition 39:317-338.

Cengiz, D., Dube, A., Lindner, A. and Zipperer, B., 2019. The effect of minimum wages on lowwage jobs. The Quarterly Journal of Economics, 134(3), pp.1405-1454.

Centers for Disease Control and Prevention. 2019. Smoking \& Tobacco Use Fast Facts. Retrieved from https://www.cdc.gov/tobacco/data statistics/fact sheets/fast facts/index.htm

Centers for Disease Control and Prevention. 2021. State Tobacco Activities Tracking and Evaluation (STATE) System.

Centers for Disease Control and Prevention. 2020a."'"Tobacco Product Use Among Adults United States, 2019”" Morbidity and Mortality Weekly Report 69 (46):1736-1742.

Centers for Disease Control and Prevention. 2020b."'Trends in the Prevalence of Tobacco Use National YRBS: 1991-2019”" https://www.cdc.gov/healthyyouth/data/yrbs/factsheets/2019 tobacco trend yrbs.htm.

Chaloupka, Frank J, David Sweanor, and Kenneth E Warner. 2015.“"Differential Taxes for Differential Risk—-Toward Reduced Harm from Nicotine-Yielding Products”" New England Journal of Medicine 373:594-597.

Chaloupka, Frank J, and Kenneth E Warner. 2000.“"The economics of smoking”" Handbook of Health Economics 1:1539-1627.

CNN. 2019.“"The US and UK see vaping very differently. Here's why”" Last Modified September 17, 2019, accessed 3/20/2020. https://www.cnn.com/2019/09/17/health/vaping-us-uk-e-cigarette-differencesintl/index.html.

Cotti, Chad, Erik Nesson, Michael F Pesko, Serena Phillips, and Nathan Tefft. 2021.""Standardising the measurement of e-cigarette taxes in the USA, 2010-2020”" Tobacco Control.

Cotti, Chad, Erik Nesson, and Nathan Tefft. 2016.“"The Effects of Tobacco Control Policies on Tobacco Products, Tar, and Nicotine Purchases among Adults: Evidence from Household Panel Data”" American Economic Journal: Economic Policy 8 (4):103-123.

Cotti, Chad, Erik Nesson, and Nathan Tefft. 2018.“"The relationship between cigarettes and electronic cigarettes: Evidence from household panel data"" Journal of Health Economics 61:205-219.

Dave, Dhaval, Daniel Dench, Michael Grossman, Donald S Kenkel, and Henry Saffer. 2019."“Does e-cigarette advertising encourage adult smokers to quit”" Journal of Health Economics 68:102227.

Dave, Dhaval, Bo Feng, and Michael F Pesko. 2019.“"The effects of e-cigarette minimum legal sale age laws on youth substance use”" Health Economics 28 (3):419-436.

Dave, Dhaval, and Henry Saffer. 2013.“"Demand for smokeless tobacco: role of advertising”" Journal of Health Economics 32 (4):682-697.

DeCicca, Philip, Donald Kenkel, and Feng Liu. 2013.“"Who pays cigarette taxes? The impact of consumer price search”" Review of Economics and Statistics 95 (2):516-529. 
DeCicca, Philip, Donald S Kenkel, and Michael F Lovenheim. 2020. The Economics of Tobacco Regulation: A Comprehensive Review. Journal of Economic Literature.

DeCicca, Philip, Donald S Kenkel, Michael F Lovenheim, and Erik Nesson. 2018."'The Economics of Smoking Prevention"" In Oxford Research Encyclopedia of Economics and Finance.

Friedman, Abigail S. 2015.“"How does electronic cigarette access affect adolescent smoking”" Journal of Health Economics 44:300-308.

Friedman, Abigail S. and Michael Pesko. 2022 (in press). "Young Adult Responses to Taxes on Cigarettes and Electronic Nicotine Delivery Systems.” Addiction.

Gehrsitz, Markus, Henry Saffer, and Michael Grossman. 2021. "The effect of changes in alcohol tax differentials on alcohol consumption." Journal of Public Economics 204: 104520.

Goodman-Bacon, Andrew. 2021. "Difference-in-differences with variation in treatment timing." Journal of Econometrics.

Hajek, Peter, Anna Phillips-Waller, Dunja Przulj, Francesca Pesola, Katie Myers Smith, Natalie Bisal, Jinshuo Li, Steve Parrott, Peter Sasieni, and Lynne Dawkins. 2019. "A randomized trial of e-cigarettes versus nicotine-replacement therapy." New England Journal of Medicine 380 (7):629-637.

Hamilton, Stephen F. 1999. "Tax incidence under oligopoly: a comparison of policy approaches." Journal of Public Economics 71 (2):233-245.

Hannan, E.J., 1971. The identification problem for multiple equation systems with moving average errors. Econometrica, pp.751-765.

Hanson, Andrew, and Ryan Sullivan. 2009. "The incidence of tobacco taxation: evidence from geographic micro-level data." National Tax Journal 62 (4):677-698.

Harding, Matthew, Ephraim Leibtag, and Michael F Lovenheim. 2012. "The heterogeneous geographic and socioeconomic incidence of cigarette taxes: evidence from Nielsen homescan data." American Economic Journal: Economic Policy 4 (4):169-98.

Hartmann-Boyce, Jamie, et al. "Electronic cigarettes for smoking cessation." Cochrane database of systematic reviews 9 (2021).

Hoehn-Velasco, Michael Pesko, and Serena Phillips. 2022. "The Long-Term Impact of In-Utero Cigarette Taxes on Adult Prenatal Smoking.” Working Paper: 1-64

Huang, Jidong, Cezary Gwarnicki, Xin Xu, Ralph S Caraballo, Roy Wada, and Frank J Chaloupka. 2018. "A comprehensive examination of own-and cross-price elasticities of tobacco and nicotine replacement products in the US." Preventive Medicine 117 (December):107-114.

Kaplan, Jacob. Annual Survey of State Government Finances 1992-2018. Ann Arbor, MI: Interuniversity Consortium for Political and Social Research [distributor], 2021-01-16. https://doi.org/10.3886/E101880V4

Kasza, Karin A, Kathryn C Edwards, Heather L Kimmel, Andrew Anesetti-Rothermel, K Michael Cummings, Raymond S Niaura, Akshika Sharma, Erin M Ellis, Rebecca Jackson, and Carlos Blanco. 2021. "Association of e-Cigarette Use With Discontinuation of Cigarette Smoking Among Adult Smokers Who Were Initially Never Planning to Quit." JAMA Network Open 4 (12):e2140880-e2140880.

Kenkel, Donald S. 2005. "Are alcohol tax hikes fully passed through to prices? Evidence from Alaska." American Economic Review 95 (2):273-277. 
Lester, Toby. 2020. "How Philip Morris Is Planning for a Smoke-Free Future." Harvard Business Review, accessed 8/8/2020. https://hbr.org/2020/07/how-philip-morris-is-planning-for-asmoke-free-future.

Levy, David T, Eric N Lindblom, David T Sweanor, Frank Chaloupka, Richard J O'connor, Ce Shang, Thomas Palley, Geoffrey T Fong, Michael K Cummings, and Maciej L Goniewicz. 2019. "An economic analysis of the Pre-Deeming us market for nicotine Vaping products." Tobacco Regulatory Science 5 (2):169-181.

Lillard, Dean R. 2020. "The Economics of Nicotine Consumption." In Handbook of Labor, Human Resources and Population Economics, 1-31. Springer.

Lillard, Dean R, and Andrew Sfekas. 2013. "Just passing through: the effect of the Master Settlement Agreement on estimated cigarette tax price pass-through." Applied Economics Letters 20 (4):353-357.

Maclean, J., Oney, M., Marti, J., \& Sindelar, J. (2018). What factors predict the passage of statelevel e-cigarette regulations? Health Economics, 27(5), 897-907.

Maclean, Johanna Catherine, and Brendan Saloner. 2018. "Substance use treatment provider behavior and healthcare reform: Evidence from Massachusetts." Health Economics 27 (1):76-101.

Manski, C.F., 2003. Identification problems in the social sciences and everyday life. Southern Economic Journal, pp.11-21.

Meer, J., \& West, J. (2016). Effects of the minimum wage on employment dynamics. Journal of Human Resources, 51(2), 500-522.

Mullahy, John. 2021. "Inverse Hyperbolic Sine Transformations and Retransformations." University of Wisconsin Working Paper.

National Academies of Sciences Engineering and Medicine. 2018. Public Health Consequences of E-Cigarettes. Edited by Kathleen Stratton, Leslie Y. Kwan and David L. Eaton. Washington, DC: The National Academies Press.

Ohsfeldt, Robert L, and Raymond G Boyle. 1994. "Tobacco excise taxes and rates of smokeless tobacco use in the US: an exploratory ecological analysis." Tobacco Control 3 (4):316.

Ohsfeldt, Robert L, Raymond G Boyle, and Eli Capilouto. 1997. "Effects of tobacco excise taxes on the use of smokeless tobacco products in the USA." Health Economics 6 (5):525-531.

Open Secrets. 2021. "Open Secrets Bulk Data." https://www.opensecrets.org/open-data/bulkdata.

Pei, Zhuan, Jörn-Steffen Pischke, and Hannes Schwandt. 2019. "Poorly measured confounders are more useful on the left than on the right." Journal of Business \& Economic Statistics 37 (2):205-216.

Pesko, Michael F, Charles J Courtemanche, and Johanna Catherine Maclean. 2020. "The Effects of Traditional Cigarette and E-Cigarette Taxes on Adult Tobacco Product Use." Journal of Risk and Uncertainty 60 (3):229-258.

Pesko, Michael F, and Janet M Currie. 2019. "E-cigarette minimum legal sale age laws and traditional cigarette use among rural pregnant teenagers." Journal of Health Economics 66:71-90.

Pesko, Michael F, Jidong Huang, Lloyd D Johnston, and Frank J Chaloupka. 2018. "E-cigarette price sensitivity among middle-and high-school students: Evidence from monitoring the future." Addiction 113 (5):896-906. 
Pesko, Michael F, Jenna M Hughes, and Fatima S Faisal. 2016. "The influence of electronic cigarette age purchasing restrictions on adolescent tobacco and marijuana use." Preventive Medicine 87 (June):207-212.

Pesko, Michael, and Casey Warman. 2022. "Re-exploring the early relationship between teenage cigarette and e-cigarette use using price and tax changes." Health Economics 31 (1):137153. doi: 10.1002/hec.4439.

Public Health Law Center. 2022. States \& Territories with Laws Taxing E-Cigarettes Enacted as of June 15, 2022. Public Health Law Center at the Mitchell Hamline School of Law. https://www.publichealthlawcenter.org/sites/default/files/inline-files/States-with-LawsTaxing-ECigarettes-June15-2022.pdf

Rees-Jones, Alex, and Kyle T Rozema. 2019. "Price isn’t everything: Behavioral response around changes in sin taxes." NBER Working Paper No. 25958.

Robinson, Peter M. 1988. "Root-N-consistent semiparametric regression." Econometrica 56 (4):931-954.

Rodu, Brad, and Nantaporn Plurphanswat. 2017. "Quit methods used by American smokers, 2013-2014." International Journal of Environmental Research and Public Health 14 (11):1403.

Royal College of Physicians. 2019. Promote e-cigarettes widely as substitute for smoking says new RCP report.

Rozema, Kyle, and Nicolas R Ziebarth. 2017. "Taxing consumption and the take-up of public assistance: The case of cigarette taxes and food stamps." The Journal of Law and Economics 60 (1):1-27.

Saffer, Henry, Daniel Dench, Dhaval Dave, and Michael Grossman. 2018. "E-cigarettes and Adult Smoking." NBER Working Paper No. 24212

Saffer, Henry, Daniel L Dench, Michael Grossman, and Dhaval M Dave. 2020. "E-Cigarettes and Adult Smoking: Evidence from Minnesota." Journal of Risk \& Uncertainty 30 (3).

Sandler, Danielle H, and Ryan Sandler. 2014. "Multiple event studies in public finance and labor economics: A simulation study with applications." Journal of Economic and Social Measurement 39 (1-2):31-57.

Sant'Anna, P. H., \& Zhao, J. 2020. Doubly robust difference-in-differences estimators. Journal of Econometrics, 219(1), 101-122.

Schneller, L. M., Bansal-Travers, M., Goniewicz, M. L., McIntosh, S., Ossip, D., \& O’Connor, R. J. 2019. Use of flavored e-cigarettes and the type of e-cigarette devices used among adults and youth in the US-Results from wave 3 of the population assessment of tobacco and health study (2015-2016). International Journal of Environmental Research and Public Health, 16(16), 2991.

Shang, Ce, Anh Ngo, and Frank J Chaloupka. 2020. "The pass-through of alcohol excise taxes to prices in OECD countries." The European Journal of Health Economics:1-13.

Shrestha, Vinish, and Sara Markowitz. 2016. "The Pass-Through of Beer Taxes to Prices: Evidence from State and Federal Tax Changes." Economic Inquiry 54 (4):1946-1962.

Sindelar, Jody. 2020. "Regulating Vaping — Policies, Possibilities, and Perils." New England Journal of Medicine 382:e54.

Soneji, Samir S, Kristin E Knutzen, and Andrea C Villanti. 2019. "Use of flavored e-cigarettes among adolescents, young adults, and older adults: findings from the population assessment for tobacco and health study." Public Health Reports 134 (3):282-292. 
Stern, Nicholas. 1987. "The effects of taxation, price control and government contracts in oligopoly and monopolistic competition." Journal of Public Economics 32 (2):133-158.

Stoklosa, Michal, Jeffrey Drope, and Frank J Chaloupka. 2016. "Prices and e-cigarette demand: evidence from the European Union." Nicotine \& Tobacco Research 18 (10):1973-1980.

Truth Initiative. 2020. Local flavored tobacco policies as of September 30, 2020.

Tuchman, Anna E. 2019. "Advertising and demand for addictive goods: The effects of ecigarette advertising." Marketing Science 38 (6):994-1022.

University of Kentucky Center for Poverty Research. 2021. UKCPR National Welfare Data, 1980-2019. Lexington, KY.

Zheng, Yuqing, Chen Zhen, Daniel Dench, and James M Nonnemaker. 2017. "US demand for tobacco products in a system framework." Health Economics 26 (8):1067-1086.

Zheng, Yuqing, Chen Zhen, James Nonnemaker, and Daniel Dench. 2016. "Advertising, habit formation, and US tobacco product demand." American Journal of Agricultural Economics 98 (4):1038-1054. 
Figure 1. Comparison of population-weighted e-cigarette and cigarette tax levels (federal + state + local): 2013-2019

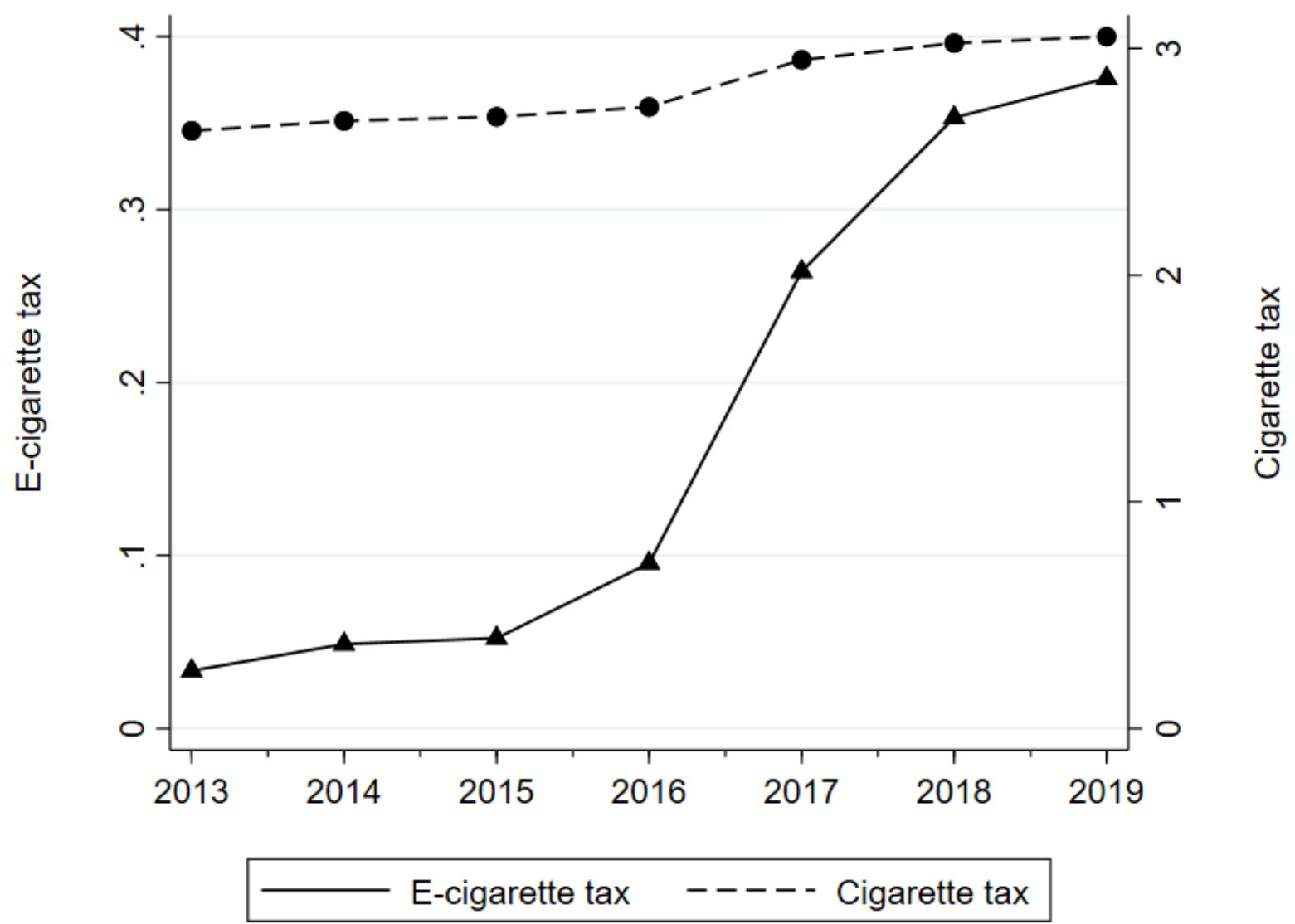

Notes: See text for details. E-cigarette tax reported in nominal dollars per fluid $\mathrm{ml}$ and cigarette tax reported in nominal dollars per pack. 
Figure 2. Effect of e-cigarette taxes on e-cigarette prices using event study models: NielsenIQ retail sales UPC-level data 2013-2019
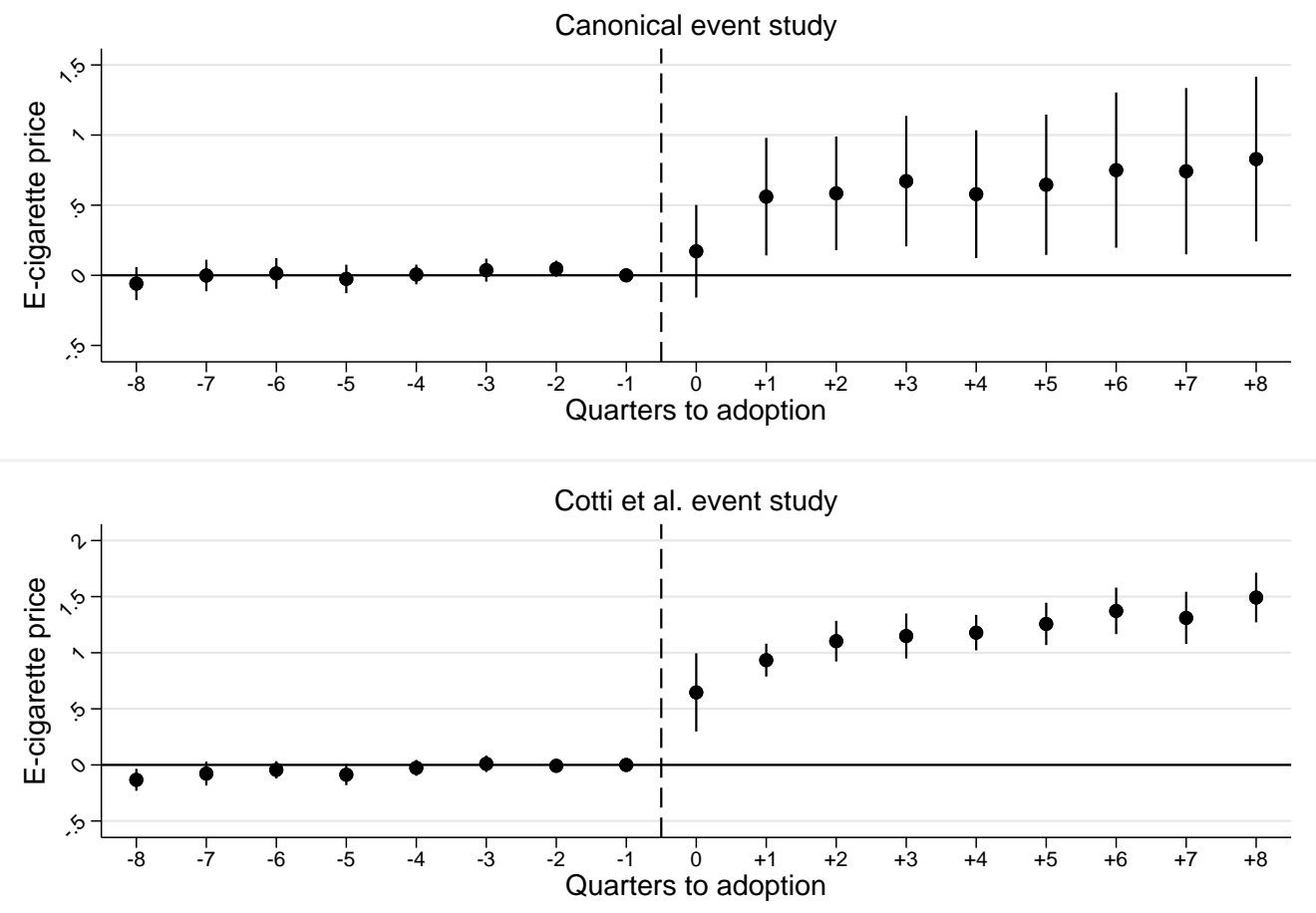

Notes: The unit of observation is a UPC-code in a locality (state or county) in a quarter (quarter-by-year). The model is estimated by equation (1) except using lag and lead indicators in the top panel and changes in the bottom panel from the first available e-cigarette tax in a given locality. The model is estimated with least squares and controls for time-varying locality characteristics, UPC-by-locality fixed effects, UPC-by-quarter fixed effects, and period (quarter-by-year) fixed effects. Data are weighted by the share of e-cigarette sales in localities that do not adopt an e-cigarette tax. Circles reflect the coefficient estimate and vertical solid lines reflect 95\% confidence intervals that account for within-locality clustering. The omitted category is one quarter prior to policy adoption, this category is normalized to zero. The data is also restricted to observations eight periods before or after policy adoption in each state. 
Figure 3. Effect of e-cigarette and cigarette taxes on e-cigarette prices using alternative samples and specifications: NielsenIQ retail sales locality-level data 2013-2019
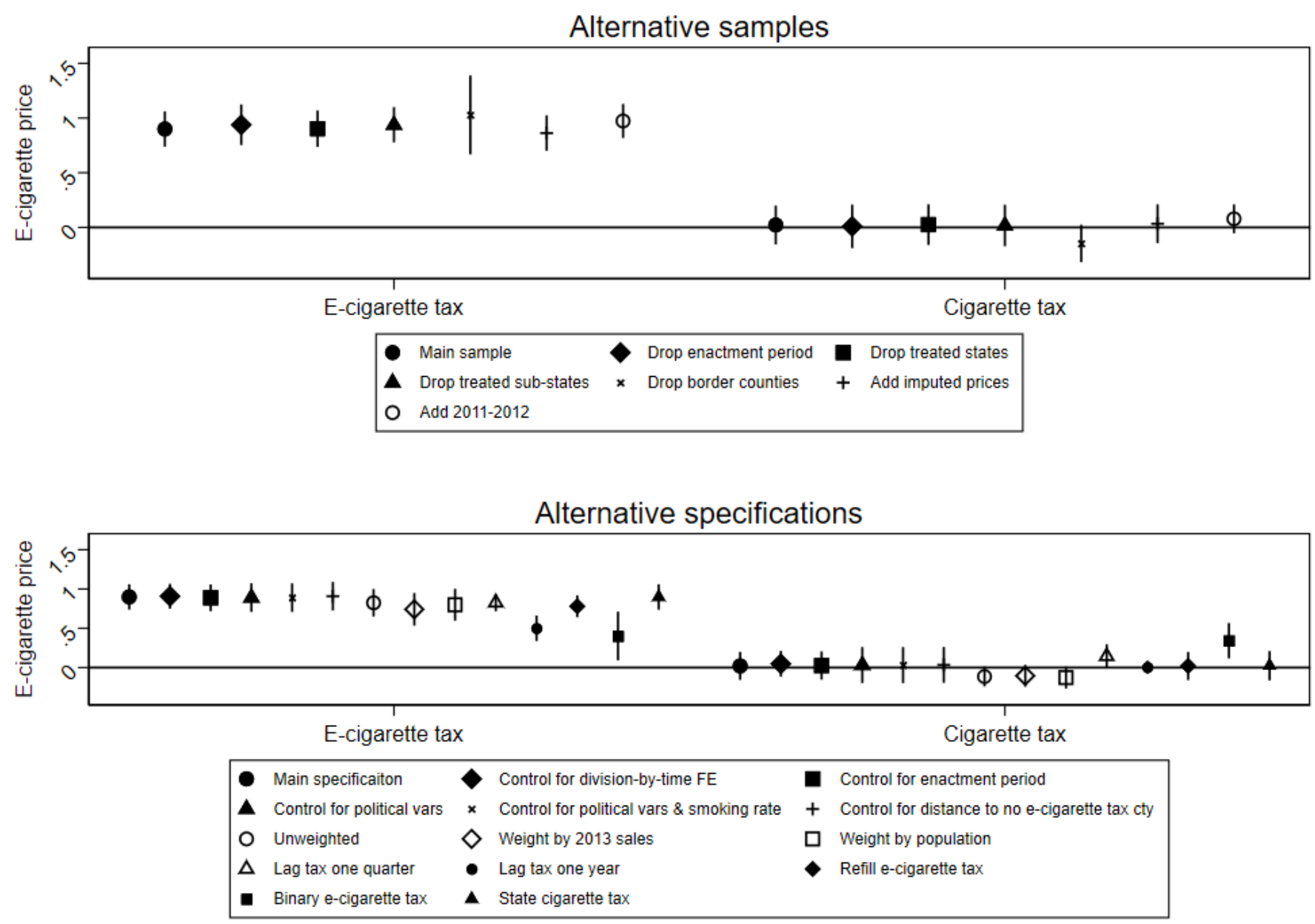

Notes: The unit of observation is a UPC-code in a locality (state or county) in a period (quarter-by-year). Unless otherwise noted, the model is estimated with least squares and controls for time-varying locality characteristics, UPC-by-locality fixed effects, UPC-by-quarter fixed effects, and period (quarter-by-year) fixed effects. Unless otherwise noted, data are weighted by the share of e-cigarette sales in localities that do not adopt an e-cigarette tax. Symbols reflect the beta coefficient estimate and vertical solid lines reflect $95 \%$ confidence intervals that account for within-locality clustering. 
Figure 4. Effect of e-cigarette taxes on e-cigarette and cigarette sales using a Cotti et al (2018) event studystyle model: NielsenIQ retail sales locality-level data 2013-2019
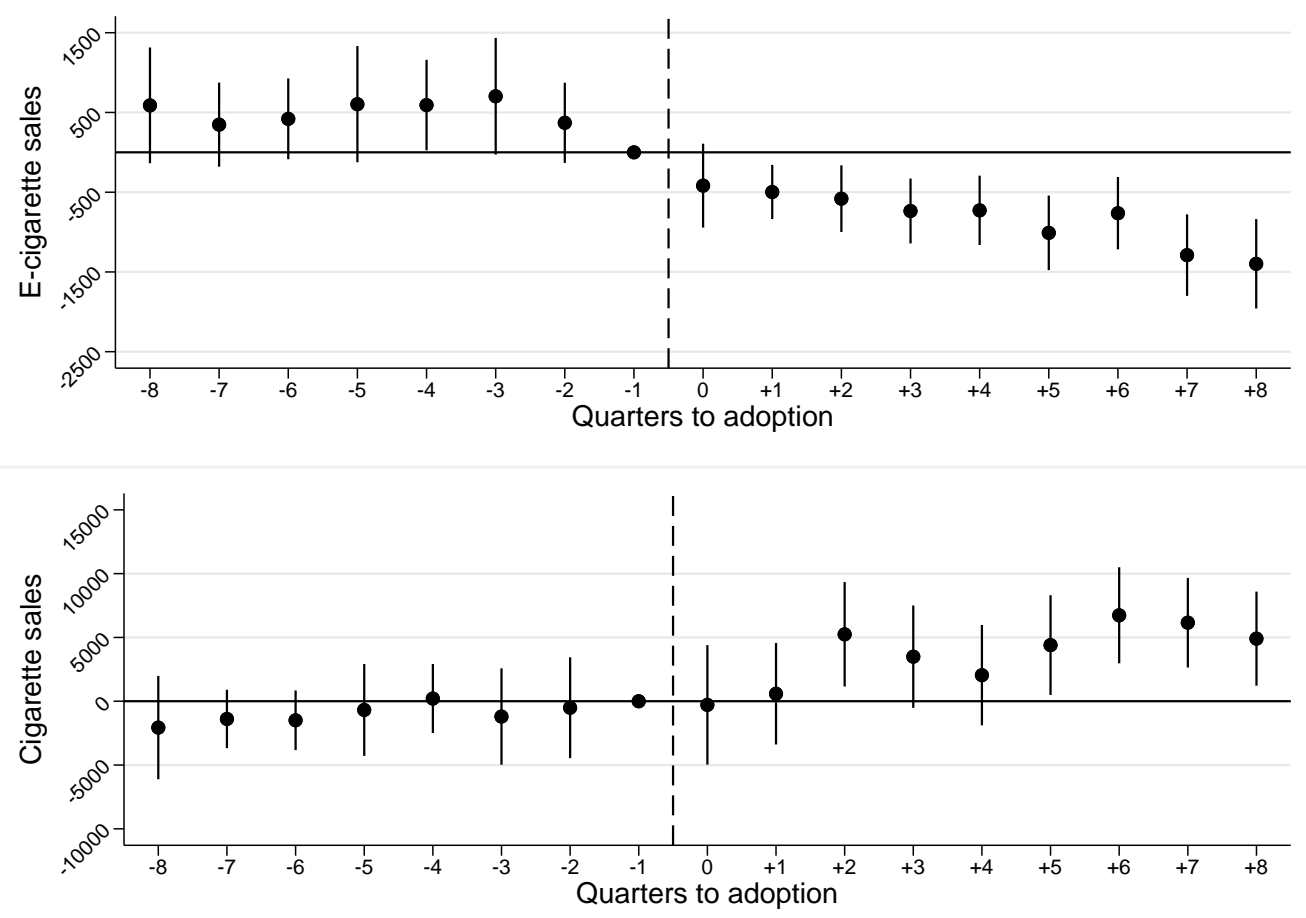

Notes: The unit of observation is a locality (state or county) in a period (quarter-by-year). The model is estimated by equation (3) except using lag and lead changes in the e-cigarette tax amount. The model is estimated with least squares and controls for time-varying locality characteristics, locality fixed effects, and period (quarter-by-year) fixed effects. Data are weighted by the locality population. Circles reflect the beta coefficient estimate and vertical solid lines reflect $95 \%$ confidence intervals that account for within locality clustering. The omitted category is the ecigarette tax change one quarter prior to policy adoption, this category is normalized to zero. The data is also restricted to observations eight periods before or after policy adoption in each state. 
Figure 5. Effect of cigarette taxes on e-cigarette and cigarette sales using a Cotti et al (2018) event study-style model: NielsenIQ retail sales locality-level data 2013-2019
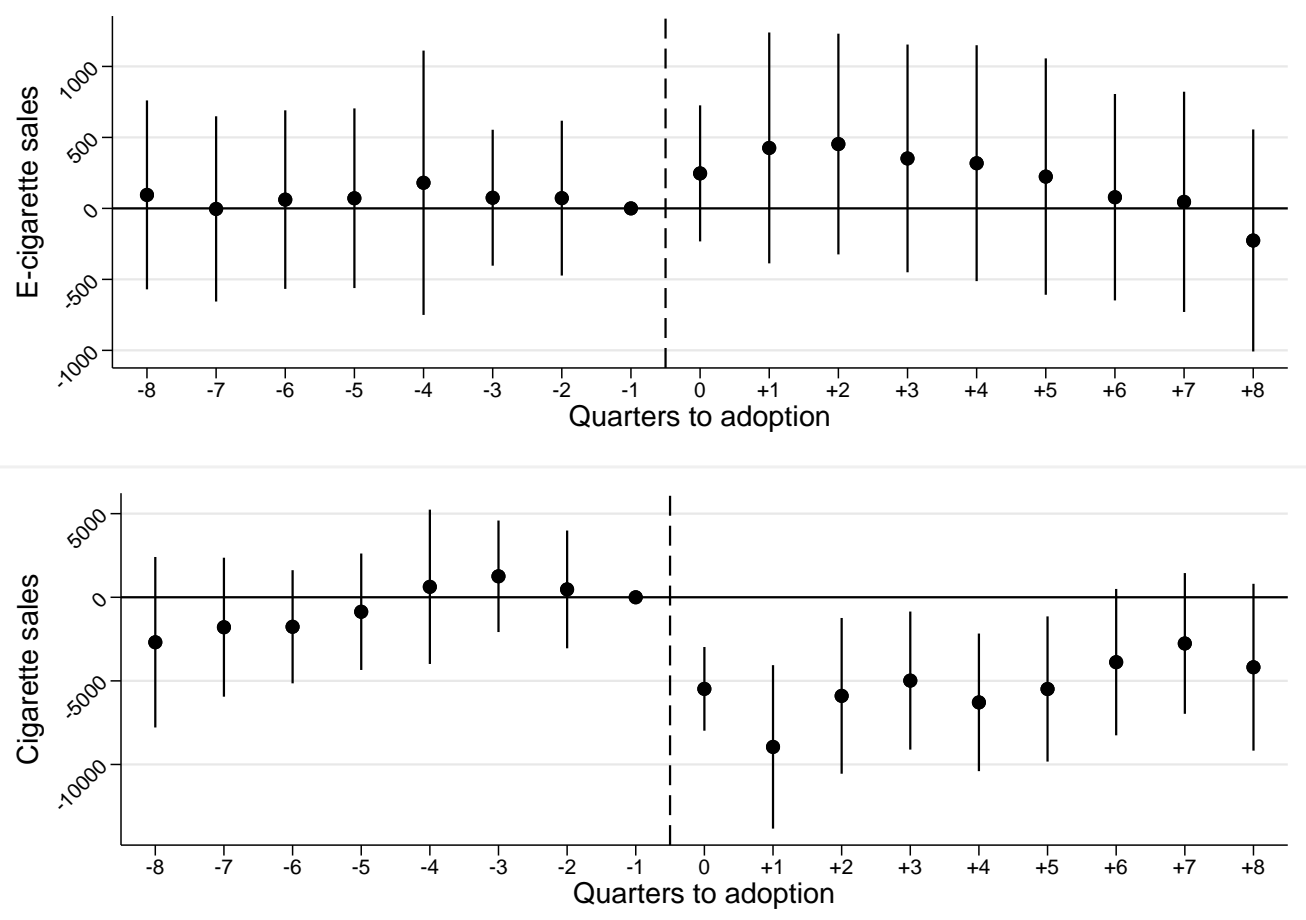

Notes: The unit of observation is a locality (state or county) in a period (quarter-by-year). The model is estimated by equation (3) except using lag and lead changes in the cigarette tax amount. The model is estimated with least squares and controls for time-varying locality characteristics, locality fixed effects, and period (quarter-by-year) fixed effects. Data are weighted by the locality population. Circles reflect the beta coefficient estimate and vertical solid lines reflect $95 \%$ confidence intervals that account for within locality clustering. The omitted category is the cigarette tax change one quarter prior to policy adoption, this category is normalized to zero. The data is also restricted to observations eight periods before or after policy adoption in each state. 
Figure 6. Effect of e-cigarette and cigarette taxes on e-cigarette and cigarette sales using alternative samples: NielsenIQ retail sales locality-level data 2013-2019
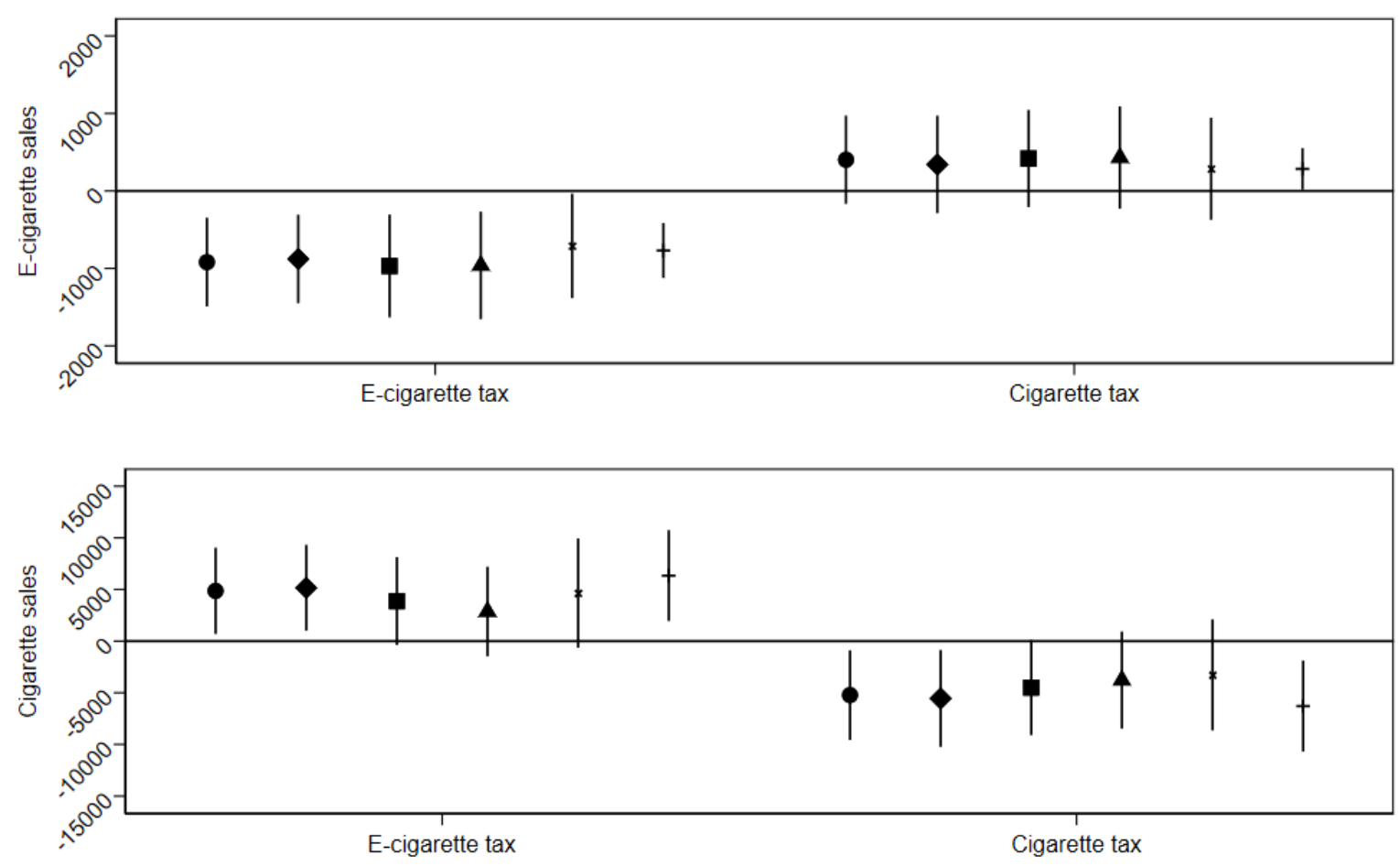

$\begin{array}{lll}\text { - Main sample } & \text { Drop enactment period } \\ \text { - Drop treated sub-states } & \times \text { Drop treated states }\end{array}$

Notes: The unit of observation is a locality (state or county) in a period (quarter-by-year). Unless otherwise noted, the model is estimated with least squares and controls for time-varying locality characteristics, locality fixed effects, and period (quarter-by-year) fixed effects. Unless otherwise noted, data are weighted by the locality population. Symbols reflect the beta coefficient estimate and vertical solid lines reflect 95\% confidence intervals that account for within-locality clustering. 
Figure 7. Effect of cigarette and e-cigarette taxes on e-cigarette and cigarette sales using alternative specifications: NielsenIQ retail sales locality-level data 2013-2019
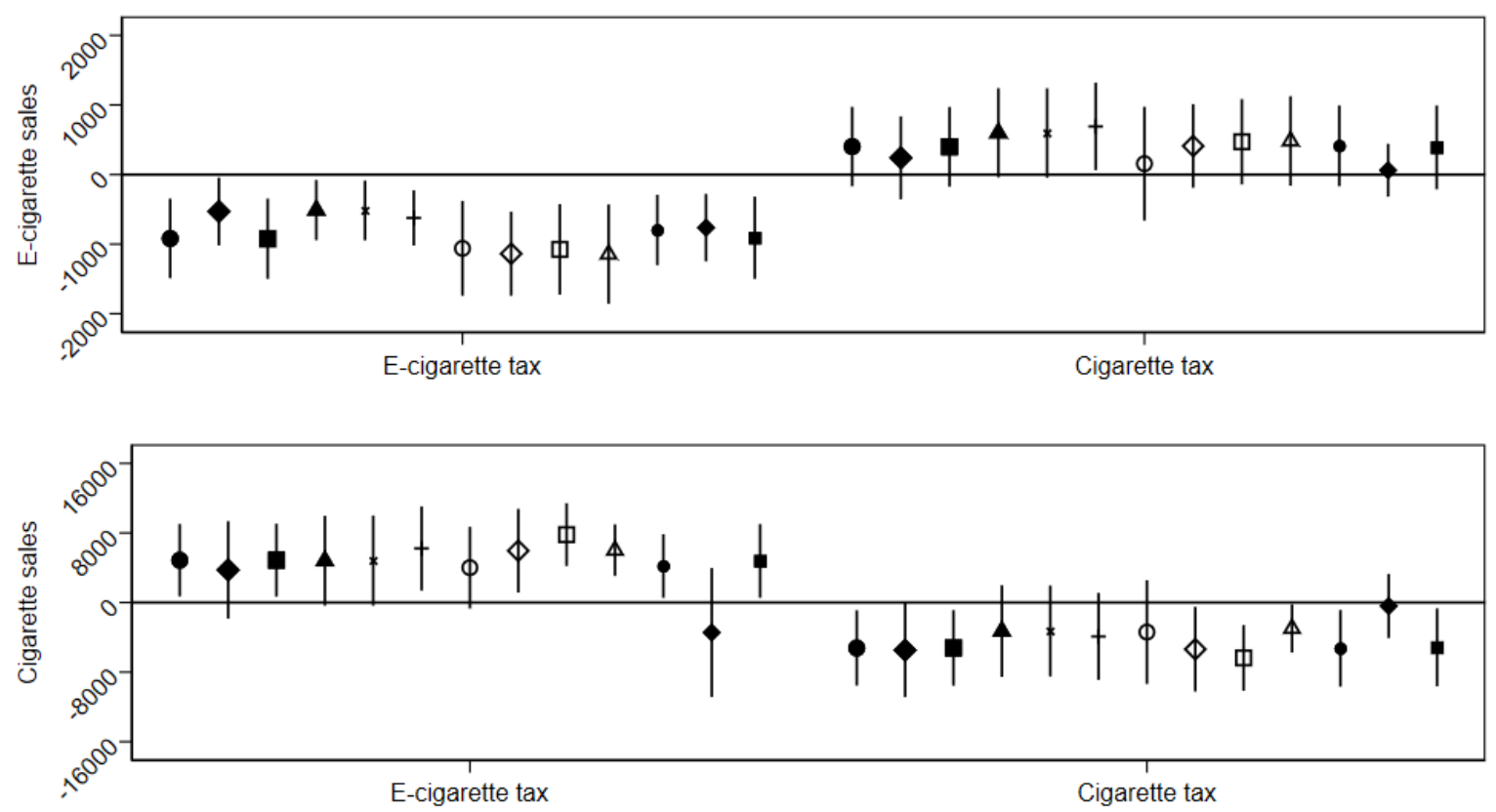

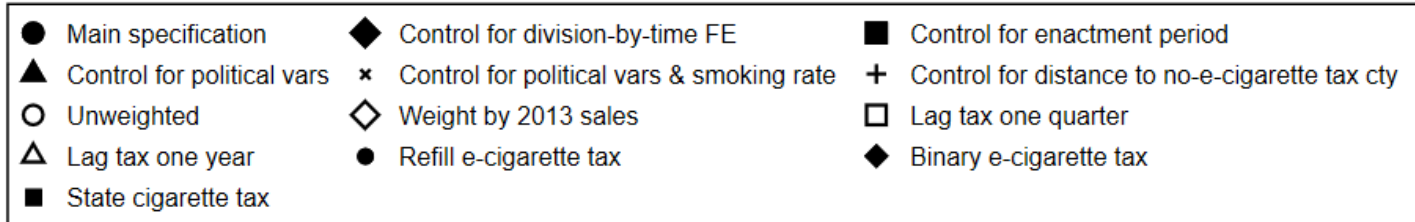

Notes: The unit of observation is a locality (state or county) in a period (quarter-by-year). Unless otherwise noted, the model is estimated with least squares and controls for time-varying locality characteristics, locality fixed effects, and period (quarter-by-year) fixed effects. Unless otherwise noted, data are weighted by the locality population. Symbols reflect the beta coefficient estimate and vertical solid lines reflect $95 \%$ confidence intervals that account for within-locality clustering. 
Table 1. Effect of e-cigarette and cigarette taxes on e-cigarette prices using a two-way fixed effects model: NielsenIQ retail sales UPC-level data 2013-

2019

\begin{tabular}{|c|c|c|c|c|c|c|}
\hline \multirow{2}{*}{$\begin{array}{l}\text { Outcome: } \\
\text { E-cigarette tax (\$): }\end{array}$} & \multicolumn{6}{|c|}{ Prices } \\
\hline & & & & & & \\
\hline $\begin{array}{l}\text { Beta } \\
(\mathrm{SE})\end{array}$ & $\begin{array}{l}1.011^{* * *} \\
(0.076)\end{array}$ & $\begin{array}{c}0.980 * * * \\
(0.072)\end{array}$ & $\begin{array}{l}0.977 * * * \\
(0.071)\end{array}$ & $\begin{array}{c}0.963^{* * *} \\
(0.076)\end{array}$ & $\begin{array}{l}0.996 * * * \\
(0.043)\end{array}$ & $\begin{array}{c}0.900 * * * \\
(0.080)\end{array}$ \\
\hline \multicolumn{7}{|l|}{ Cigarette tax (\$): } \\
\hline $\begin{array}{l}\text { Beta } \\
(\mathrm{SE})\end{array}$ & $\begin{array}{l}0.157^{*} \\
(0.085)\end{array}$ & $\begin{array}{c}0.124 \\
(0.087)\end{array}$ & $\begin{array}{c}0.127 \\
(0.086)\end{array}$ & $\begin{array}{c}0.135 \\
(0.085) \\
\end{array}$ & $\begin{array}{c}0.016 \\
(0.022)\end{array}$ & $\begin{array}{c}0.022 \\
(0.089)\end{array}$ \\
\hline $\begin{array}{l}\text { Period (quarter-by-year) fixed } \\
\text { effects }\end{array}$ & $\mathrm{Y}$ & $\mathrm{Y}$ & $\mathrm{Y}$ & $\mathrm{Y}$ & $\mathrm{n} / \mathrm{a}$ & $\mathrm{n} / \mathrm{a}$ \\
\hline Locality fixed effects & $\mathrm{Y}$ & $\mathrm{Y}$ & $\mathrm{Y}$ & $\mathrm{Y}$ & $\mathrm{Y}$ & $\mathrm{n} / \mathrm{a}$ \\
\hline Tobacco control policies & $\mathrm{N}$ & $\mathrm{Y}$ & $\mathrm{Y}$ & $\mathrm{Y}$ & $\mathrm{Y}$ & $\mathrm{Y}$ \\
\hline Substance use policies & $\mathrm{N}$ & $\mathrm{N}$ & $\mathrm{Y}$ & $\mathrm{Y}$ & $\mathrm{Y}$ & $\mathrm{Y}$ \\
\hline Demographics & $\mathrm{N}$ & $\mathrm{N}$ & $\mathrm{N}$ & $\mathrm{Y}$ & $\mathrm{Y}$ & $\mathrm{Y}$ \\
\hline UPC-by-period fixed effects & $\mathrm{N}$ & $\mathrm{N}$ & $\mathrm{N}$ & $\mathrm{N}$ & $\mathrm{Y}$ & $\mathrm{Y}$ \\
\hline UPC-by-locality fixed effects & $\mathrm{N}$ & $\mathrm{N}$ & $\mathrm{N}$ & $\mathrm{N}$ & $\mathrm{N}$ & $\mathrm{Y}$ \\
\hline Observations & 126,725 & 126,725 & 126,725 & 126,725 & 126,725 & 126,725 \\
\hline $\begin{array}{l}\text { Mean: E-cigarette price in e- } \\
\text { cigarette tax adopting localities, } \\
\text { year prior to the tax }(\$)\end{array}$ & 4.769 & 4.769 & 4.769 & 4.769 & 4.769 & 4.769 \\
\hline
\end{tabular}


Table 2. Effect of e-cigarette and cigarette taxes on e-cigarette and cigarette sales per 100,000 state adult residents using a two-way fixed effects model: NielsenIQ retail sales locality-level data 2013-2019

\begin{tabular}{|c|c|c|c|c|c|c|c|c|}
\hline Sales outcome: & E-cigarettes & E-cigarettes & E-cigarettes & E-cigarettes & Cigarettes & Cigarettes & Cigarettes & Cigarettes \\
\hline \multicolumn{9}{|l|}{$\begin{array}{l}\text { Panel A: Reduced } \\
\text { form }\end{array}$} \\
\hline \multicolumn{9}{|l|}{ E-cigarette tax (\$) } \\
\hline Beta & $-967 * * *$ & $-927 * * *$ & $-928 * * *$ & $-919 * * *$ & $6,785^{* * *}$ & $4,644^{* *}$ & $4,818 * *$ & $4,863 * *$ \\
\hline$(\mathrm{SE})$ & (278) & (289) & (289) & (285) & $(1,988)$ & $(2,150)$ & $(2,157)$ & $(2,080)$ \\
\hline Tax elasticity & -0.67 & -0.64 & -0.64 & -0.63 & 0.17 & 0.12 & 0.12 & 0.12 \\
\hline Implied price elasticity & -2.15 & -2.23 & -2.20 & -2.20 & 0.56 & 0.41 & 0.42 & 0.43 \\
\hline \multicolumn{9}{|l|}{ Cigarette tax $(\$)$} \\
\hline Beta & $445 *$ & 379 & 379 & 403 & $-4,783^{* *}$ & $-4,932 * *$ & $-5,030 * *$ & $-5,226 * *$ \\
\hline$(\mathrm{SE})$ & $(263)$ & $(296)$ & $(298)$ & $(284)$ & $(2,001)$ & $(2,234)$ & $(2,253)$ & $(2,159)$ \\
\hline Tax elasticity & 0.91 & 0.78 & 0.78 & 0.83 & -0.22 & -0.22 & -0.23 & -0.24 \\
\hline Implied price elasticity & 1.70 & 1.43 & 1.44 & 1.53 & -0.40 & -0.41 & -0.42 & -0.44 \\
\hline \multicolumn{9}{|l|}{$\begin{array}{l}\text { Panel B: } \\
\text { Instrumental } \\
\text { variables }\end{array}$} \\
\hline \multicolumn{9}{|l|}{$\begin{array}{l}\text { Instrumented e- } \\
\text { cigarette price (\$) }\end{array}$} \\
\hline Beta & $-816 * * *$ & $-852 * * *$ & $-837 * * *$ & $-837 * * *$ & $5,710 * * *$ & $4,264^{* *}$ & $4,346 * *$ & $4,417 * *$ \\
\hline$(\mathrm{SE})$ & (228) & (272) & (274) & (274) & $(1,712)$ & $(1,926)$ & $(1,884)$ & $(1,803)$ \\
\hline Price elasticity & -2.14 & -2.23 & -2.20 & -2.20 & 0.55 & 0.41 & 0.42 & 0.43 \\
\hline \multicolumn{9}{|l|}{$\begin{array}{l}\text { Instrumented cigarette } \\
\text { price (\$) }\end{array}$} \\
\hline Beta & 335 & 262 & 245 & 263 & $-3,877^{* *}$ & $-4,080 * *$ & $-4,073 * *$ & $-4,223 * * *$ \\
\hline$(\mathrm{SE})$ & $(222)$ & $(252)$ & $(253)$ & (238) & $(1,612)$ & $(1,696)$ & $(1,671)$ & $(1,565)$ \\
\hline Price elasticity & 1.39 & 1.09 & 1.02 & 1.09 & -0.35 & -0.37 & -0.37 & -0.39 \\
\hline $\begin{array}{l}\text { Cragg-Donald Wald F- } \\
\text { statistic }\end{array}$ & 148.899 & 114.880 & 122.096 & 117.686 & 148.899 & 114.880 & 122.096 & 117.686 \\
\hline \multicolumn{9}{|l|}{ Covariates: } \\
\hline Locality fixed effects & $\mathrm{Y}$ & $\mathrm{Y}$ & $\mathrm{Y}$ & $\mathrm{Y}$ & $\mathrm{Y}$ & $\mathrm{Y}$ & $\mathrm{Y}$ & $\mathrm{Y}$ \\
\hline $\begin{array}{l}\text { Period (quarter-by- } \\
\text { year) fixed effects }\end{array}$ & $\mathrm{Y}$ & $\mathrm{Y}$ & $\mathrm{Y}$ & $\mathrm{Y}$ & $\mathrm{Y}$ & $\mathrm{Y}$ & $\mathrm{Y}$ & $\mathrm{Y}$ \\
\hline $\begin{array}{l}\text { Tobacco control } \\
\text { policies }\end{array}$ & $\mathrm{N}$ & $\mathrm{Y}$ & $\mathrm{Y}$ & $\mathrm{Y}$ & $\mathrm{N}$ & $\mathrm{Y}$ & $\mathrm{Y}$ & $\mathrm{Y}$ \\
\hline Substance use policies & $\mathrm{N}$ & $\mathrm{N}$ & $\mathrm{Y}$ & $\mathrm{Y}$ & $\mathrm{N}$ & $\mathrm{N}$ & $\mathrm{Y}$ & $\mathrm{Y}$ \\
\hline Demographics & $\mathrm{N}$ & $\mathrm{N}$ & $\mathrm{N}$ & $\mathrm{Y}$ & $\mathrm{N}$ & $\mathrm{N}$ & $\mathrm{N}$ & $\mathrm{Y}$ \\
\hline Observations & 1,428 & 1,428 & 1,428 & 1,428 & 1,428 & 1,428 & 1,428 & 1,428 \\
\hline
\end{tabular}

Means in e-cigarette 


\begin{tabular}{|c|c|c|c|c|c|c|c|c|}
\hline \multicolumn{9}{|l|}{$\begin{array}{l}\text { tax localities, year } \\
\text { prior to tax }\end{array}$} \\
\hline Sales & 1,770 & 1,770 & 1,770 & 1,770 & 47,956 & 47,956 & 47,956 & 47,956 \\
\hline Prices & 4.643 & 4.643 & 4.643 & 4.643 & 7.185 & 7.185 & 7.185 & 7.185 \\
\hline \multicolumn{9}{|c|}{$\begin{array}{l}\text { Means in cigarette tax } \\
\text { localities, year prior to } \\
\text { tax }\end{array}$} \\
\hline Sales & 1,445 & 1,445 & 1,445 & 1,445 & 65,637 & 65,637 & 65,637 & 65,637 \\
\hline Prices & 4.406 & 4.406 & 4.406 & 4.406 & 5.992 & 5.992 & 5.992 & 5.992 \\
\hline \multicolumn{9}{|c|}{$\begin{array}{l}\text { Notes: The unit of observation is a locality (state or county) in a period (quarter-by-year). All models estimated with least squares or two-stage least squares and } \\
\text { control for time-varying locality characteristics, locality fixed effects, and period (quarter-by-year) fixed effects unless otherwise noted. Data are weighted by th } \\
\text { locality population. Excluded instruments are cigarette taxes and e-cigarette taxes. Tax elasticities are calculated as tax coefficient x non-zero tax mean / year- } \\
\text { prior sales. Non-zero tax mean is used since this is otherwise } 0 \text { for many locality-periods for e-cigarette taxes. Implied price elasticities are calculated as tax } \\
\text { coefficient x year-prior price / year-prior sales / pass-through. We use pass-through rates calculated from locality-level regressions of prices on taxes, available } \\
\text { upon request. The pass-through rates are } 1.366 \text { and } 1.180 \text { for e-cigarettes (without and with time-varying controls) and } 1.085 \text { and } 1.093 \text { for cigarettes. Price } \\
\text { elasticities in the instrumental variables specifications are estimated as price coefficient x year-prior price / year-prior sales. Standard errors that account for } \\
\text { within-locality clustering are reported in parentheses. SE }=\text { standard error. } \\
* * *, * * \text {, and } * \text { statistically different from zero at the } 1 \%, 5 \% \text {, and } 10 \% \text { level. }\end{array}$} \\
\hline
\end{tabular}


Table 3. Decomposition of treatment effects using a Goodman-Bacon decomposition: NielsenIQ retail sales UPC-level data 2013-2019

\begin{tabular}{|c|c|c|c|c|}
\hline $\begin{array}{l}\text { Column: } \\
\text { Outcome: }\end{array}$ & $\begin{array}{c}\text { (1) } \\
\begin{array}{c}\text { E-cigarette } \\
\text { price }\end{array} \\
\end{array}$ & $\begin{array}{c}\text { (2) } \\
\text { E-cigarette } \\
\text { sales }\end{array}$ & $\begin{array}{c}\text { (3) } \\
\text { Cigarette sales }\end{array}$ & $\begin{array}{c}\text { (4) } \\
\text { Weight }\end{array}$ \\
\hline $\begin{array}{l}\text { Earlier treated vs. later treated as } \\
\text { controls }\end{array}$ & 0.501 & -839 & 891 & 0.188 \\
\hline $\begin{array}{l}\text { Later treated vs. earlier treated as } \\
\text { controls }\end{array}$ & 0.361 & 102 & -852 & 0.044 \\
\hline Treated vs. never treated as controls & 0.839 & $-1,449$ & 3,181 & 0.745 \\
\hline Treated vs. always treated as controls & -1.382 & 474 & $-8,153$ & 0.024 \\
\hline Overall TWFE & 0.701 & $-1,221$ & 2,303 & -- \\
\hline Callaway and & $0.727 * * *$ & $-1,152 * * *$ & 2,702 & -- \\
\hline Sant'Anna ATT & $(0.229)$ & $(274)$ & $(2,943)$ & \\
\hline Observations & 1,428 & 1,428 & 1,428 & -- \\
\hline $\begin{array}{l}\text { Mean: E-cigarette tax adopting } \\
\text { localities, year prior to the tax } \\
\text { (unweighted) }\end{array}$ & 4.737 & 2,665 & 61,439 & -- \\
\hline $\begin{array}{l}\text { Mean: Cigarette tax adopting } \\
\text { localities, year prior to the first } \\
\text { cigarette tax increase (unweighted) }\end{array}$ & 4.463 & 1,909 & 96,050 & -- \\
\hline \multicolumn{5}{|c|}{$\begin{array}{l}\text { Notes: The unit of observation is a period (quarter-by-year). Two-by-two difference-in-differences estimates are } \\
\text { reported. Weights, reported in Column (4), are constant across outcomes as the source of variation (i.e., cigarette tax } \\
\text { adoption) is constant. The overall TWFE results are generated in a model that dichotomizes the e-cigarette tax and } \\
\text { controls for locality and time fixed effects and clusters standard errors around the locality. Callaway and Sant'Anna } \\
\text { applies the difference-in-differences with multiple periods estimator proposed by Callaway and Sant'Anna (2020) } \\
\text { using Sant'Anna and Zhao (2020) improved doubly robust difference-in-differences estimator based on inverse } \\
\text { probability of tilting and weighted least squares. Standard errors are calculated using the bootstrap approach outlined } \\
\text { in Callaway and Sant'Anna (2020) using } 999 \text { repetitions. TWFE = two-way fixed effects. ATT = average treatment } \\
\text { effect on the treated. SE=standard error. See text for details. } \\
* * *, * * \text {, and } *=\text { statistically different from zero at the } 1 \%, 5 \% \text {, and } 10 \% \text { level. }\end{array}$} \\
\hline
\end{tabular}


Table 4. Effect of e-cigarette and cigarette taxes on flavored e-cigarettes and cigarettes sales per 100,000 adults using a two-way fixed effects model: NielsenIQ state-level sales data 2013-2019

\begin{tabular}{|c|c|c|c|c|c|}
\hline \multirow{2}{*}{$\begin{array}{l}\text { Cigarette type: } \\
\text { Outcome: }\end{array}$} & \multicolumn{3}{|c|}{$\underline{\text { E-cigarettes }}$} & \multicolumn{2}{|c|}{ Cigarettes } \\
\hline & $\begin{array}{c}\text { Non- } \\
\text { flavored }\end{array}$ & $\begin{array}{l}\text { Menthol } \\
\text { /mint }\end{array}$ & Flavored & $\begin{array}{c}\text { Non- } \\
\text { flavored }\end{array}$ & Menthol \\
\hline \multicolumn{6}{|l|}{ Panel A: Reduced form } \\
\hline \multicolumn{6}{|l|}{ E-cigarette tax (\$) } \\
\hline Beta & $-235^{* * *}$ & $-126 * * *$ & $-557 * * *$ & $4,054^{* * *}$ & 809 \\
\hline (SE) & & (43) & (200) & $(1,488)$ & (739) \\
\hline Tax elasticity & -0.44 & -0.40 & -0.93 & 0.14 & 0.08 \\
\hline Implied price elasticity & -1.54 & -1.37 & -3.22 & 0.49 & 0.26 \\
\hline \multicolumn{6}{|l|}{ Cigarette tax (\$) } \\
\hline Beta & $127^{*}$ & 61 & 215 & $-3,733 * *$ & $-1,493 * *$ \\
\hline (SE) & (67) & (43) & (212) & $(1,634)$ & (696) \\
\hline Tax elasticity & 0.61 & 0.56 & 1.26 & -0.23 & -0.27 \\
\hline Implied price elasticity & 1.13 & 1.03 & 2.33 & -0.41 & -0.50 \\
\hline \multicolumn{6}{|l|}{$\begin{array}{l}\text { Panel B: Instrumental } \\
\text { variables }\end{array}$} \\
\hline \multicolumn{6}{|l|}{$\begin{array}{l}\text { Instrumented e-cigarette } \\
\text { price (\$) }\end{array}$} \\
\hline $\begin{array}{l}\text { Beta } \\
\text { (SE) }\end{array}$ & $\begin{array}{l}-214^{* * *} \\
(65)\end{array}$ & $\begin{array}{c}-115^{* * *} \\
(38)\end{array}$ & $\begin{array}{l}-508 * * * \\
(193)\end{array}$ & $\begin{array}{c}3,685 * * * \\
(1,267)\end{array}$ & $\begin{array}{c}732 \\
(650)\end{array}$ \\
\hline Price elasticity & -1.54 & -1.37 & -3.22 & 0.49 & 0.26 \\
\hline \multicolumn{6}{|l|}{$\begin{array}{l}\text { Instrumented cigarette } \\
\text { price }(\$)\end{array}$} \\
\hline Beta & 89 & 41 & 133 & $-2,950 * *$ & $-1,273^{* *}$ \\
\hline$(\mathrm{SE})$ & (55) & (30) & (181) & $(1,228)$ & (504) \\
\hline Price elasticity & 0.87 & 0.76 & 1.57 & -0.36 & -0.47 \\
\hline $\begin{array}{l}\text { Cragg-Donald Wald } F \text { - } \\
\text { statistic }\end{array}$ & 117.686 & 117.686 & 117.686 & 117.686 & 117.686 \\
\hline Observations & 1,428 & 1,428 & 1,428 & 1,428 & 1,428 \\
\hline $\begin{array}{l}\text { Mean: Sales in e- } \\
\text { cigarette tax adopting } \\
\text { localities, year prior to } \\
\text { the tax }\end{array}$ & 647 & 389 & 732 & 34,936 & 13,020 \\
\hline $\begin{array}{l}\text { Mean: Sales in cigarette } \\
\text { tax adopting localities, } \\
\text { year prior to the first } \\
\text { cigarette tax increase }\end{array}$ & 614 & 323 & 506 & 49,274 & 16,363 \\
\hline \multicolumn{6}{|c|}{$\begin{array}{l}\text { Notes: The unit of observation is a locality (state or county) in a period (quarter-by-year). All models estimated with } \\
\text { least squares or two-stage least squares and control for time-varying area characteristics, area fixed effects, and } \\
\text { period (quarter-by-year) fixed effects. Data are weighted by the locality population. Excluded instruments are } \\
\text { cigarette taxes and e-cigarette taxes. Tax elasticities, implied price elasticities, and price elasticities are calculated as } \\
\text { described in Table } 2 \text {. Standard errors that account for within-locality clustering are reported in parentheses. } \\
\text { SE=standard error. } \\
* * * * * \text { and } *=\text { statistically different from zero at the } 1 \%, 5 \% \text {, and } 10 \% \text { level. }\end{array}$} \\
\hline
\end{tabular}


Table 5. Effect of e-cigarette and cigarette taxes on the number of new e-cigarette products, liquid per unit, and nicotine concentration using a two-way fixed effects model: NielsenIQ retail sales state-level data 20132019

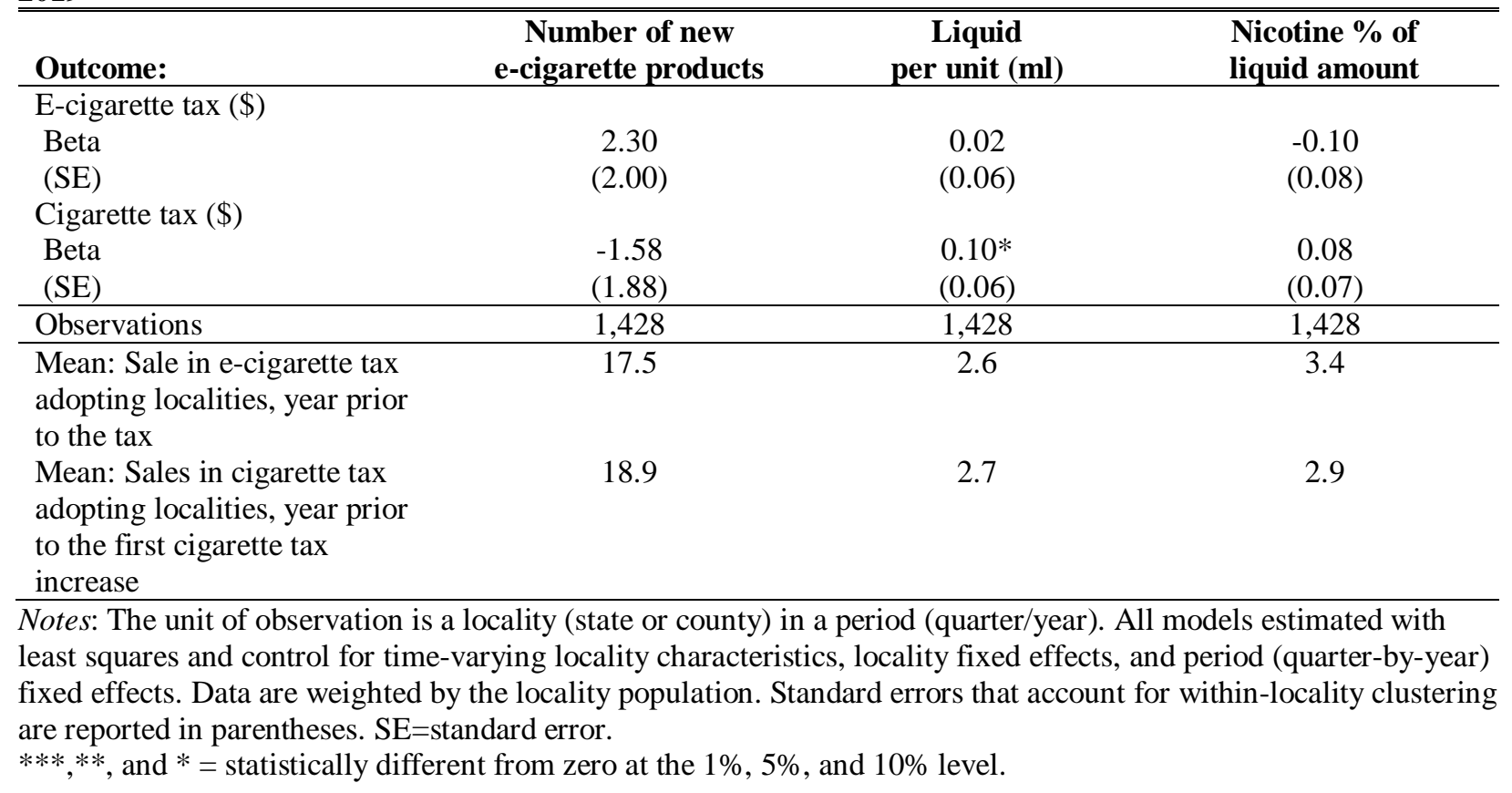


Online Appendix Figure 1. Map of e-cigarette taxes per ml of vaping liquid in 2019 Q4

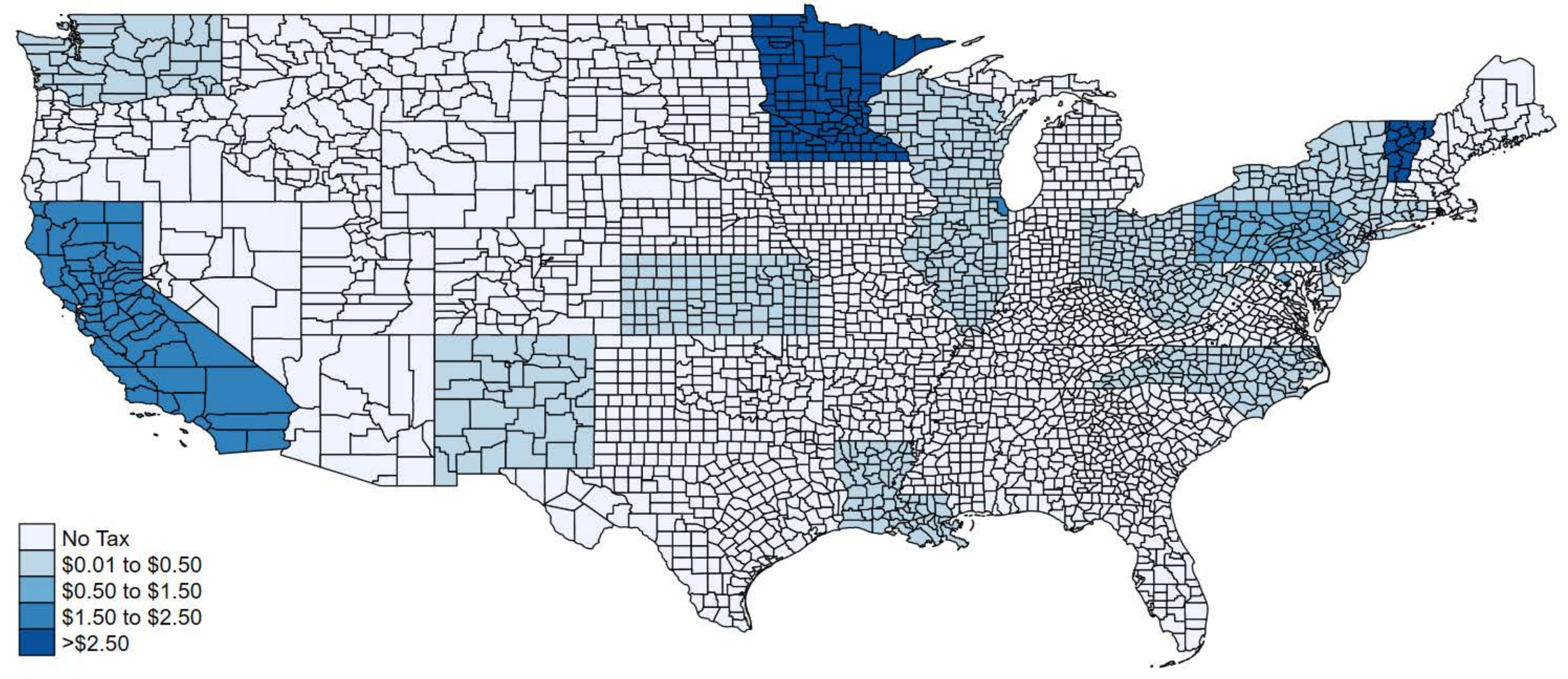

Notes: See text for details. 
Online Appendix Figure 2. Effect of e-cigarette taxes on e-cigarette prices using a two-way fixed effects model and alternative wholesale prices: NielsenIQ retail sales UPC-level data 2013-2019

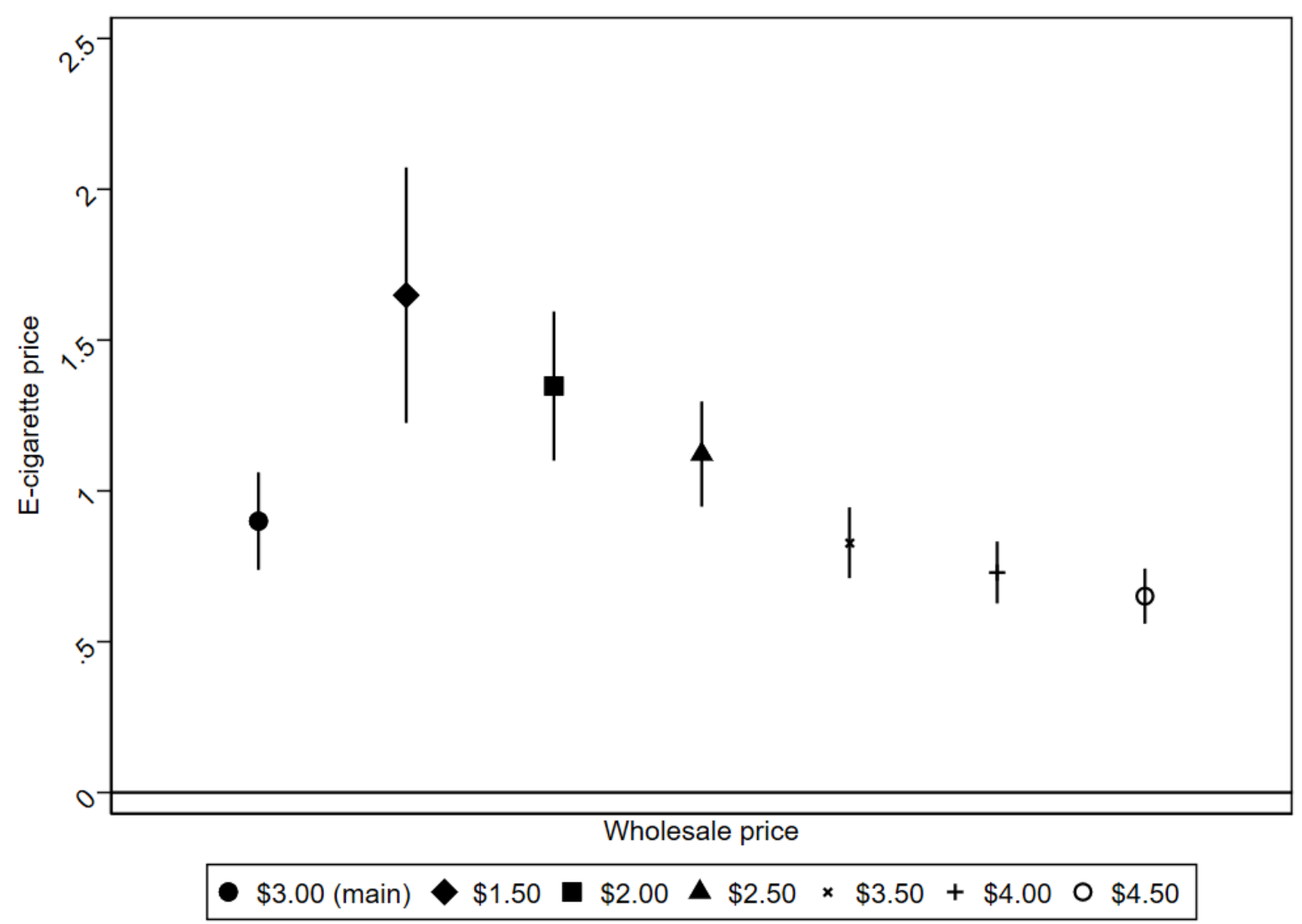

Notes: The unit of observation is a UPC-code in a locality (state or county) in a period (quarter-by-year). The model is estimated by equation (1). The model is estimated with least squares and controls for time-varying locality characteristics, UPC-by-locality fixed effects. UPC-by-period fixed effects, and period (quarter-by-year) fixed effects. Data are weighted by the share of e-cigarette sales in localities that do not adopt an e-cigarette tax. Symbols reflect the beta coefficient estimate and vertical solid lines reflect $95 \%$ confidence intervals that account for withinlocality clustering. 
Online Appendix Figure 3. Effect of e-cigarette and cigarette taxes on e-cigarette prices using a two-way fixed effects model excluding treated localities one at a time tax (leave one out analysis): NielsenIQ retail sales UPClevel data 2013-2019
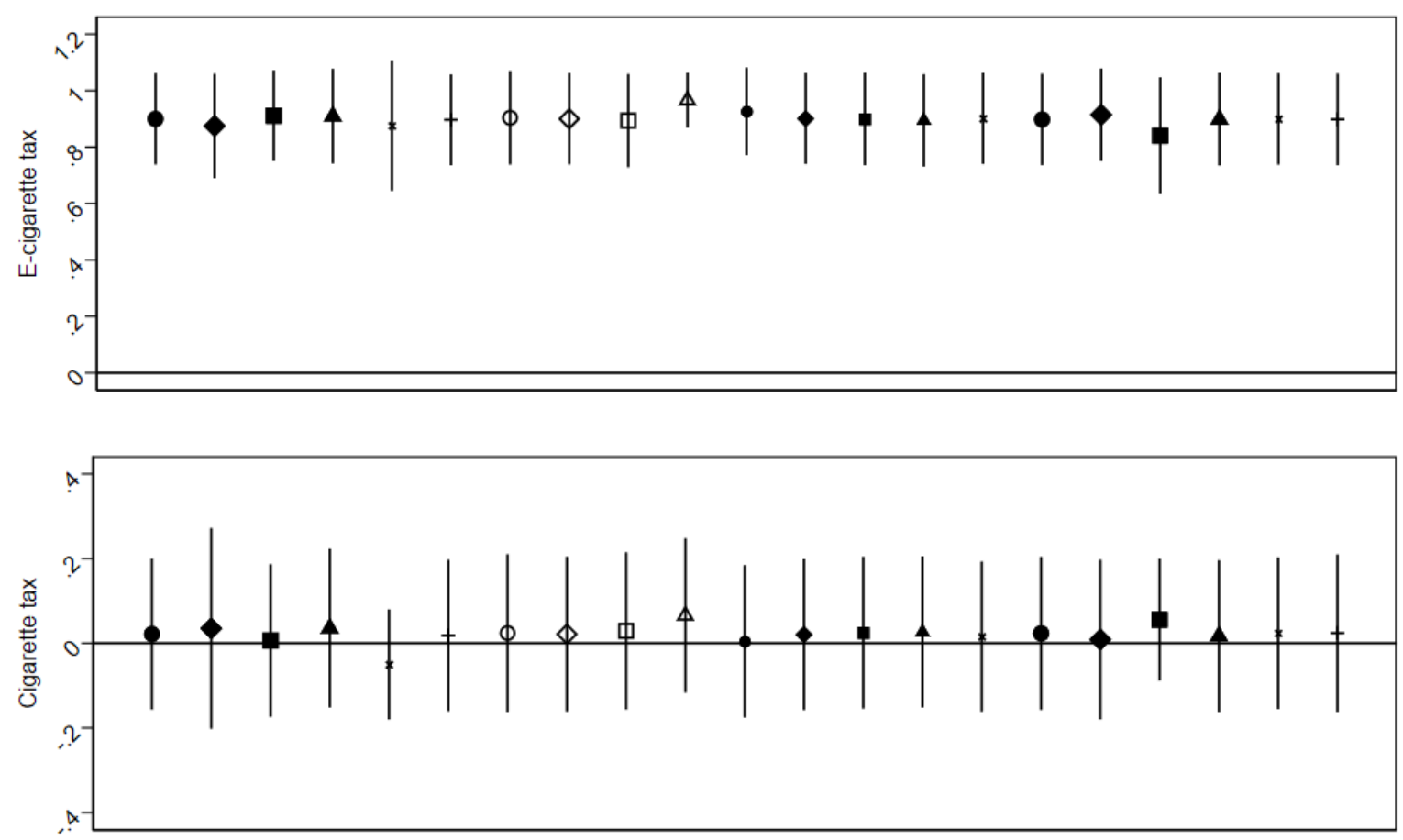

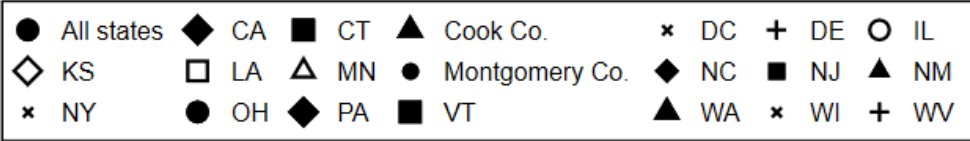

Notes: The unit of observation is a UPC-code in a locality (state or county) in a period (quarter-by-year). The model is estimated with least squares and controls for time-varying locality characteristics, UPC-by-locality fixed effects, UPC-by-period fixed effects, and period (quarter-by-year) fixed effects. Data are weighted by the share of ecigarette sales in localities that do not adopt an e-cigarette tax. Symbols represent coefficient estimates and vertical lines indicate 95\% confidence intervals that account for within-locality clustering. The locality abbreviation indicates the dropped locality. 
Online Appendix Figure 4. Effect of e-cigarette taxes on e-cigarette and cigarette sales using a two-way fixed effects model and alternative wholesale prices: NielsenIQ retail sales locality-level data 2013-2019
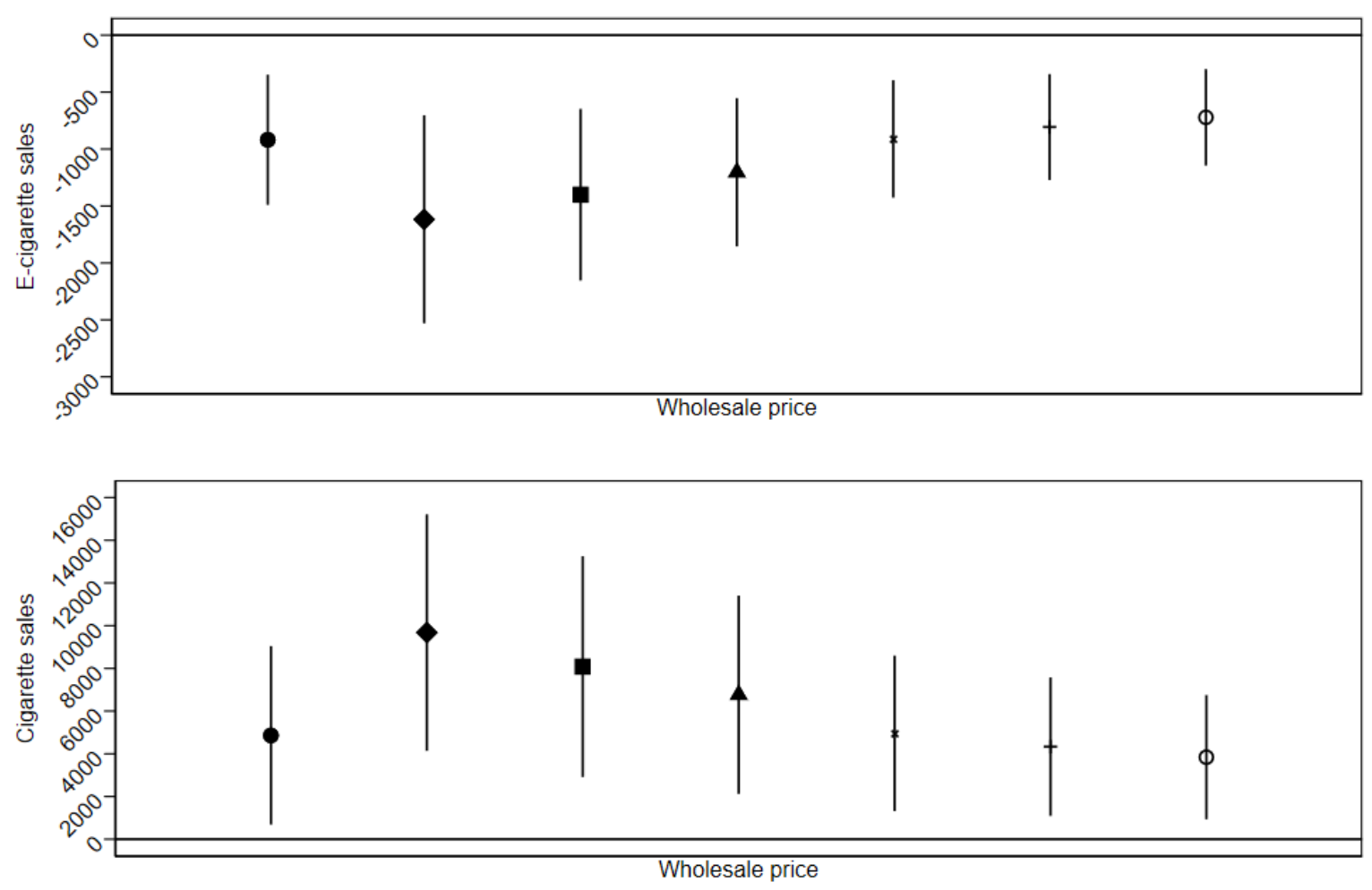
$\$ 3.00$ (main)
$\$ 1.50$
$\$ 2.00$
$\$ 2.50 \times \$ 3.50+\$ 4.00 \circ \$ 4.50$

Notes: The unit of observation is a locality (state or county) in a period (quarter-by-year). The model is estimated by equation (3). The model is estimated with least squares and controls for time-varying locality characteristics, locality fixed effects, and period (quarter-by-year) fixed effects. Data are weighted by the locality population. Symbols reflect the beta coefficient estimate and vertical solid lines reflect $95 \%$ confidence intervals that account for withinlocality clustering. 
Online Appendix Figure 5. Effect of e-cigarette and cigarette taxes on e-cigarette sales per 100,000 adults using a two-way fixed-effects model (leave one out analysis): NielsenIQ state-level sales data 2013-2019
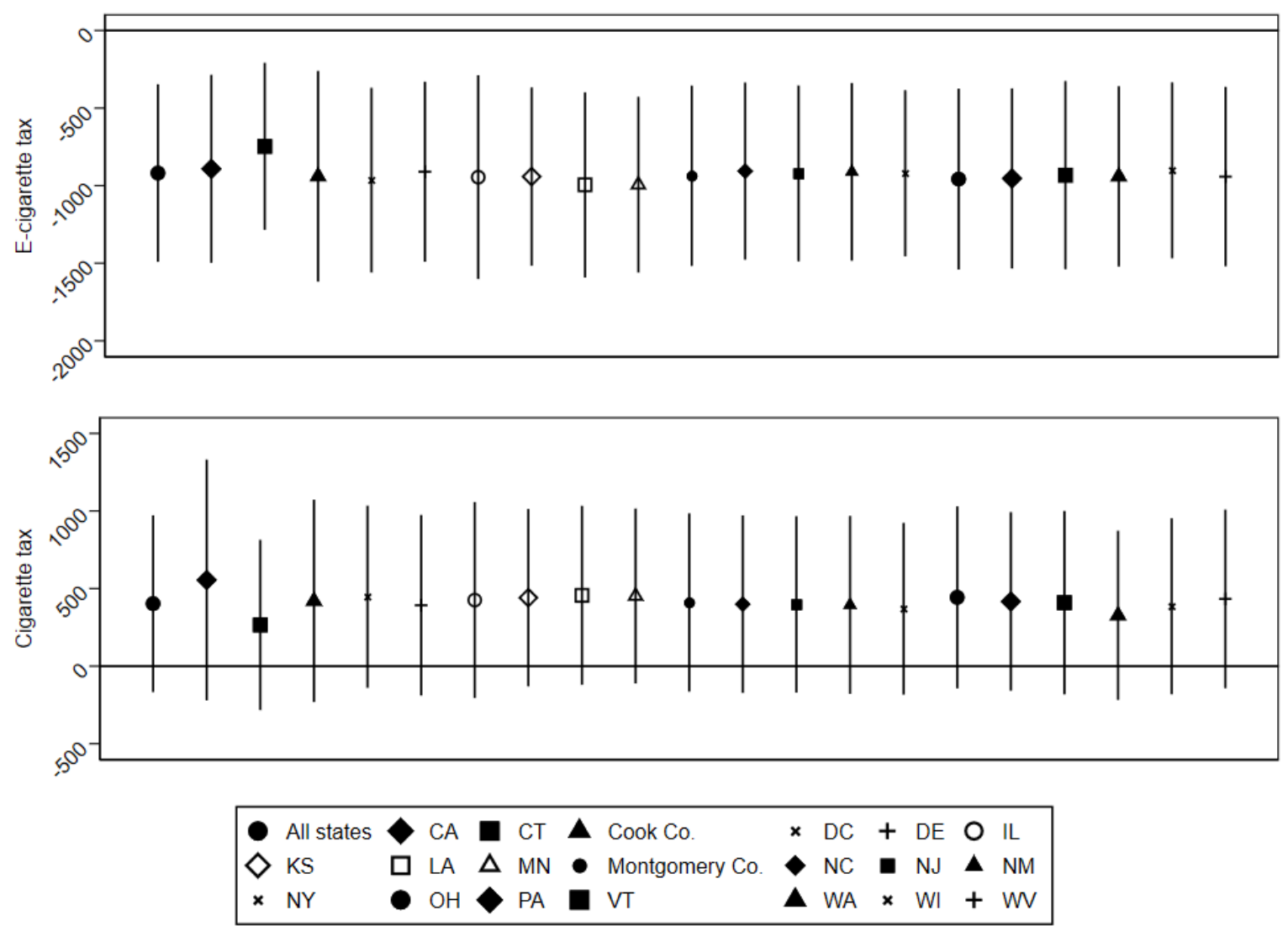

Notes: The unit of observation is a locality (state or county) in a period (quarter-by-year). The model is estimated with least squares and controls for time-varying locality characteristics, state fixed effects, and period (quarter-byyear) fixed effects. Data are weighted by the locality population. Symbols represent coefficient estimates and vertical lines indicate $95 \%$ confidence intervals that account for within-locality clustering. The locality abbreviation indicates the dropped locality. 
Online Appendix Figure 6. Effect of cigarette and e-cigarette taxes on cigarette sales per 100,000 adults using a two-way fixed-effects model (leave one out analysis): NielsenIQ state-level sales data 2013-2019
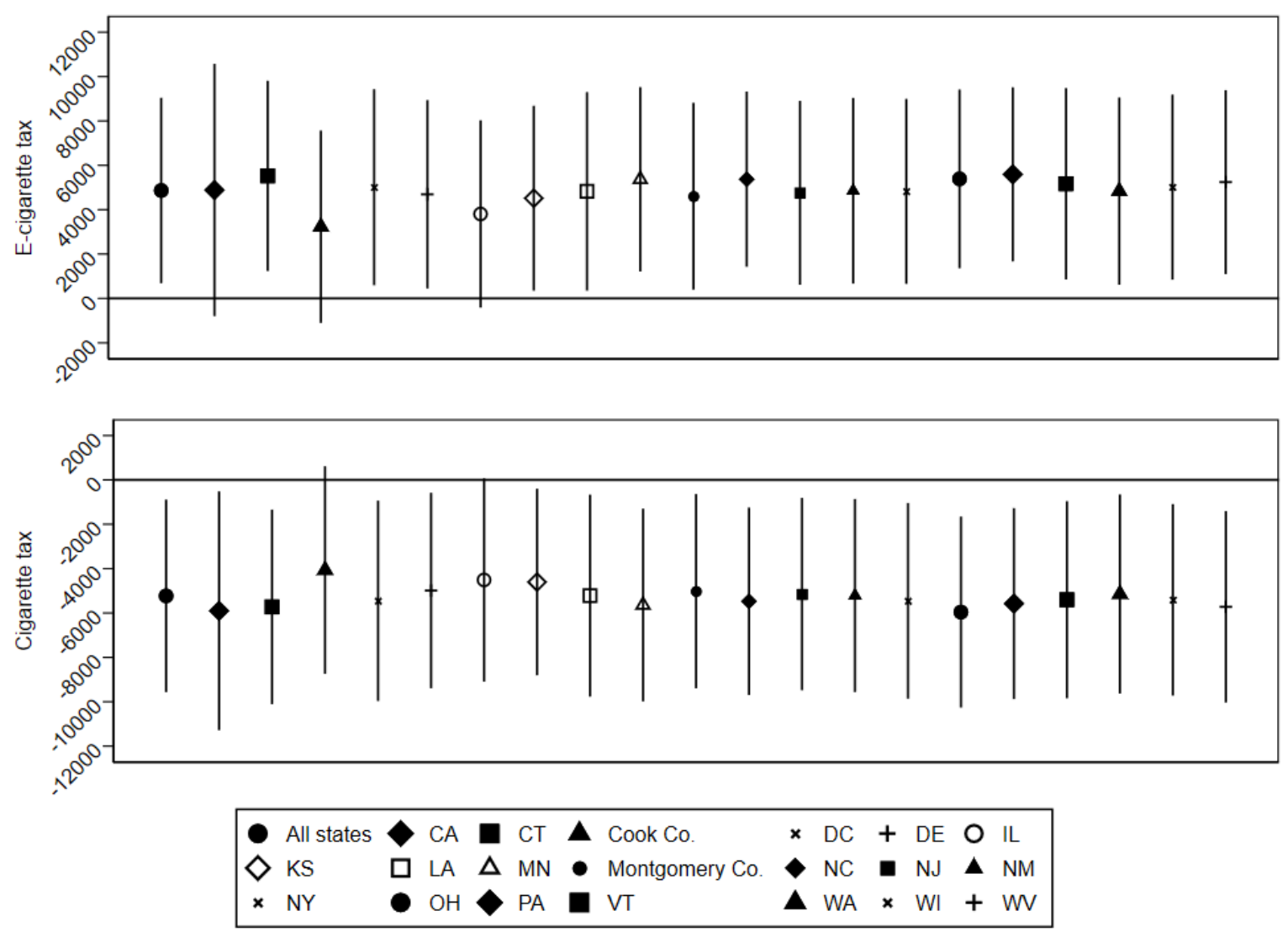

Notes: The unit of observation is a locality (state or county) in a period (quarter-by-year). The model is estimated with least squares and controls for time-varying locality characteristics, state fixed effects, and period (quarter-byyear) fixed effects. Data are weighted by the locality population. Symbols represent coefficient estimates and vertical lines indicate 95\% confidence intervals that account for within-locality clustering. The locality abbreviation indicates the dropped locality. 
Online Appendix Table 1: E-cigarette tax changes through the end of 2019

\begin{tabular}{l|c|c|c|c}
\hline \hline Locality & $\begin{array}{c}\text { Effective } \\
\text { date }\end{array}$ & $\begin{array}{c}\text { Unit } \\
\text { taxed }\end{array}$ & $\begin{array}{c}\text { Tax } \\
\text { amount }\end{array}$ & $\begin{array}{c}\text { Tax value in } \\
\text { 2019 Q4 (\$) }\end{array}$ \\
\hline District/State & & & & \\
\hline California & $4 / 2017,7 / 2017,7 / 2018$, & Wholesale price & $27.3 \%, 65.1 \%$, & 1.78 \\
Connecticut & $7 / 2019$ & Per fluid milliliter & $62.8 \%, 59.3 \%$ & $\$ 0.40$ \\
Delaware & $10 / 2019$ & Per fluid milliliter & $\$ 0.05$ & 0.40 \\
Illinois & $1 / 2018$ & Wholesale price & $15 \%$ & 0.05 \\
Kansas & $7 / 2019$ & Per fluid milliliter & $\$ 0.20, \$ 0.05$ & 0.05 \\
Louisiana & $1 / 2017,7 / 2017$ & Per fluid milliliter & $\$ 0.05$ & 0.05 \\
Minnesota & $7 / 2015$ & Wholesale price & $35.0 \%, 95.0 \%$ & 2.85 \\
North Carolina & $8 / 2010,7 / 2013$ & Per fluid milliliter & $\$ 0.05$ & 0.05 \\
New Jersey & $6 / 2015$ & Per fluid milliliter, Sales tax & $\$ 0.10,10 \%$ & 0.30 \\
New Mexico & $10 / 2018,11 / 2019$ & Per container & $\$ 0.50$ & 0.49 \\
New York & $7 / 2019$ & Sales tax & $20 \%$ & 0.27 \\
Ohio & $12 / 2019$ & Per fluid milliliter & $\$ 0.10$ & 0.10 \\
Pennsylvania & $10 / 2019$ & Wholesale price & $40.0 \%$ & 1.20 \\
Vermont & $7 / 2016$ & Wholesale price & $92.0 \%$ & 2.76 \\
Washington, DC & $7 / 2019$ & Wholesale price & $67.0 \%, 65.0 \%$, & 2.88 \\
& $10 / 2015,10 / 2016$, & & $60 \%, 96 \%$ & \\
Washington & $10 / 2017,10 / 2018$ & Per fluid milliliter & $\$ 0.27$ & 0.27 \\
West Virginia & $10 / 2019$ & Per fluid milliliter & $\$ 0.075$ & 0.075 \\
Wisconsin & $7 / 2016$ & Per fluid milliliter & $\$ 0.05$ & 0.05 \\
\hline County/City & $10 / 2019$ & & & \\
\hline Chicago, Illinois & $1 / 2016,1 / 2019$ & Per container / per fluid & $\$ 0.80 / \$ 0.55$, & 1.89 \\
Cook County, Illinois & $5 / 2016$ & milliliter & $\$ 1.50 / \$ 1.20$ & 1.89 \\
Montgomery County, & $8 / 2015$ & Per fluid milliliter & $\$ 0.20$ & 0.90 \\
Maryland & & Wholesale price & $30.0 \%$ & \\
\hline
\end{tabular}

Notes: $\wedge$ Following Cotti et al. (2021), the Chicago tax is added to the Cook County tax based on the share of the population residing in Chicago. 
Online Appendix Table 2. Summary statistics: NielsenIQ retail sales locality-level data 2013-2019

\begin{tabular}{|c|c|c|c|}
\hline Sample: & $\begin{array}{c}\text { All } \\
\text { localities }\end{array}$ & $\begin{array}{c}\text { Localities that } \\
\text { adopt a tax by 2019, } \\
\text { pre-tax }\end{array}$ & $\begin{array}{c}\text { Localities that do } \\
\text { not adopt a tax } \\
\text { by } 2019\end{array}$ \\
\hline \multicolumn{4}{|l|}{$\begin{array}{l}\text { Sales per 100,000 locality adult } \\
\text { residents }\end{array}$} \\
\hline E-cigarette (ml) & $\begin{array}{c}1,711 \\
(1,307)\end{array}$ & $\begin{array}{l}1,538 \\
(890)\end{array}$ & $\begin{array}{c}1,949 \\
(1,550)\end{array}$ \\
\hline Cigarette (packs) & $\begin{array}{c}64,636 \\
(52,784)\end{array}$ & $\begin{array}{c}53,253 \\
(26,282)\end{array}$ & $\begin{array}{c}78,289 \\
(64,940)\end{array}$ \\
\hline Non-flavored e-cigarettes (ml) & $\begin{array}{c}661 \\
(392)\end{array}$ & $\begin{array}{c}657 \\
(317)\end{array}$ & $\begin{array}{c}720 \\
(440)\end{array}$ \\
\hline Menthol e-cigarettes (ml) & $\begin{array}{c}375 \\
(232)\end{array}$ & $\begin{array}{c}391 \\
(217)\end{array}$ & $\begin{array}{c}390 \\
(243)\end{array}$ \\
\hline Flavored e-cigarettes (ml) & $\begin{array}{c}674 \\
(855)\end{array}$ & $\begin{array}{c}489 \\
(500)\end{array}$ & $\begin{array}{c}837 \\
(1,058)\end{array}$ \\
\hline Non-flavored cigarettes (packs) & $\begin{array}{c}47,907 \\
(42,201)\end{array}$ & $\begin{array}{c}39,119 \\
(18,875)\end{array}$ & $\begin{array}{c}58,506 \\
(52,810)\end{array}$ \\
\hline Menthol cigarettes (packs) & $\begin{array}{l}16,730 \\
(11,317)\end{array}$ & $\begin{array}{l}14,134 \\
(8,289)\end{array}$ & $\begin{array}{l}19,783 \\
(12,664)\end{array}$ \\
\hline Refill e-cigarettes (ml) & $\begin{array}{c}1,288 \\
(1,190)\end{array}$ & $\begin{array}{l}1,139 \\
(751)\end{array}$ & $\begin{array}{c}1,478 \\
(1,453)\end{array}$ \\
\hline Cigars (units) & $\begin{array}{c}21,981 \\
(15,710)\end{array}$ & $\begin{array}{c}14,225 \\
(13,178)\end{array}$ & $\begin{array}{c}27,022 \\
(12,777)\end{array}$ \\
\hline Chewing tobacco (ounces) & $\begin{array}{c}4,200 \\
(5,472)\end{array}$ & $\begin{array}{c}2,595 \\
(4,941)\end{array}$ & $\begin{array}{c}5,142 \\
(4,695)\end{array}$ \\
\hline Loose tobacco (ounces) & $\begin{array}{c}705 \\
(748) \\
\end{array}$ & $\begin{array}{r}643 \\
(533) \\
\end{array}$ & $\begin{array}{c}681 \\
(842) \\
\end{array}$ \\
\hline E-cigarette and cigarette prices & & & \\
\hline E-cigarette price $(\$)$ & $\begin{array}{c}4.82 \\
(1.08)\end{array}$ & $\begin{array}{c}4.62 \\
(0.82)\end{array}$ & $\begin{array}{c}4.68 \\
(0.90)\end{array}$ \\
\hline Cigarette price (\$) & $\begin{array}{c}6.71 \\
(1.64) \\
\end{array}$ & $\begin{array}{c}7.43 \\
(1.91) \\
\end{array}$ & $\begin{array}{c}5.98 \\
(0.97)\end{array}$ \\
\hline E-cigarette and cigarette taxes & & & \\
\hline E-cigarette tax $(\$)$ & $\begin{array}{c}0.18 \\
(0.58)\end{array}$ & $\begin{array}{l}-- \\
--\end{array}$ & $\begin{array}{l}-- \\
--\end{array}$ \\
\hline Conditional e-cigarette tax (\$) & $\begin{array}{c}1.22 \\
(0.98)\end{array}$ & $\begin{array}{l}-- \\
--\end{array}$ & $\begin{array}{l}-- \\
--\end{array}$ \\
\hline Conditional e-cigarette tax (\$) - unit & $\begin{array}{l}0.26 \\
(0.44)\end{array}$ & $\begin{array}{l}-- \\
--\end{array}$ & $\begin{array}{l}-- \\
--\end{array}$ \\
\hline $\begin{array}{l}\text { Conditional e-cigarette tax (\$) - ad } \\
\text { valorem }\end{array}$ & $\begin{array}{l}1.88 \\
(0.64)\end{array}$ & $\begin{array}{l}-- \\
--\end{array}$ & $\begin{array}{l}-- \\
--\end{array}$ \\
\hline Cigarette tax $(\$)$ & $\begin{array}{c}2.97 \\
(1.35)\end{array}$ & $\begin{array}{c}3.62 \\
(1.65)\end{array}$ & $\begin{array}{c}2.38 \\
(0.77)\end{array}$ \\
\hline Policies and demographics & & & \\
\hline \% covered by indoor vaping ban & $\begin{array}{c}0.23 \\
(0.33)\end{array}$ & $\begin{array}{c}0.29 \\
(0.36)\end{array}$ & $\begin{array}{c}0.11 \\
(0.21)\end{array}$ \\
\hline \% covered by indoor smoking ban & $\begin{array}{c}0.71 \\
(0.33)\end{array}$ & $\begin{array}{c}0.89 \\
(0.17)\end{array}$ & $\begin{array}{c}0.55 \\
(0.35)\end{array}$ \\
\hline E-cigarette licensure laws & $\begin{array}{c}0.18 \\
(0.38)\end{array}$ & $\begin{array}{c}0.10 \\
(0.30)\end{array}$ & $\begin{array}{c}0.09 \\
(0.28)\end{array}$ \\
\hline Other tobacco licensure laws & $\begin{array}{c}0.76 \\
(0.43)\end{array}$ & $\begin{array}{c}0.90 \\
(0.30)\end{array}$ & $\begin{array}{c}0.65 \\
(0.48)\end{array}$ \\
\hline E-cigarette bans & $\begin{array}{l}0.002 \\
(0.04)\end{array}$ & $\begin{array}{c}0 \\
(0)\end{array}$ & $\begin{array}{l}0.002 \\
(0.03)\end{array}$ \\
\hline Share of border localities without an e- & 0.89 & 0.92 & 0.88 \\
\hline
\end{tabular}




\begin{tabular}{|c|c|c|c|}
\hline cigarette tax & $(0.18)$ & $(0.15)$ & $(0.18)$ \\
\hline Vape-free public K-12 schools & 0.18 & 0.18 & 0.12 \\
\hline Smoke-free public K-12 schools & 0.35 & 0.49 & 0.22 \\
\hline Tobacco 21 law & 0.100 & 0.066 & 0.033 \\
\hline Beer tax $(\$)$ & $\begin{array}{c}0.30 \\
(0.27)\end{array}$ & $\begin{array}{c}0.21 \\
(0.12)\end{array}$ & $\begin{array}{c}0.37 \\
(0.34)\end{array}$ \\
\hline $\begin{array}{l}\text { Affordable Care Act Medicaid } \\
\text { expansion }\end{array}$ & 0.51 & 0.70 & 0.32 \\
\hline Unemployment rate & $\begin{array}{c}5.09 \\
(1.46)\end{array}$ & $\begin{array}{c}5.88 \\
(1.44)\end{array}$ & $\begin{array}{c}4.80 \\
(1.42)\end{array}$ \\
\hline Age & $\begin{array}{c}38.6 \\
(1.60)\end{array}$ & $\begin{array}{c}38.7 \\
(1.16)\end{array}$ & $\begin{array}{c}38.5 \\
(1.91)\end{array}$ \\
\hline Male & $\begin{array}{c}0.49 \\
(0.01)\end{array}$ & $\begin{array}{c}0.49 \\
(0.01)\end{array}$ & $\begin{array}{c}0.49 \\
(0.01)\end{array}$ \\
\hline Female & $\begin{array}{c}0.51 \\
(0.01)\end{array}$ & $\begin{array}{c}0.51 \\
(0.01)\end{array}$ & $\begin{array}{c}0.51 \\
(0.01)\end{array}$ \\
\hline White & $\begin{array}{c}0.78 \\
(0.08)\end{array}$ & $\begin{array}{c}0.77 \\
(0.06)\end{array}$ & $\begin{array}{c}0.79 \\
(0.09)\end{array}$ \\
\hline African American & $\begin{array}{c}0.13 \\
(0.08)\end{array}$ & $\begin{array}{c}0.11 \\
(0.06)\end{array}$ & $\begin{array}{c}0.14 \\
(0.09)\end{array}$ \\
\hline Other race & $\begin{array}{c}0.09 \\
(0.05)\end{array}$ & $\begin{array}{c}0.12 \\
(0.06)\end{array}$ & $\begin{array}{c}0.07 \\
(0.03)\end{array}$ \\
\hline Hispanic & $\begin{array}{c}0.18 \\
(0.13)\end{array}$ & $\begin{array}{c}0.19 \\
(0.12)\end{array}$ & $\begin{array}{c}0.17 \\
(0.13)\end{array}$ \\
\hline Born outside the U.S. & $\begin{array}{c}0.15 \\
(0.08)\end{array}$ & $\begin{array}{c}0.17 \\
(0.09)\end{array}$ & $\begin{array}{c}0.13 \\
(0.07)\end{array}$ \\
\hline Less than high school & $\begin{array}{c}0.15 \\
(0.03)\end{array}$ & $\begin{array}{c}0.16 \\
(0.03)\end{array}$ & $\begin{array}{c}0.15 \\
(0.03)\end{array}$ \\
\hline High school & $\begin{array}{c}0.28 \\
(0.04)\end{array}$ & $\begin{array}{c}0.28 \\
(0.05)\end{array}$ & $\begin{array}{c}0.28 \\
(0.03)\end{array}$ \\
\hline Some college & $\begin{array}{c}0.27 \\
(0.03)\end{array}$ & $\begin{array}{c}0.26 \\
(0.03)\end{array}$ & $\begin{array}{c}0.27 \\
(0.03)\end{array}$ \\
\hline College & $\begin{array}{c}0.30 \\
(0.05)\end{array}$ & $\begin{array}{c}0.31 \\
(0.04)\end{array}$ & $\begin{array}{c}0.29 \\
(0.05)\end{array}$ \\
\hline Population (millions) & $\begin{array}{c}14.2 \\
(11.8)\end{array}$ & $\begin{array}{c}17.1 \\
(12.8)\end{array}$ & $\begin{array}{c}11.3 \\
(9.04)\end{array}$ \\
\hline Observations & 1,428 & 369 & 868 \\
\hline
\end{tabular}

Notes: The unit of observation is a locality (state or county) in a period (quarter-by-year). Data are weighted by the locality population. Values in parentheses are standard deviations for continuous variables. 
Online Appendix Table 3. Test of covariate balance

\begin{tabular}{|c|c|}
\hline Outcome & E-cigarette tax (\$) \\
\hline \multirow{2}{*}{ Cigarette tax (\$) } & $0.710^{* * *}$ \\
\hline & $(0.080)$ \\
\hline \multirow[t]{2}{*}{ Full smoking ban } & 0.115 \\
\hline & $(0.094)$ \\
\hline \multirow[t]{2}{*}{ \% covered by indoor vaping ban } & -0.074 \\
\hline & $(0.423)$ \\
\hline \multirow[t]{2}{*}{ E-cigarette licensure laws } & $0.191 * *$ \\
\hline & $(0.074)$ \\
\hline \multirow[t]{2}{*}{ Other tobacco licensure laws } & 0.503 \\
\hline & $(0.379)$ \\
\hline \multirow[t]{2}{*}{ E-cigarette bans } & 0.098 \\
\hline & $(0.172)$ \\
\hline \multirow[t]{2}{*}{ Share of border localities without an e-cigarette tax } & -0.149 \\
\hline & $(0.099)$ \\
\hline \multirow[t]{2}{*}{ Vape-free public K-12 schools } & 0.026 \\
\hline & $(0.071)$ \\
\hline \multirow[t]{2}{*}{ Smoke-free public K-12 schools } & 0.006 \\
\hline & $(0.064)$ \\
\hline \multirow[t]{2}{*}{ Tobacco 21 law } & 0.029 \\
\hline & $(0.049)$ \\
\hline \multirow[t]{2}{*}{ Beer tax $(\$)$} & 0.011 \\
\hline & $(0.054)$ \\
\hline \multirow[t]{2}{*}{ ACA Medicaid expansion } & -0.025 \\
\hline & $(0.044)$ \\
\hline \multirow[t]{2}{*}{ Unemployment rate } & -0.018 \\
\hline & $(0.025)$ \\
\hline \multirow[t]{2}{*}{ Age } & -0.008 \\
\hline & $(0.016)$ \\
\hline \multirow[t]{2}{*}{ Female } & -0.081 \\
\hline & $(0.747)$ \\
\hline \multirow[t]{2}{*}{ African American } & -2.127 \\
\hline & (1.819) \\
\hline \multirow[t]{2}{*}{ Other race } & -0.656 \\
\hline & $(0.527)$ \\
\hline \multirow[t]{2}{*}{ Hispanic } & $-1.203^{* *}$ \\
\hline & $(0.564)$ \\
\hline \multirow[t]{2}{*}{ Born outside the U.S. } & 1.038 \\
\hline & (1.017) \\
\hline \multirow[t]{2}{*}{ High school } & -0.416 \\
\hline & $(0.783)$ \\
\hline \multirow[t]{2}{*}{ Some college } & $-1.687 * *$ \\
\hline & $(0.664)$ \\
\hline \multirow[t]{2}{*}{ College } & 0.099 \\
\hline & $(0.776)$ \\
\hline \multirow[t]{2}{*}{ Population (millions) } & $0.049 *$ \\
\hline & $(0.026)$ \\
\hline$F$-statistic for joint significance of time-varying covariates ( $p$ - & 923 \\
\hline value) & $(<0.000)$ \\
\hline Mean e-cigarette tax (\$) & 0.183 \\
\hline Observations & 1,428 \\
\hline
\end{tabular}

Notes: The unit of observation is a locality (state or county) in a period (quarter-by-year). All models estimated with least squares and control for locality fixed effects, and period (quarter-by-year) fixed effects. Omitted categories are male, white, nonHispanic, U.S. born, and less than HS education. Data are weighted by state population. Standard errors account for withinlocality clustering reported in parentheses. $* * *, * *$, and $*=$ statistically different from zero at the $1 \%, 5 \%$, and $10 \%$ level. 
Online Appendix Table 4. Effect of e-cigarette and cigarette taxes on e-cigarette prices, and e-cigarette and cigarettes sales per 100,000 using a two-way fixed effects model (only include ad valorem localities and localities that have not adopted an e-cigarette tax by 2019 in the sample, and keep e-cigarette taxes in natural units): NielsenIQ UPC-level and state-level sales data 2013-2019

\begin{tabular}{|c|c|c|c|}
\hline Outcome: & E-cigarette price (\$) & E-cigarette sales & Cigarette sales \\
\hline \multicolumn{4}{|l|}{ E-cigarette tax (percent) } \\
\hline Beta & $0.028 * * *$ & $-32.521 * * *$ & $168.620^{* *}$ \\
\hline$(\mathrm{SE})$ & $(0.003)$ & $(10.411)$ & (62.688) \\
\hline Tax elasticity & - & -1.35 & 0.30 \\
\hline Observations & 95,867 & 1,092 & 1,092 \\
\hline Dataset & NielsenIQ UPC & NielsenIQ state & NielsenIQ state \\
\hline Unit of observation & $\begin{array}{l}\text { UPC-code in a locality } \\
\text { in a period }\end{array}$ & $\begin{array}{l}\text { Locality } \\
\text { in a period }\end{array}$ & $\begin{array}{l}\text { Locality } \\
\text { in a period }\end{array}$ \\
\hline $\begin{array}{l}\text { Mean: e-cigarette tax adopting } \\
\text { localities, year prior to the tax }\end{array}$ & 4.683 & 1,392 & 32,363 \\
\hline \multicolumn{4}{|c|}{$\begin{array}{l}\text { Notes: A locality is a state or county. A period is a quarter-by-year. All price regression models estimated with least } \\
\text { squares. Price data are weighted by the share of e-cigarette sales in localities that do not adopt an e-cigarette tax. All } \\
\text { sales regression models estimated with least squares and control for time-varying area characteristics, area fixed } \\
\text { effects, and period (quarter-by-year) fixed effects. Sales data are weighted by the locality population. Tax elasticities } \\
\text { are calculated as described in Table } 2 \text {, using a conditional ad valorem tax mean of } 57.98 \text {. Standard errors that } \\
\text { account for within-locality clustering are reported in parentheses. SE=standard error. } \\
* * * * * \text {, and } *=\text { statistically different from zero at the } 1 \%, 5 \% \text {, and } 10 \% \text { level. }\end{array}$} \\
\hline
\end{tabular}


Online Appendix Table 5. Effect of e-cigarette and cigarette taxes on other tobacco product sales per 100,000 adults using a two-way fixed effects model: NielsenIQ state-level sales data 2013-2019

\begin{tabular}{|c|c|c|c|}
\hline Tobacco product: & Cigars & $\begin{array}{c}\text { Chewing } \\
\text { tobacco }\end{array}$ & $\begin{array}{c}\text { Loose } \\
\text { tobacco }\end{array}$ \\
\hline \multicolumn{4}{|l|}{ E-cigarette tax (\$) } \\
\hline Beta & $-2,262$ & 123 & 10 \\
\hline$(\mathrm{SE})$ & $(2,184)$ & (228) & (111) \\
\hline Tax elasticity & -0.17 & 0.04 & 0.01 \\
\hline Implied price elasticity & -0.58 & 0.15 & 0.05 \\
\hline \multicolumn{4}{|l|}{ Cigarette tax (\$) } \\
\hline Beta & 2,729 & -186 & 97 \\
\hline (SE) & $(1,970)$ & (194) & (102) \\
\hline Tax elasticity & 0.47 & -0.16 & 0.46 \\
\hline Implied price elasticity & 0.86 & -0.29 & 0.84 \\
\hline Observations & 1,428 & 1,428 & 1,428 \\
\hline $\begin{array}{l}\text { Mean: Sales in e-cigarette tax } \\
\text { adopting localities, year prior to } \\
\text { the tax }\end{array}$ & 16,641 & 3,389 & 897 \\
\hline $\begin{array}{l}\text { Mean: Sales in cigarette tax } \\
\text { adopting localities, year prior to } \\
\text { the first cigarette tax increase }\end{array}$ & 17,355 & 3,513 & 631 \\
\hline \multicolumn{4}{|c|}{$\begin{array}{l}\text { Notes: The unit of observation is a locality (state or county) in a period (quarter-by-year). All models estimated with } \\
\text { least squares and control for time-varying area characteristics, area fixed effects, and period (quarter-by-year) fixed } \\
\text { effects. Data are weighted by the locality population Tax elasticities and implied price elasticities are calculated as } \\
\text { described in Table } 2 \text {. Standard errors that account for within-locality clustering are reported in parentheses. } \\
\mathrm{SE}=\text { standard error. } \\
* * * * * \text {, and } *=\text { statistically different from zero at the } 1 \%, 5 \% \text {, and } 10 \% \text { level. }\end{array}$} \\
\hline
\end{tabular}


Online Appendix Discussion 1: E-cigarette taxes through 2019 are most commonly levied using either specific unit taxes per fluid $\mathrm{ml}$ or ad valorem taxes. Thus, in their natural units there is no obvious way to compare the taxes in terms of their magnitudes.

This paper follows an e-cigarette tax standardization process as explained in Cotti et al. (2021), which uses policy data on e-cigarette taxes with the NielsenIQ Retail Scanner data in order to convert ad valorem, sales taxes, and excise taxes per container into excise taxes per fluid ml. Here is the formula used to convert ad valorem taxes into taxes per ml of fluid, which is the conversion needed for the most localities (see Online Appendix Table 1).

Wholesale Price per $m l_{2013} *$ ad valorem tax rate $_{\text {st }}=$ tax per ml of fluid $_{s t}$

Where $s$ indexes a tax locality on a quarter-by-year basis $t$. As shown above, the standardization formula requires an estimate of the e-cigarette wholesale price per fluid ml. We calculate an average sales-weighted e-cigarette price of \$4.04 per fluid $\mathrm{ml}$ in 2013 for 23 tax localities that had not adopted e-cigarette taxes by the end of $2020 .{ }^{39}$ We then divide this by $135 \%$ to estimate a wholesale price of $\$ 2.99$. We then multiply this wholesale price estimate by the ad valorem tax in jurisdiction $s$ for each time period $t$ (quarter-year). This step provides us with an estimate of the tax per fluid ml for each jurisdiction using an ad valorem tax, and is now measured consistently with the excise taxes measures used by other treated localities.

In our paper, we check the robustness of estimates by alternatively utilizing a range of different assumed wholesale prices (see Online Appendix Figures 2 and 4).

\footnotetext{
${ }^{39}$ Utilizing a time-invariant wholesale price separates the analysis from many potential sources of bias that could otherwise be affecting wholesale prices (e.g., endogeneity of prices). The only factor that now affects the e-cigarette tax measure is the legislated tax changes. Manufacturer correspondence suggests that major e-cigarette companies do not use a geographic adjustment, suggesting a common wholesale price for a given e-cigarette product across the country at a given point in time (Cotti et al., 2021). This is consistent with observed minimal variation in retail prices observed across the 23 non-taxing jurisdictions for the same product at the same time (Cotti et al., 2021). Additionally, we use 2013 and compare retail prices for the top three selling e-cigarette UPCs (in the top selling retail chain) and show that retail prices are very similar between states that do not adopt taxes by 2020 and states that adopt between 2014 to 2020, and within each group there is little price variation.
} 
Online Appendix Discussion 2 (Event Studies):

Below we test the sensitivity of the event studies presented in Figures 4 and 5. Specifically, we have re-run the e-cigarette and cigarette tax event studies multiple ways to explore the sensitivity of results to different model specification.

In Online Appendix Figure 6, we begin with the most simplified model possible, using no controls and unrestricted endpoints (e.g., we use catch-all endpoints, so -8 and +8 capture the effects of all earlier [for -8] or later [for +8 ] time periods), but we continue to control for fixed effects. Next, in Online Appendix Figure 7 we add cigarette taxes as a control. In Online Appendix Figure 8 we add all other time-varying controls. Figures 4 and 5 of the main text then build off Online Appendix Figure 8, but restricts the end points to periods no more than eight periods before or after policy adoption. ${ }^{40}$ All of these figures use Cotti et al (2018) event study-style models that compensates for tax magnitude.

The event study estimates are generally consistent across all models. All e-cigarette models show relatively flat trends prior to an e-cigarette tax and declining e-cigarette sales after the tax. Furthermore, while results are noisier across specifications, cigarette sales generally rise in the quarters after an e-cigarette tax. Cigarette taxes do not affect cigarette sales in the quarters before a tax, but reduce cigarette sales after the tax implementation.

One difference across specifications is that the catch-all end points magnify the effects of ecigarette taxes more than 8 quarters after the tax implementation. Another exception is the effect of cigarette taxes on e-cigarette sales, which largely show no effect (top-right panel of Online Appendix Figure 6) until differences in cigarette taxes are controlled for (top-right panel of Online Appendix Figures 7 and 8), at which point substitution effects appear.

\section{Online Appendix Figure 6: Sales; no controls with catch all end points}

(E-Cigarette tax)
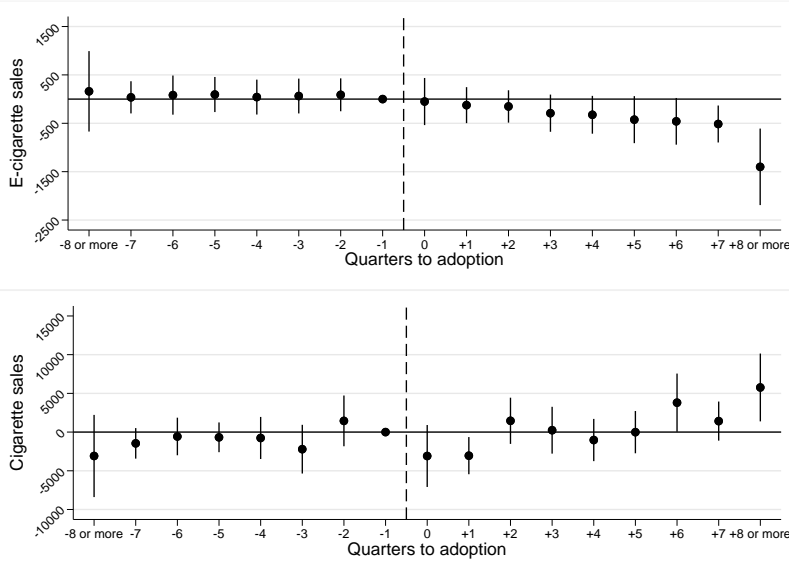

(Cigarette tax)
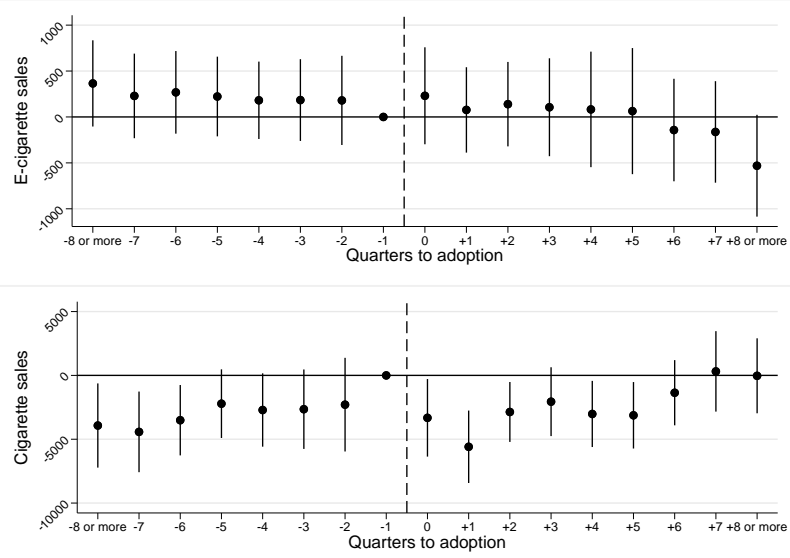

\footnotetext{
${ }^{40}$ Estimates are also robust to examining the effects of restricting the treatment states to be those that have observations in all periods within eight quarters (in both directions) of an e-cigarette tax change. This removes CT, DE, IL, MN, NJ, NM, NY, OH, VT, WA and WI. The results of this sensitivity test continue to have parallel trends and a notable drop in e-cigarette sales and an increase in cigarette sales.
} 
Online Appendix Figure 7: Sales; with cigarette tax as the only control and catch all end points

(E-Cigarette tax)
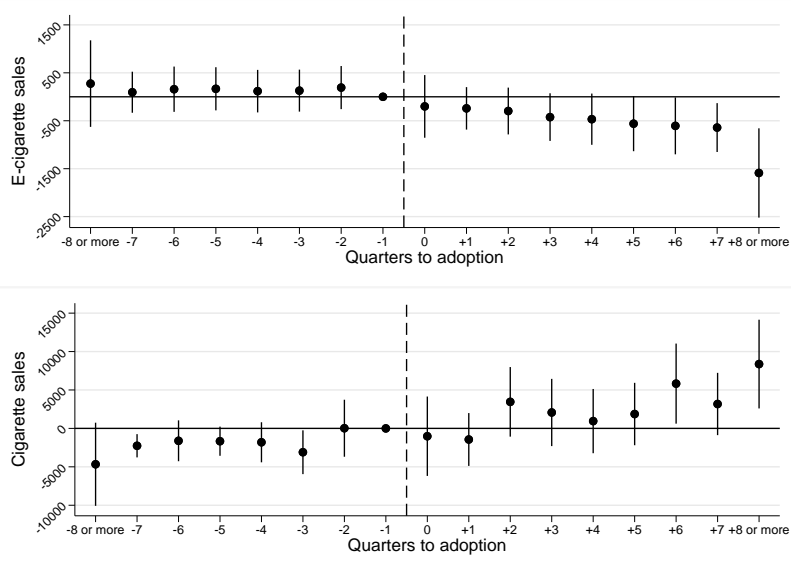

(Cigarette tax)
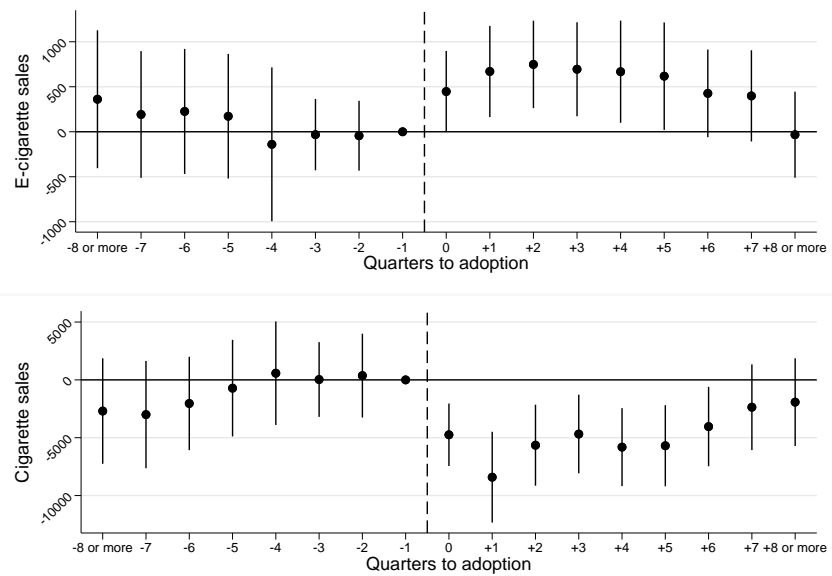

Online Appendix Figure 8: Sales; with all controls, with catch all end points

(E-Cigarette tax)
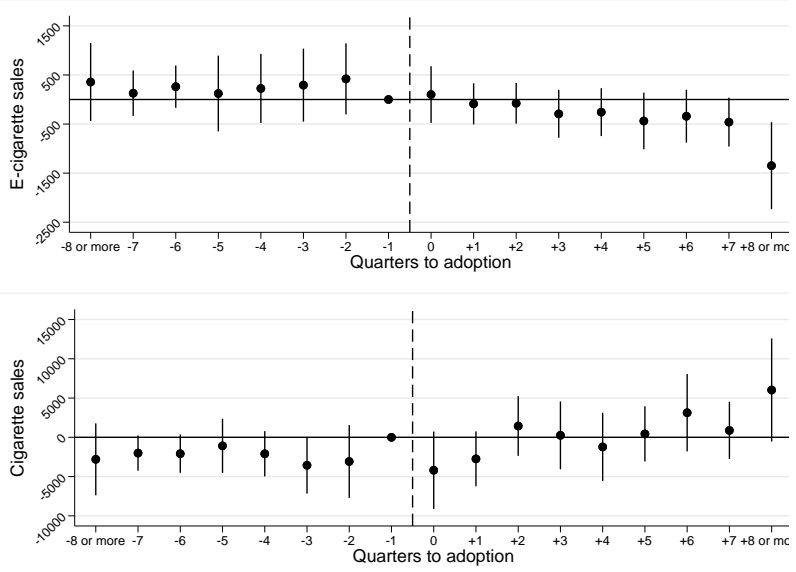

(Cigarette tax)
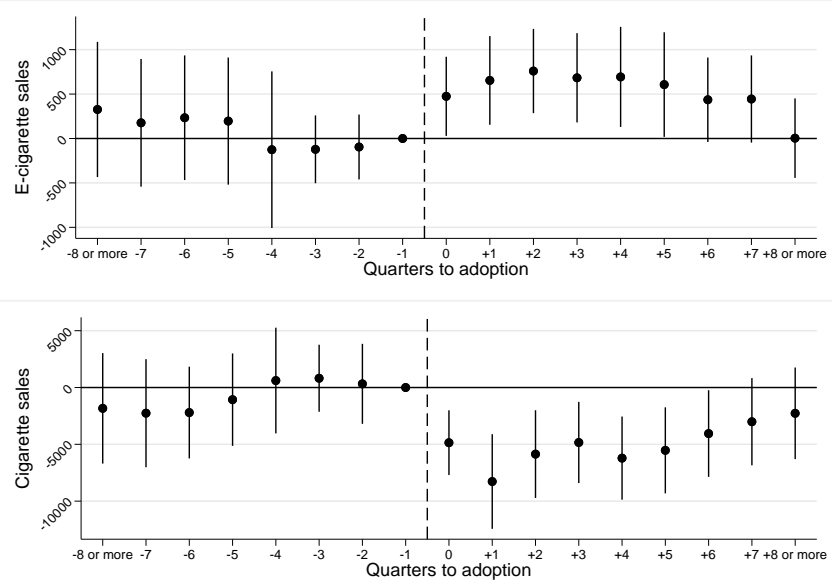